Universidade de São Paulo

Faculdade de Medicina de Ribeirão Preto

\title{
2016
}

\section{Alterações no equilíbrio funcional em pacientes com migrânea crônica e episódica}
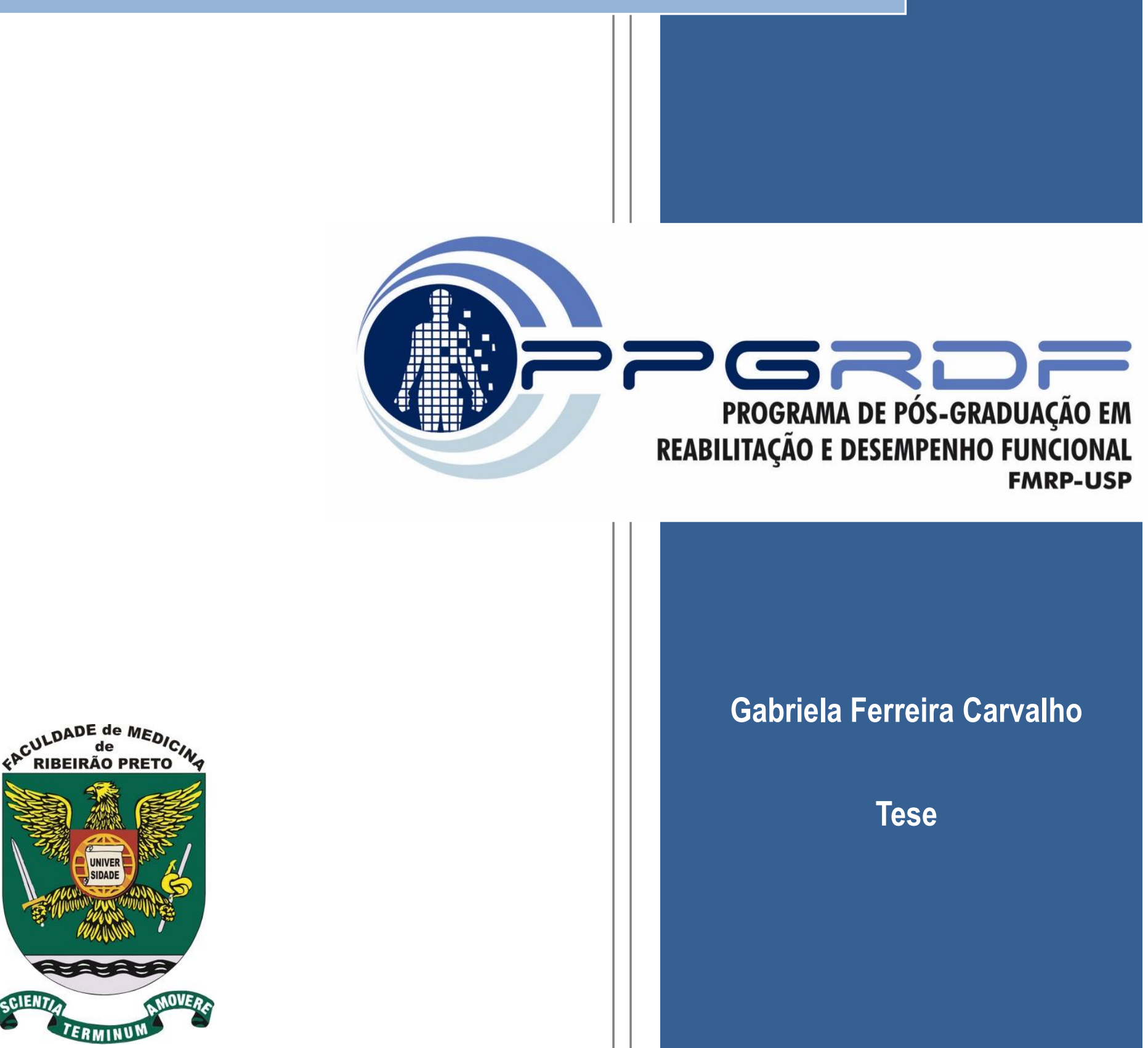

Gabriela Ferreira Carvalho

Tese 


\section{Alterações no equilíbrio funcional em pacientes com migrânea crônica e episódica}

Tese apresentada à Faculdade de Medicina de Ribeirão Preto da Universidade de São Paulo junto ao Departamento de Biomecânica, Medicina e Reabilitação do Aparelho Locomotor, para obtenção do título de Doutor em Ciências pelo programa de pós-graduação em Reabilitação e Desempenho Funcional.

Área de concentração: Fisioterapia

Orientadora: Profa. Dra. Débora Bevilaqua Grossi

Versão corrigida. A versão original encontra-se disponível tanto na Biblioteca da Unidade que aloja o Programa, quanto na Biblioteca Digital de Teses e Dissertações da USP (BDTD).

\section{Ribeirão Preto}


AUTORIZO A REPRODUÇÃO E DVULGAÇÃO TOTAL OU PARCIAL DESTE TRABALHO, POR QUALQUER MEIO CONVENCIONAL OU ELETRÔNICO, PARA FINS DE ESTUDO E PESQUISA, DESDE QUE CITADA A FONTE.

\section{Catalogação da Publicação}

Faculdade de Medicina de Ribeirão Preto da Universidade de São Paulo

Carvalho, Gabriela Ferreira

Alterações no equilíbrio funcional em pacientes com migrânea crônica e episódica / Gabriela Ferreira Carvalho; Orientador Débora Bevilaqua Grossi. - Ribeirão Preto, 2016.

89p. il., $30 \mathrm{~cm}$.

Tese (Doutorado) - Faculdade de Medicina de Ribeirão Preto da Universidade de São Paulo/USP - Programa de Pós-Graduação em Reabilitação e Desempenho Funcional, Área de concentração: Fisioterapia. 


\section{FOLHA DE APROVAÇÃO}

Nome: CARVALHO, Gabriela Ferreira

Título: Alterações no equilíbrio funcional em pacientes com migrânea crônica e episódica.

Tese apresentada à Faculdade de Medicina de Ribeirão Preto da Universidade de São Paulo junto ao Departamento de Biomecânica, Medicina e Reabilitação do Aparelho Locomotor, Área de concentração: Fisioterapia. Para obtenção do título de Doutor em Ciências pelo programa de pós-graduação em Reabilitação e Desempenho Funcional.

Aprovado em:

\section{Banca Examinadora}

Prof. Dr. Instituição:

Julgamento:

Assinatura:

Prof. Dr.

Instituição:

Julgamento:

Assinatura:

Prof. Dr.

Instituição:

Julgamento:

Assinatura:

Prof. Dr.

Instituição:

Julgamento:

Assinatura:

Prof. Dr.

Instituição:

Julgamento:

Assinatura: 
Dedico esta tese aos meus pais,

Reconhecer o brilho nos olhos de vocês ao acompanhar a minha caminhada é de imensurável realização e felicidade.

Aos meus pacientes, pelo imenso privilégio de poder fazer diferença em suas vidas; por dar sentido e agregar experiências ímpares aos meus dias. 


\section{Agradecimentos}

Agradeço primeiramente a Deus, pela minha vida, pela minha saúde. Por acompanhar todos os meus passos e me conduzir em um caminho de muito aprendizado e crescimento, que espero que não tenha fim. Agradeço, pois ele cuidadosamente colocou obstáculos e dificuldades neste caminho, onde a transposição de cada um deles teve um papel fundamental para que o conjunto de acontecimentos fizesse sentido; afinal, um mar calmo nunca fez um bom marinheiro e em seus planos tudo possui uma razão. Agradeço por ele ter colocado na minha vida pessoas fantásticas, que neste período tiveram sempre uma palavra de incentivo, ensinamento, apoio, confiança e que me ajudaram a ver o lado bom das adversidades, mantendo de pé a minha fé, otimismo e persistência.

Tenho muito a agradecer meus pais, Antônio Carlos e Izilda. Obrigada pelo ensinamento de valores, pelas cobranças e incentivo, pela formação, que é parte de quem eu sou e de como eu me vejo. Obrigada pelo amor, demonstrado constantemente, porém de forma especial durante a minha ausência morando em Boston. Talvez eu não tenha dito, mas foi extremamente dolorida a falta que me fizeram. O sentimento completamente oposto foi sentido ao receber vocês lá. Obrigada pelos bons exemplos e pelo orgulho que demonstram por mim.

Querida orientadora-amiga-professora Débora, nenhuma palavra consegue descrever o quanto é maravilhoso trabalhar e conviver com a senhora e seu contagiante senso de humor. A motivação de cada passo ou de cada conhecimento construído está na ínfima tentativa de retribuir tudo que a senhora me ensinou e fez por mim. E não é somente o que ensinou, mas como ensinou: com amor, com ética, exigindo excelência e desamarrando nós, dando prioridade ao senso comum. A senhora é leve, divertida, competente e justa. A sua fé é uma fortaleza. Palavras são poucas para expressar o quanto eu te admiro e me inspiro na senhora.

Gostaria de agradecer a oportunidade de trabalhar um ano sob a orientação do Prof. Dr. Paolo Bonato no Spaulding Rehabilitation Hospital/Harvard Medical School em Boston. Em conjunto com sua equipe de excelência do Motion Analysis Lab vivi momentos de extrema aprendizagem e amadurecimento profissional/pessoal, lidando com experiências que nunca imaginei passar um dia. Considero este período de descobertas "the time of my life" e jamais esquecerei da contribuição de todos os colegas que sempre lembrarei com muito carinho: Gloria Vergara Diaz, Catherine Adans-Dester, Alessandra 
Scarton, Gianluca Constante, Anne O’Brien, Jean-François Daneault, Noushin Golabchi, Ryan McIntosh, Sunghoon Ivan Lee, Edoardo Bonizzoni, José Garcia Vivas Miranda e Eric Farbara.

Queridos amigos do laboratório, Lidiane e Maria Cláudia: como é maravilhoso crescer junto com vocês e ter tido a oportunidade de partilhar tanto conhecimento, descobertas e viagens... Agradeço a todos do LAPOMH pela agradável convivência, pelas oportunidades de aprendizado: Jaqueline, Denise, Carina, Cesário, Gabriel, Marcelo, Thiele, Daiane, Marcela, Isadora, Izabela, Harumi, Mariana Benatto, Samuel, Marília, Ana Cristina, Diego, Amanda, Ramon. Obrigada minhas alunas de IC Flávia e Carolina por tanto aprendizado, em conjunto com as outras alunas do grupo de cefaleia: Gabriela, Ana Paula, Camila e Laís.

Agradeço toda a minha família pelo carinho e apoio ao longo dessa jornada. Minhas irmãs Carolina e Ana Luiza, meus avós Maria e Zulmiro.

Agradeço a todos os meus mestres, que sempre me incentivaram e instigaram a curiosidade e a vontade de ser um bom profissional: Profa Dra Fabíola Dach, Profa Dra Anamaria, Dr Marcelo Bigal, Prof Dr José Speciali, Profa Dra Thaís. Meu agradecimento aos meus queridos professores da UNIFRAN, que me formaram e me inspiram desde a graduação: Prof. Dr. José Alexandre Bachur, Profa Dra Cynthia Bachur, Profa Dra Renata Licursi, Profa Dra Ana Paula Borges. Agradeço ainda, os membros da banca julgadora pela disponibilidade e contribuições à esta tese.

Sou grata à minha vocação como Fisioterapeuta e à convicta realização que ela me proporciona. Sou imensamente grata aos meus pacientes, por me fazerem humana, por todos os ensinamentos e pela indescritível felicidade que me proporcionam a cada objetivo alcançado ou dor solucionada. Agradeço pela confiança e por cada sorriso. O verdadeiro sentido de desenvolver este trabalho vem do desejo em solucionar ou mesmo amenizar o seu sofrimento.

Agradeço aos os voluntários deste estudo, aos funcionários do Laboratório e do HCRP e do prédio da fisioterapia, que direta ou indiretamente proporcionaram condições e facilidades para que eu pudesse desenvolver este trabalho.

Obrigada meus queridos amigos que desde sempre vibram e acompanham as minhas conquistas com muito orgulho e me apoiam em todos os momentos difíceis: Luciana, Thaís, Alexandre, Mariana, Priscila, Marcelo, Josiana, Michele, Lívia, Cristiane, Maria Rita, Letícia, Maísa. Meus queridos amigos de Boston Sabrina, Aline, Beatriz, 
Priscila, Tereza, Camila, Gisele, Cicero, Luan, além de tantos outros que passaram pelo meu caminho. Agradeço ao meu namorado Guilherme. A minha vida faz mais sentido e é muito mais feliz com vocês por perto!

Sou muito grata a todos os professores da UFSCar, que me acolheram com na Universidade como professora substituta com todo o carinho e respeito. Obrigada Profa Dra Mariana Vera pela parceria e tantas colaborações. Obrigada Profa Dra Stela Matiello e todo o LAFar pela acolhida maravilhosa. É muito bom trabalhar com vocês.

Agradeço a Fundação de Amparo e Pesquisa do Estado de São Paulo (FAPESP), processo no 2012/20046-2, pelo apoio financeiro e suporte, que viabilizaram a execução deste trabalho. 
"Evoluir é adquirir a consciência sobre o que é essencialmente importante para você se sentir pleno"

(um cartão) 


\section{Resumo}

\section{CARVALHO GF. Alterações no equilíbrio funcional em pacientes com migrânea}

crônica e episódica. [tese]. Ribeirão Preto: Universidade de São Paulo, Faculdade de Medicina de Ribeirão Preto, 2016. 89f.

Estudos recentes verificaram a presença de distúrbios relacionados ao equilíbrio postural estático e agilidade em pacientes com migrânea com e sem aura, sugerindo uma dependência alterada nos sistemas sensoriais que controlam o equilíbrio. No entanto, não são conhecidas as alterações dinâmicas e funcionais, tampouco a influência da cronicidade sobre estes parâmetros. O objetivo deste estudo foi identificar as alterações de equilíbrio dinâmicas e funcionais em pacientes com migrânea crônica (MC), migrânea com aura (MA) e sem aura (M) e indivíduos controle (GC). Foram avaliados 35 indivíduos em cada grupo, triados do Ambulatório de Cefaleia e Algias Craniofaciais do HC-FMRP, por meio do teste modificado de integração sensorial do equilíbrio, limites de estabilidade, sentado para em pé, subida e descida do degrau, caminhada e caminhada tandem, realizados no equipamento Balance Master $^{\circledast}$. Além disso, os pacientes foram avaliados quanto ao relato de quedas e foram aplicados os questionários FES-1 e DHI. Os dados foram analisados por meio do teste exato de Fisher e ANCOVA no software SAS 9.2 com nível de significância de 5\%. Os resultados deste estudo sugerem que pacientes com migrânea apresentam alterações de equilíbrio em todos os testes avaliados em comparação ao grupo controle $(p<0,05)$. Pacientes MA e MC apresentaram pior desempenho que o grupo $\mathrm{M}$ em duas condições do teste modificado de integração sensorial do equilíbrio. Além disso, o grupo MA e MC apresentaram maior relato de história quedas, número de quedas no último ano, maior incapacidade devido à tontura e preocupação com quedas superior comparado ao grupo $M(p<0,001)$. Pacientes com migrânea apresentam em geral um impacto funcional decorrente das alterações de equilíbrio, que é exacerbado na presença de aura e cronicidade. Futuros estudos com o objetivo de investigar aspectos clínicos e implementação de estratégias de avaliação e reabilitação da deterioração do controle postural podem ser benéficas para esta população.

Palavras-chave: Cefaleia, enxaqueca, equilíbrio, avaliação da incapacidade, reabilitação, fisioterapia. 


\begin{abstract}
CARVALHO GF. Functional balance impairment in patients with episodic and chronic migraine. [thesis]. Ribeirão Preto: University of São Paulo, Ribeirão Preto Medical School, 2016. 89p.
\end{abstract}

Recent studies have demonstrated the presence of impairment of the static postural control and agility in patients with migraine with and without aura, suggesting an altered dependency of the sensorial systems accounted to control the corporal balance. However, neither the dynamic and functional changes nor the chronicity influence on the postural control of migraine patients have been investigated. The objective of this study was to identify the dynamic and functional changes in patients with chronic migraine (CM), migraine with aura (MA) and without aura (M) and controls (CG). It was assessed 35 patients in each group, screened from the Headache and Craniofacial Pain outpatient clinic from the HC-FMRP, through the tests: modified clinical test of sensory interaction in balance, limits of stability, sit to stand, step up and over, walk across and tandem walk, performed at the Balance Master System $^{\circledast}$. In addition, patients completed a questionnaire regarding the self-report of falls, FES and DHI. The data was contrasted using Fisher's exact test and ANCOVA in the SAS 9.2 and level of significance of 5\%. Patients with migraine presented balance changes in all outcomes of all tests compared to controls $(\mathrm{p}<0.05)$. Patients with MA and CM exhibited greater history of falls, more falls during the prior year, greater handicap due dizziness, and concern about falls compared to $M(p<0.001)$. This study suggests the presence of functional impact due balance changes in patients with migraine, which becomes worse due the presence of aura and chronicity. Future studies that investigate the clinical aspects and implement assessment and rehabilitation strategies regarding the postural control deterioration might benefit patients with migraine.

Keywords: Headache, migraine, balance, handicap assessment, rehabilitation, physical therapy. 


\section{Lista de Figuras}

Página

Figura 1. Divisão temporal de uma crise de migrânea

Figura 2. Plataforma Neurocom Balance Master System ${ }^{\circledR}$

Figura 3. Teste modificado de integração sensorial do equilíbrio

Figura 4. Uso da espuma sobre a plataforma de força para aumentar a perturbação durante o teste

Figura 5. Representação da tela do teste Limites de Estabilidade no equipamento Balance Master System

Figura 6. Representação do deslocamento durante o teste de caminhada

Figura 7. Caminhada Tandem

Figura 8. Teste de subida e descida do degrau.

Figura 9. Teste sentado para em pé

Figura 10. Teste modificado de integração sensorial do equilíbrio

Figura 11. Níveis de autopercepção de incapacidade de acordo com as dimensões físicas, funcionais e emocionais do questionário DHI Brasileiro 


\section{Lista de Tabelas}

Página

Tabela 1. Critérios diagnósticos para a migrânea de acordo com a International Classification of Headache Disorders $-3^{\text {rd }}$ edition beta

Tabela 2. Valores médios e desvio padrão das variáveis demográficas da amostra média e IC $95 \%$

Tabela 3. Tamanhos de efeito e IC $95 \%$ das diferenças no teste modificado de integração sensorial do equilíbrio

Tabela 4. Tempo de Reação do teste Limites de Estabilidade (segundos) - média (IC $95 \%)$

Tabela 5. Velocidade de movimento do teste Limites de Estabilidade (graus/segundo) - média (IC 95\%)

Tabela 6. Excursão final no teste Limites de Estabilidade (\% da máxima excursão estimada) - média (IC 95\%)

Tabela 7. Excursão Máxima no teste Limites de Estabilidade (\% da máxima excursão estimada) - média (IC 95\%)

Tabela 8. Tamanhos de efeito e IC $95 \%$ das diferenças no teste limites de estabilidade

Tabela 9. Média e IC95\% nas variáveis dos testes de caminhada e caminhada tandem

Tabela 10. Tamanhos de efeito e IC $95 \%$ das diferenças nos testes de caminhada e caminhada tandem.

Tabela 11. Média e IC95\% nas variáveis do teste de subida e descida do degrau

Tabela 12. Tamanhos de efeito e IC $95 \%$ das diferenças no teste subida e descida do degrau

Tabela 13. Média e IC95\% nas variáveis do teste sentado para em pé 
Tabela 14. Tamanhos de efeito e IC $95 \%$ das diferenças no teste sentado para em pé.

Tabela 15. Média e desvio padrão da pontuação do DHI e prevalência de tontura dentro e fora das crises de migrânea

Tabela 16. Prevalência e número de quedas no último ano (média e DP), razão de prevalência de quedas e pontuação no questionário FES-I 


\section{Lista de abreviaturas e siglas}

A

$\mathrm{ABC}$

AD

$\mathrm{AE}$

CGRP

$\mathrm{Cm}$

D

DCA

DGI

DHI

E

ES

FES-I

GC

ICHD-III

IPAQ

LOS

M

MA

$\mathrm{MC}$

OAest

OAinst

OFest

OFinst

$\mathrm{P}$

PD

PE

RP

Seg.

SP

TUG
Direção anterior

Activities-Specific Balance Confidence Scale

Direção anterior-direita

Direção anterior-esquerda

Peptídeo relacionado ao gene da calcitonina

Centímetros

Direção direita

Depressão cortical alastrante

Dynamic Gait Index

Dizziness Handicap Inventory

Direção esquerda

Tamanho de Efeito (Effect size)

Escala internacional de eficácia de quedas

Grupo controle

Terceira Classificação Internacional de Cefaleias (versão beta)

Questionário Internacional de Atividade Física

Limites de estabilidade

Grupo migrânea sem aura

Grupo migrânea com aura

Grupo migrânea crônica

Olhos abertos em superfície estável

Olhos abertos em superfície instável

Olhos fechados em superfície estável

Olhos fechados em superfície instável

Direção posterior

Direção posterior-direita

Direção posterior-esquerda

Razão de prevalência

Segundos

Substância P

Timed Up and Go 


\section{SUMÁRIO}

1. INTRODUÇ̃̃̃O

1.1. REVISÃo BIBLIOGRÁFICA 20

1.1.1. MIGRÂNEA 20

1.1.2. EPIDEMIOLOGIA E IMPACTO 20

1.1.3. MANIFESTAÇÕES CLÍNICAS 20

1.1.4. FISIOPATOLOGIA DA MIGRÂNEA 24

1.1.5. ALTERAÇÕES NOS SISTEMAS SENSORIAIS RELACIONADOS AO CONTROLE POSTURAL EM PACIENTES COM MIGRÂNEA

1.1.6. AVALIAÇ̃̃o DO EQUILÍBRIO FUNCIONAL

1.1.7. AVALIAÇÃO DA TONTURA E QUEDAS 28

1.2. JUSTIFICATIVA E HiPÓTESE 29

2. OBJETIVOS $\quad 31$

2.1. OBJETIVOS PRIMÁRIOS 31

2.2. OBJETIVOS SECUNDÁRIOS 31

3. MATERIAL E MÉTODOS

3.1. AMOSTRA 33

3.2. PRocedimento eXPerimental $\quad 34$

3.3. BaLANCE MASTER

3.4. Protocolo de testes Selecionados

3.4.1. TESTE MODIFICADO DE INTEGRAÇÃO SENSORIAL DO EQUILÍBRIO

3.4.2. LIMITES DE ESTABILIDADE 37

3.4.3. TESTE DE CAMINHADA 38

3.4.4. CAMINHADA TANDEM 39

3.4.5. TESTE DE SUBIDA E DESCIDA DO DEGRAU 40

3.4.6. TESTE SENTADO PARA EM PÉ 41

3.5. QUESTIONÁRIOS $\quad \mathbf{4 2}$

3.5.1. QUESTIONÁRIO INTERNACIONAL DE ATIVIDAdE FÍSICA - IPAQ (VERSÃo CURTA) 42

3.5.2. DIZZINESS HANDICAP INVENTORY (DHI BRASILEIRO) 43

3.5.3. ESCALA INTERNACIONAL DE EFICÁCIA DE QUEDAS (FES-1 BRASIL) 43

3.6. ANÁLISE ESTATÍSTICA $\quad \mathbf{4 4}$

3.6.1. CÁlCULO AMOSTRAL 44

3.6.2. ANÁLISE DOS DADOS $\quad 45$

4. RESULTADOS $\quad 47$

\begin{tabular}{ll} 
4.1. & AMOSTRA \\
\hline
\end{tabular}

4.2. TESTE MODIFICADO DE INTEGRAÇÃO SENSORIAL DO EQUILÍBRIO 49

4.3. LIMITES DE ESTABILIDADE

4.4. TESTE DE CAMINHADA E CAMINHADA TANDEM 56

4.5. TESTE DE SUBIDA E DESCIDA DO DEGRAU

4.6. TESTE DE SENTADO PARA EM PÉ

4.7. TONTURA E DHI BRASILEIRO

4.8. QUEDAS E FES-I BRASIL $\quad 63$ 
5. DISCUSSÃO 66

5.1. SUMÁRIO 66

5.2. DISCUSSÃO DOS RESULTADOS

5.3. LIMITAÇÕES E FORÇAS DO ESTUDO 70

6. CONCLUSÕES 73

6.1. CONCLUSÕES PRIMÁRIAS 73

6.2. CONCLUSÕES SECUNDÁRIAS 73

7. REFERÊNCIAS BIBLIOGRÁFICAS 75

8. APÊNDICES 83

9. ANEXOS 85 


\section{Introdução}

1.1 Revisão bibliográfica

1.1.1 Migrânea

1.1.2 Epidemiologia e impacto

1.1.3 Manifestações clínicas

1.1.4 Fisiopatologia da migrânea

1.1.5 Alterações nos sistemas sensoriais relacionados ao controle postural em pacientes com migrânea

1.1.6 Avaliação do equilíbrio funcional

1.1.7 Avaliação da tontura e quedas

1.2 Justificativa e hipótese 


\section{INTRODUÇÃO}

A migrânea é uma doença neurológica caracterizada por cefaleia e sintomas associados. ${ }^{1}$ Além da dor de cabeça de moderada a forte intensidade, o paciente pode apresentar alterações no controle postural. ${ }^{2-13}$ A comorbidade com a queixa de tontura é um fator comum nesta população, ${ }^{14-18}$ especialmente em pacientes que relatam a presença de aura migranosa. ${ }^{1,4}$

Estudos prévios reportaram maior deslocamento do Centro de Pressão (CP) na plataforma de força em pacientes com migrânea comparados a indivíduos controles ${ }^{3-7,9,10,13} \mathrm{e}$ em pacientes com outros tipos de cefaleias. ${ }^{8}$ Pacientes com migrânea com aura demonstram uma maior oscilação comparados ao migranosos sem aura. ${ }^{4}$

A etiologia das alterações do controle postural nestes pacientes ainda é desconhecida, mas pode estar relacionada à presença de microisquemias no território das artérias vértebrobasilares, especialmente incidindo sobre o cerebelo, ${ }^{19-21}$ tronco encefálico e ouvido interno. $^{22,23}$ Associada ou decorrente desta condição, pode ser observado ainda anomalias no funcionamento do sistema otoneurológico em pacientes com migrânea. ${ }^{7,13,24,25}$ As disfunções otoneurológicas são mais severas nos migranosos com aura ${ }^{7}$ e está estabelecida uma correlação positiva entre a frequência de crises e presença de aura com a quantidade de lesões isquêmicas na região do cerebelo. ${ }^{19-21,26-28}$

No entanto, a repercussão funcional destas alterações, tampouco a influência de diferentes tipos de migrânea no controle postural ainda é desconhecido. Assim, este estudo visou explorar estes aspectos em pacientes com diferentes subtipos de migrânea e indivíduos sem dor de cabeça. 


\subsection{REVISÃo BIBLIOGRÁFICA}

\subsubsection{MIGRÂNEA}

A migrânea é uma cefaleia primária de manifestação episódica, caracterizada por uma combinação de alterações neurológicas, gastrointestinais e autonômicas. ${ }^{29,30}$ É considerada uma doença neurovascular, com alterações vasculares secundárias a uma ativação neuronal excessiva, causada por uma disfunção primária cerebral. ${ }^{30}$ A hiperexcitabilidade do sistema nervoso central presente em pacientes com migrânea é determinado geneticamente e influenciado por fatores ambientais. ${ }^{31}$

\subsubsection{EPIDEMIOLOGIA E IMPACTO}

A migrânea é considerada a segunda cefaleia primária mais predominante, com prevalência populacional de $12 \%$, sendo mais prevalente no sexo feminino (17 a 20\%) comparado ao masculino (4 a 6\%). ${ }^{32-34} \mathrm{O}$ pico de prevalência da migrânea gira em torno dos anos produtivos de idade, de 22 aos 55 anos, ${ }^{34}$ e apresenta prévio início no sexo masculino em relação ao feminino. Além disso, a migrânea com aura se inicia em indivíduos mais jovens comparada à migrânea sem aura. ${ }^{33}$

Devido à sua prevalência na idade produtiva, a migrânea provoca impacto significativo na economia e no bem-estar social devido à grande incapacidade gerada pela dor. ${ }^{35}$ Cerca de $92 \%$ das mulheres e $89 \%$ dos homens com migrânea apresentam severa incapacidade ou precisam de repouso no leito, reduzindo significativamente a qualidade de vida. ${ }^{33}$ Por isso, a migrânea ocupa a sexta posição dentre as doenças crônicas com maior número de anos vividos com incapacidade de acordo com a Global Burden of Disease Survey, ${ }^{36}$ gerando despesas anuais aos serviços de saúde no Brasil ao redor de R\$ 144 mil reais/ano. ${ }^{37}$

\subsubsection{MANIFESTAÇÕES CLÍNICAS}

As migrânea é considerada uma síndrome que pode variar em relação a duração, intensidade, frequência e presença de sintomas associados. ${ }^{38}$ 
Estes pacientes apresentam um aumento da excitabilidade cortical comparados a indivíduos sem cefaleia, respondendo facilmente a estímulos extrínsecos e intrínsecos, mesmo no período intercrise. Apresentam sensibilidade aumentada à luz, ao som, movimento, cheiro e outros estímulos sensoriais. ${ }^{39}$

Em 75,9\% dos pacientes, a resposta a estes estímulos desencadeia uma crise migranosa. Os principais fatores desencadeantes, denominados triggers, descritos pelos pacientes são: alterações emocionais (estresse), alterações hormonais na mulher (período menstrual), jejum prolongado, mudanças climáticas, distúrbios do sono, perfumes ou odores, dor cervical, luminosidade, bebidas alcoólicas, fumaça, tipos específicos de alimentos e atividade física excessiva. ${ }^{38,39}$

Uma crise de migrânea é didaticamente dividida em quatro fases temporais que podem se sobrepor ou mesmo estar ausentes: sintomas premonitórios (pródromo), aura, a fase de dor e o período de resolução da crise (pósdromo) (Figura 1).

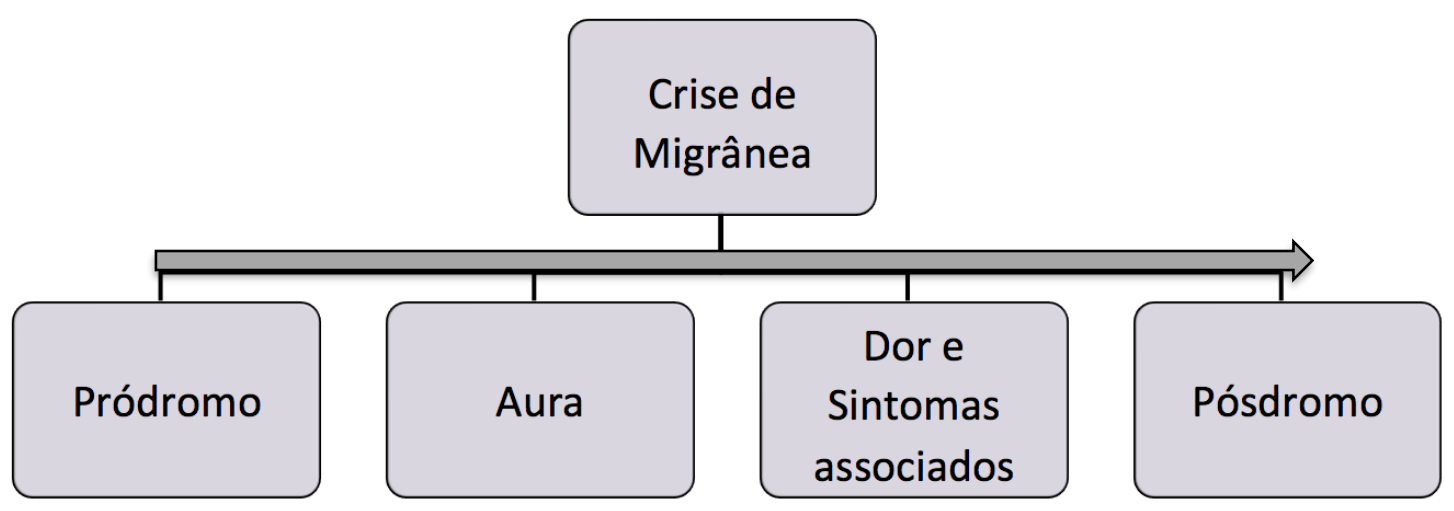

Figura 1. Divisão temporal de uma crise de migrânea.

\section{A. Pródromo}

Cerca de $72 \%$ dos migranosos apresentam sintomas físicos e/ou cognitivos predizendo o aparecimento de uma crise, ${ }^{40,41}$ que são relatados de horas até dias antes de um episódio migranoso. ${ }^{38}$ Dentre os sintomas mais comuns se encontram alterações do humor, distúrbios do sistema digestório e mudanças de apetite, dificuldade de concentração, irritabilidade, fadiga, rigidez cervical, bocejos repetidos e alterações no sono. ${ }^{1,38,41}$ Mesmo pacientes com alto nível de instrução podem apresentar dificuldade em reconhecer tais sintomas. ${ }^{38}$ 


\section{B. Aura}

Cerca de $25 \%$ dos portadores de migrânea apresentam sintomas neurológicos focais transitórios e completamente reversíveis, chamados de aura. ${ }^{42} \mathrm{~A}$ aura pode anteceder a fase de dor, acompanhá-la ou surgir como manifestação isolada da crise, com duração obrigatória de 5 a 60 minutos. ${ }^{38}$

A mesma pode se manifestar como alucinações visuais, vertigem, parestesias, paresias ou disfasias. Os pacientes que não apresentam este sintoma são diagnosticados com migrânea sem aura. A aura é dividida em três subtipos de acordo com os sintomas referidos pelo paciente: migrânea com aura típica, migrânea basilar e migrânea hemiplégica. ${ }^{1}$

A migrânea com aura típica inclui as seguintes categorias de aura:

- Aura típica visual - presente em cerca de $90 \%$ dos pacientes com aura e consiste na presença de alucinações visuais, pontos de luminosidade intermitentes, escotomas, pequenas manchas no campo visual, flashes, pontos cegos centrais ou paracentrais, hemianopsias, espectros de fortificação, macro e micropsias (mudanças de cor e forma dos objetos);

- Aura típica sensitiva - é caracterizada pela presença de formigamento e/ou dormência que usualmente atinge a região da mão, face e língua;

- Aura típica disfásica - estão presentes disfasias e distúrbios de linguagem. ${ }^{1}$

A aura hemiplégica inclui alterações motoras como hemiparesia somados ao sintomas de uma aura típica. Por apresentar sintomas motores, este tipo de aura é considerado um subtipo caracterizado por diferenças genéticas e fisiopatológicas em relação a pacientes com aura típica. A aura do tipo basilar se caracteriza por presença de disartria, vertigem, zumbido, diplopia, ataxia ou diminuição no nível de consciência. ${ }^{1}$

\section{Fase de dor e sintomas acompanhantes}

A cefaleia da migrânea é classicamente descrita como pulsátil, unilateral, de intensidade moderada a forte e geralmente é agravada por esforço físico rotineiro. A dor pode durar de 4 a 72 horas (habitualmente menos de 24 horas) e as localizações mais comuns são frontal e temporal. Entre os sintomas acompanhantes predominam náuseas, vômitos, fotofobia 
e fonofobia. ${ }^{1,38}$ Algumas destas características podem estar ausentes e o diagnóstico da migrânea é realizado de acordo com a Classificação Internacional de Cefaleias (Tabela 1). ${ }^{1}$

Tabela 1. Critérios diagnósticos para a migrânea de acordo com a International Classification of Headache Disorders $-3^{\text {rd }}$ edition beta. ${ }^{1}$

\begin{tabular}{|l|}
\hline A. Pelo menos 5 crises preenchendo os critérios de B a D: \\
\hline B. Crises de cefaleia com duração de 4 a 72 horas (sem tratamento ou \\
com tratamento ineficaz) \\
\hline C. Cefaleia com pelo menos duas das quarto características abaixo: \\
1. Localização unilateral \\
2. Caráter pulsátil \\
3. Dor de intensidade moderada a forte \\
4. Dor exacerbada por ou levando o indivíduo a evitar atividades \\
físicas rotineira (ex. caminhar, subir escadas) \\
\hline D. Durante a cefaleia, pelo menos um dos seguintes: \\
1. Náusea e/ou vômitos \\
2. Fotofobia e fonofobia \\
\hline E. Não atribuída a outro transtorno
\end{tabular}

Além dos sintomas acompanhantes já citados, conforme a cefaleia progride, podem estar presentes outras alterações que não são consideradas critérios para o diagnóstico da migrânea, mas também são decorrentes da excessiva ativação cortical. Estes podem ser de origem autonômica (congestão nasal, rinorréia, lacrimejamento, ptose palpebral, bocejos, poliúria, diarreia), emocional (depressão e irritabilidade), cognitiva (déficit de atenção, afasia, amnésia transitória, desorientação temporo-espacial) e/ou sensorial (além da foto e fonofobia podem estar presentes quadros de hipersensibilidade muscular, alodinia cutânea e osmofobia). ${ }^{43,44}$

A migrânea é comumente classificada de acordo com a presença de aura e também de acordo com a frequência das crises. Quando o paciente apresenta uma frequência de dor igual ou superior a 15 dias dentro de um mês, é diagnosticado com crônica. ${ }^{1,45}$ A cronicidade da migrânea está relacionada à outras comorbidades dolorosas e emocionais, sendo considerada altamente incapacitante e de difícil manejo. Além disso, pacientes com migrânea crônica comumente apresentam uma associação com abuso de medicamentos - fator relacionado com o aumento da frequência de crises e agravamento da migrânea. ${ }^{45-47}$ A cronificação da migrânea está relacionada à mudanças no processamento e nos limiares de ativação da dor. ${ }^{42}$ 


\section{Pósdromo}

Após o período da cefaleia, cerca de $68 \%$ dos pacientes com migrânea apresentam alguns sintomas associados com a resolução da crise. Eles frequentemente se sentem cansados, letárgicos, irritados ou apáticos, com alterações no humor e na capacidade de concentração, que podem permanecer durante dias. Alguns atipicamente relatam euforia e disposição e outros, depressão, anorexia, tontura e mal-estar. ${ }^{29,48}$

\subsubsection{FISIOPATOLOGIA DA MIGRÂNEA}

Devido à grande associação de diversos sintomas, a migrânea não é mais vista como só uma cefaleia, mas sim como uma disfunção neurológica complexa, que afeta múltiplas regiões corticais, subcorticais e estruturas do tronco cerebral que regulam as funções autonômicas, afetivas, cognitivas e sensorais. ${ }^{44}$ Esta disfunção encefálica na regulação do tráfego sensorial resulta em um estado de susceptibilidade à crises, que dentre vários sintomas, pode incluir a cefaleia. ${ }^{42,49}$

As crises de migrânea se iniciam no sistema nervoso central, em áreas do cérebro capazes de gerar os sintomas neurológicos clássicos do pródromo e aura, enquanto que a fase de cefaleia se inicia com consequente ativação dos nociceptores da meninge na origem do sistema trigeminovascular. ${ }^{50}$

O pródromo está relacionado a distúrbios na atividade neuronal nas regiões do córtex, diencéfalo e/ou estruturas no tronco cerebral, secundários à uma hipersensibilidade dopaminérgica. ${ }^{50,51}$

Já a aura é causada por uma onda de despolarização cortical, denominada Depressão Cortical Alastrante de Leão (DCA), que se caracteriza por uma depressão da atividade elétrica cortical que se propaga pelo córtex em uma velocidade de 3 a $4 \mathrm{~mm} / \mathrm{min} .{ }^{1,52,53} \mathrm{O}$ funcionamento neuronal anormal nesta fase causa um decréscimo da demanda metabólica com uma consequente redução transitória do fluxo sanguíneo cerebral. ${ }^{42}$

A DCA ativa o sistema trigeminovascular nos vasos sanguíneos periféricos e no núcleo trigeminal, no tronco cerebral. Alguns autores acreditam que a DCA também pode estar presente em migranosos sem aura, se manifestando de forma subclínica. ${ }^{42,49}$

A ativação do sistema trigeminovascular desencadeia uma liberação dos neurotransmissores CGRP e SP (peptídeo relacionado ao gene da calcitonina e substância P) 
no espaço perivascular das meninges, que interagem com outras substâncias liberadas pelo próprio vaso e por fibras nervosas simpáticas e parassimpáticas, provocando vasodilatação e aumento da permeabilidade vascular com consequente extravasamento de plasma. Este processo, chamado de inflamação neurogênica, é difundido por meio das redes perivasculares devido a excitação do sistema trigeminal. A estimulação das aferências nociceptivas trigeminais geram estímulos algógenos que serão levados ao gânglio trigeminal, ao tálamo e finalmente ao córtex, originando a percepção de dor. ${ }^{29,40,42,49}$

Os sintomas de fotofobia são desencadeados por uma alteração da resposta ao estímulo visual decorrente do bombardeamento de sinais nociceptivos pela via trigeminovascular na convergência com o córtex visual, que está hiperexcitado em migranosos. ${ }^{50}$ Já a fonofobia pode ser decorrente de uma desinibição no tronco cerebral mediado por um estado de hipofunção serotoninérgica causando uma falha no processamento do input acústico. ${ }^{54}$ Os sintomas de náusea e vômitos são desencadeados por uma disfunção autonômica na região cinzenta periarquedutal do quarto ventrículo. ${ }^{55}$

As alterações presentes na fase do pósdromo ainda não estão bem elucidadas. As mesmas podem estar relacionadas à ativação persistente de estruturas do tronco cerebral envolvidas na fase de pródromo ou podem ser causadas por mecanismos neurais completamente diferentes. ${ }^{48}$

As alterações hemodinâmicas presentes na crise de migrânea são mais evidentes na presença de aura, onde há uma vasoconstrição dos vasos sanguíneos cerebrais mais definida. ${ }^{42}$

Em consequência as alterações vasculares são verificadas regiões de micro isquemias em migranosos, especialmente naqueles com aura, no território das artérias vértebro-basilares com maior comprometimento do cerebelo. ${ }^{19-21}$ Além do cerebelo, o tronco encefálico e o sistema vestibular também podem ser atingidos pela isquemia. ${ }^{22}$

Acredita-se que a migrânea com aura pode ser responsável por anormalidades na substância branca cerebral, por hipoperfusão e infartos cerebelares, além de alterações cocleovestibulares. ${ }^{21,22,56}$ É possível ainda, que a depressão alastrante, presente na crise de aura, possa produzir sintomas vestibulares. ${ }^{57}$

A repetição sucessiva destes mecanismos relacionados a inflamação neurogênica podem resultar em desarranjo irreversível do sistema nervoso periférico e central, ${ }^{13}$ com permanente disfunção do tronco cerebral, cerebelo ${ }^{28,58}$ e alterações nas vias centrais vestibulares. ${ }^{3,6,8,59}$ 
Além disso, as alterações locais durante as crises, como ativação neuronal excessiva, inflamação neurogênica e liberação de neuropeptídeos e citocinas podem causar diretamente danos nos tecidos cerebrais de migranosos. ${ }^{60}$

Alguns fatores podem influenciar a presença destas alterações. Estudos de imagem relacionam o aumento da frequência de crises com a maior incidência de lesões isquêmicas, encontradas especialmente no cerebelo. ${ }^{21,26-28}$ Portanto além da presença da aura, a cronicidade pode ser fator agravante para presença de alterações isquêmicas.

\subsubsection{ALTERAÇÕES NOS SISTEMAS SENSORIAIS RELACIONADOS AO CONTROLE POSTURAL EM PACIENTES COM MIGRÂNEA}

Em associação à migrânea, é verificada alta prevalência dos sintomas de vertigem e tontura, sensibilidade ao movimento ${ }^{14-16,61,62}$ e alterações no equilíbrio postural tanto estático quanto dinâmico. ${ }^{3,8,11-15,63}$

Cerca de $38 \%$ dos pacientes com migrânea relatam também a presença de sintomas de tontura e vertigem. ${ }^{64}$ Além disso, 58\% dos migranosos apresentam evidências de disfunção vestibular, distúrbios vestíbulo-cerebelares e oculomotores, baseados em avaliações laboratoriais otoneurológicas, ${ }^{13,24,25,28}$ que podem estar presentes independentemente da queixa de tontura. ${ }^{59,65}$ Celebisoy et $\mathrm{al}^{5}$ e Teggi et $\mathrm{al}^{13}$ demonstraram um déficit no controle postural de pacientes com migrânea em comparação à migrânea associada à queixa de vertigem, descrita por alguns autores como migrânea vestibular. No entanto, o mesmo não foi evidenciado por Furman et al, ${ }^{6}$ Panichi et al $^{10}$ ou Ongun et al, ${ }^{9}$ sugerindo que a disfunção vestíbulo-cerebelar muitas vezes pode estar presente sem nenhum sintoma clínico relatado pelo paciente.

A prevalência de tontura é maior em pacientes com aura ${ }^{4}$ e assim como as alterações otoneurológicas, tendem a ser mais severas nestes pacientes quando avaliadas por meio da eletronistagmografia, vídeo-oculografia e prova calórica. ${ }^{7}$

Estudos utilizando a posturografia como método de avaliação demonstraram alterações no controle postural semi-estático em migranosos, ${ }^{3,5-13}$ associada à redução dos limites de estabilidade, ${ }^{2,3}$ e diminuição na velocidade da marcha e marcha tandem. ${ }^{2-4,66}$ Além disso, foram verificados aumento no tempo de execução do teste Timed Up and Go (TUG). ${ }^{4}$ Algumas destas alterações parecem progredir com o tempo ${ }^{2}$ e são influenciadas pela presença da aura. ${ }^{4}$ 
A presença de maior oscilação postural diante de estímulos realizados por meio da estimulação galvânica e estimulação optocinética em indivíduos com migrânea evidenciaram que estes pacientes apresentam distúrbios de origem central; ${ }^{3,11}$ e sugerem que as alterações do sistema vestibular não são compensadas com a utilização da visão. ${ }^{12,13}$ Isso pode estar relacionado a um quadro de alteração na dependência dos sistemas sensoriais que controlam o equilíbrio. $^{12}$

Ishizaki et al, compararam através da estabilometria indivíduos com migrânea, cefaleia do tipo tensional e controles. Os dados revelaram maior oscilação postural com os olhos fechados em migranosos comparados aos controles. Os pacientes com dor de cabeça do tipo tensional não apresentaram diferenças em relação ao controle, sugerindo que a maior oscilação postural seja uma característica da migrânea. ${ }^{8}$

Por sua vez, a presença de hipermetria e movimentos balísticos durante uma tarefa de alcance em pacientes com migrânea com e sem aura indicam a presença de anormalidades no funcionamento do cerebelo. ${ }^{58}$

A lesões microisquêmicas em migranosos descritas anteriormente podem acarretar consequências clínicas e funcionais. ${ }^{68-71}$ No entanto, não existe evidência de relação etiológica entre as lesões e as alterações clínicas descritas nesta seção.

\subsubsection{AVALIAÇÃO DO EQUILÍBRIO FUNCIONAL}

Os estudos que avaliaram o equilíbrio em pacientes com migrânea demonstraram anormalidades que são referidas em sua maioria como subclínicas ou assintomáticas; ;,3,6-8,11 ou seja, ainda não é elucidado se as alterações do controle postural encontradas em migranosos apresentam algum impacto funcional.

Assim, o uso de ferramentas que permitam a quantificação da performance durante a execução de atividades funcionais pode ser aplicada na avaliação de pacientes com migrânea. Atuais técnicas têm sido desenvolvidas para mensurar os amplos aspectos relacionados ao controle do equilíbrio corporal, entre eles o equipamento Balance Master (NeuroCom ${ }^{\circledR}$ ). Este sistema permite a mensuração de vários desfechos relacionados ao equilíbrio estático, dinâmico e ao controle motor durante atividades funcionais em indivíduos assintomáticos ${ }^{72-75}$ e portadores de doenças específicas. ${ }^{76-78}$

O equipamento quantifica variáveis relacionadas ao equilíbrio com alta confiabilidade, ${ }^{79}$ tendo sido considerado padrão ouro para a validação de uma escala clínica 
de avaliação do equilíbrio e marcha. ${ }^{80}$ Além disso é possível realizar a reabilitação do controle motor e dos sistemas sensoriais do equilíbrio por meio de exercícios disponíveis associados a um feedback visual. ${ }^{81}$

Assim, movimentos dinâmicos como subir e descer degraus, transferências de sentado para em pé, marcha e outras diversas atividades funcionais podem ser avaliadas com precisão e de maneira quantitativa por meio do Balance Master ${ }^{\circledR}$.

\subsubsection{AVALIAÇÃO DA TONTURA E QUEDAS}

De acordo com o comitê para formulação de uma classificação de disfunções vestibulares, ${ }^{82}$ os sintomas vestibulares podem ser classificados em três grandes grupos:

- Tontura: definida como uma falsa percepção de movimento ou desorientação espacial;

- Vertigem: sensação de auto-movimento quando nenhum auto-movimento está ocorrendo, com sensação rotatória;

- Instabilidade ou sintomas posturais: sensação de desequilíbrio enquanto sentado, em pé ou andando, sem alguma preferência direcional.

Além de importante a adequada diferenciação de acordo com a sintomatologia, é necessário também conhecer o impacto dos sintomas vestibulares na vida diária. $\mathrm{O}$ questionário Dizziness Handicap Inventory (DHI) avalia a autopercepção dos efeitos incapacitantes provocados pela tontura, demonstrando a interferência psicológica no quadro clínico e no sofrimento destes pacientes, avaliando também os prejuízos funcionais relacionados a este sintoma.

Tanto as alterações vestibulares quanto as anormalidades do controle postural são preditores para incapacidade e presença de quedas e quedas recorrentes. ${ }^{83-85}$

Queda é definida pela Organização Mundial de Saúde como "evento que resulta em uma pessoa a ir inadvertidamente ao solo ou em algum nível inferior, excluindo mudanças de posição intencionais para se apoiar em móveis, paredes ou outros objetos". ${ }^{86}$

A queda é considerada um problema relevante em idosos pois ocupa a segunda posição como causa de mortalidade e morbidade decorrente de causas externas. ${ }^{87}$ Idosos apresentam alta susceptibilidade à lesões decorrentes da queda, acarretando em redução da mobilidade, autoconfiança e qualidade de vida, contribuindo para deterioração do controle postural e risco de recorrência de quedas. ${ }^{88}$ 
Outro fator que contribui para a recorrência de quedas é a presença do medo de cair. O medo de cair tem como consequência a restrição de atividades, ansiedade e também redução da qualidade de vida, acarrentando em declínio funcional. ${ }^{89}$ Este pode ser avaliado por meio da Escala Internacional de Eficácia de Quedas (FES-I Brasil) que é uma escala que mensura o nível de confiança ao realizar uma série de atividades de vida diária sem cair. Este questionário se correlaciona com medidas de marcha e equilíbrio, predizendo quedas futuras e declínio funcional. ${ }^{90}$

\subsection{JUSTIFiCATIVA E Hipótese}

Apesar da maior prevalência de alterações do sistema vestibular a anormalidades no sistema de controle postural, não está estabelecido se pacientes com migrânea apresentam algum prejuízo em atividades funcionais, como subir e descer degraus ou transferências de sentado para em pé. Além disso, é desconhecida a prevalência de quedas, presença de preocupação com quedas ou o impacto gerado pela presença da tontura nesta população. Os efeitos da aura ou cronicidade sobre os parâmetros relacionados ao equilíbrio dinâmico de migranosos e variáveis relacionadas às quedas também é desconhecido.

A partir das evidências de que a migrânea com aura e a cronicidade ocasionam alterações nos sistemas de controle do equilíbrio (diante do maior dano observado por estes parâmetros no SNC), a hipótese do trabalho é que estes indivíduos apresentam mais distúrbios de locomoção e alterações funcionais em relação aos migranosos sem aura e indivíduos controle. Além disso, é esperado que pacientes com migrânea apresentem maior preocupação com quedas e maior impacto na qualidade de vida devido à tontura. Se a hipótese for verdadeira, a identificação das limitações físicas e planejamento de metas preventivas do deterioramento do sistema de controle postural neste grupo de pacientes é crucial. 


\section{Objetivos}

2.1 Objetivos primários

2.2 Objetivos secundários 


\section{OBJETIVOS}

\subsection{OBJETIVOS PRIMÁRIOS}

- Verificar a influência da migrânea crônica, migrânea com e sem aura em seis atividades funcionais relacionadas ao equilíbrio semi-estático e dinâmico descritas a seguir: teste modificado de integração sensorial do equilíbrio, limites de estabilidade, caminhada, caminhada tandem, teste sentado para em pé e teste de subida e descida do degrau.

\subsection{OBJETIVOS SECUNDÁRIOS}

- Avaliar a prevalência de tontura bem como a autopercepção dos efeitos incapacitantes provocados pela mesma nos três subgrupos de migranosos.

- Avaliar a história de quedas e autorrelato de desequilíbrio, número de quedas no último ano e o nível de preocupação com quedas em atividades de vida diária nestas mesmas populações. 


\section{Material e Métodos}

\subsection{Amostra}

3.2 Procedimento experimental

3.3 Balance Master

3.4 Protocolo de testes selecionados

3.4.1 Teste modificado de integração sensorial do equilíbrio

3.4.2 Limites de estabilidade

3.4.3 Teste de caminhada

3.4.4 Caminhada tandem

3.4.5 Teste de subida e descida do degrau

3.4.6 Teste de sentado para em pé

3.5 Questionários

3.5.1 Questionário Internacional de Atividade Física (IPAQ)

3.5.2 Dizziness Handicap Inventory (DHI Brasileiro)

3.5.3 Escala Internacional de Eficácia de Quedas (FES-I Brasil)

3.6 Análise dos dados

3.6.1 Cálculo amostral

3.6.2 Análise dos dados 


\section{MATERIAL E MÉTODOS}

\subsection{Amostra}

Foram considerados neste estudo quatro grupos de indivíduos na faixa etária de 18 a 55 anos, do sexo feminino, com pelo menos três crises por mês de migrânea:

- 35 pacientes com migrânea com aura (MA);

- 35 pacientes com migrânea sem aura $(\mathrm{M})$;

- 35 pacientes com migrânea crônica (MC);

- 35 pacientes sem migrânea (GC).

Os pacientes foram selecionados no ambulatório de Cefaleia e Algias Craniofaciais do Hospital das Clínicas de Ribeirão Preto/FMRP-USP, a partir da análise de prontuários. Os pacientes com migrânea foram diagnosticados por neurologistas especialistas em cefaleia de acordo com a terceira Classificação Internacional de Cefaleias (ICHD-III beta). ${ }^{1}$

A estratificação das variáveis da amostra foi realizada por meio de um questionário (Apêndice A) incluindo: idade, sexo, diagnóstico, tempo da doença, número de crises por mês, intensidade e duração das crises, medicação utilizada, comorbidades associadas, autorrelato de quedas no último ano, desequilíbrio, tontura e presença de lesões decorrente das quedas.

Nos grupos de migrânea com e sem aura foram considerados os pacientes com até 12 dias de dor por mês, há pelo menos 6 meses. Pacientes com migrânea com aura foram incluídos se apresentassem aura típica. No grupo de migrânea crônica foram considerados os pacientes com mais de 15 dias de dor por mês, há pelo menos 6 meses. No grupo controle, foram incluídos indivíduos acompanhantes do mesmo ambulatório ou funcionários do hospital, sem queixa de dor de cabeça há pelo menos 20 anos.

Foram excluídos do estudo os pacientes com:

1. Doenças sistêmicas como fibromialgia, diabetes mellitus, artrite reumatoide, hipertensão arterial mal controlada e outras que interfiram na força ou na coordenação dos movimentos;

2. Relato de vestibulopatias;

3. Ter diagnóstico de qualquer outra cefaleia associada que não fosse a migrânea;

4. Pacientes com aura hemiplégica ou aura basilar;

5. Índice de massa corpórea (IMC) acima de 30; 
6. Pacientes em crise de cefaleia no momento da avaliação;

7. Qualquer comprometimento musculoesquelético que interferisse na execução dos testes.

8. Mulheres em período gestacional.

Este projeto foi aprovado pelo Comitê de Ética em Pesquisa do Hospital das Clínicas de Ribeirão Preto (Processo $n^{\circ} 16693 / 2012$ ) e antes da avaliação todos os pacientes assinaram o Termo de Consentimento Livre e Esclarecido (Anexo A).

\subsection{Procedimento experimental}

O procedimento foi dividido em duas etapas e realizado por dois avaliadores. $\mathrm{O}$ avaliador I realizou a triagem inicial dos sujeitos e após a triagem os mesmos foram conduzidos à sala de exames de maneira aleatória a fim de que o avaliador II fosse cego para a sua condição. Os indivíduos usuários de lentes corretivas visuais foram instruídos a permanecer com as mesmas durante todo o exame.

$\mathrm{Na}$ sala de exames, o examinador II realizou a avaliação do equilíbrio postural por meio de um protocolo de testes aplicados de forma sorteada e questionários, totalizando cerca de 60 minutos o tempo total de coleta, descrita a seguir:

\subsection{Balance Master}

O Balance Master System ${ }^{\circledR}$ é uma ferramenta amplamente utilizada para a avaliação quantitativa e reabilitação de disfunções relacionadas ao controle postural. ${ }^{81}$

É composto por duas plataformas de $1,40 \mathrm{~m}$ de comprimento por $0,43 \mathrm{~cm}$ de largura unidas por um pino, em cujas extremidades estão posicionadas quatro células de carga. As plataformas são conectadas a um computador com monitor localizado $1,85 \mathrm{~m}$ à frente das mesmas e ao nível dos olhos do indivíduo, para fornecer um feedback visual (Figura 2). Os sensores registram as forças verticais produzidas sobre a plataforma além dos deslocamentos nas direções anterior-posterior, mediolateral e em sentidos combinados, coletadas em uma frequência de $100 \mathrm{hz}^{81}$

Esta ferramenta é considerada eficiente para se avaliar equilíbrio e função ${ }^{91}$ já que permite analisar o controle postural em diversas situações que mimetizam atividades de vida diária, tais como, levantar-se da posição sentada ou transpor um degrau, entre outros. ${ }^{91}$ 
De acordo com os protocolos escolhidos, é possível ter acesso à variáveis referentes ao tempo de reação após o comando do software, velocidade e amplitude de oscilação do centro de massa corporal, força aplicada, impacto, controle de direção, estabilidade e simetria, entre outros. $^{81}$

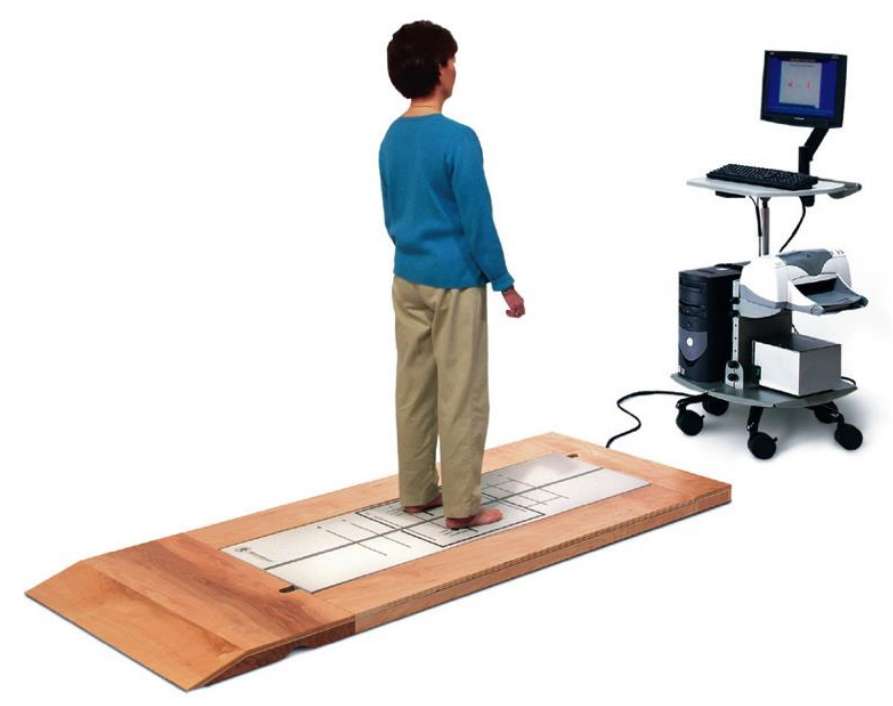

Figura 2. Plataforma Neurocom Balance Master System ${ }^{\circledR}$.

\subsection{Protocolo de testes Selecionados}

\subsubsection{TESTE MODIFICADO DE INTEGRAÇÃO SENSORIAL DO EQUILÍBRIO}

Este teste foi inicialmente proposto por Shumway Cook e Horak em 1986, e é ainda amplamente utilizado na avaliação do equilíbrio pois analisa a contribuição relativa dos receptores somatossensoriais, visuais e vestibulares na estabilidade postural, indicando de acordo com os padrões de distribuição sensorial, qual dos sistemas utilizados para a manutenção do equilíbrio está relacionado à instabilidade. ${ }^{92,93}$

Este teste consiste em manter-se em posição ortostática durante 30 segundos sob quatro diferentes condições (Figura 3):

- Olhos abertos em superfície estável (OAest);

- Olhos fechados em superfície estável (OFest)

- Olhos abertos em superfície instável (OAinst);

- Olhos fechados em superfície instável (OFinst). 


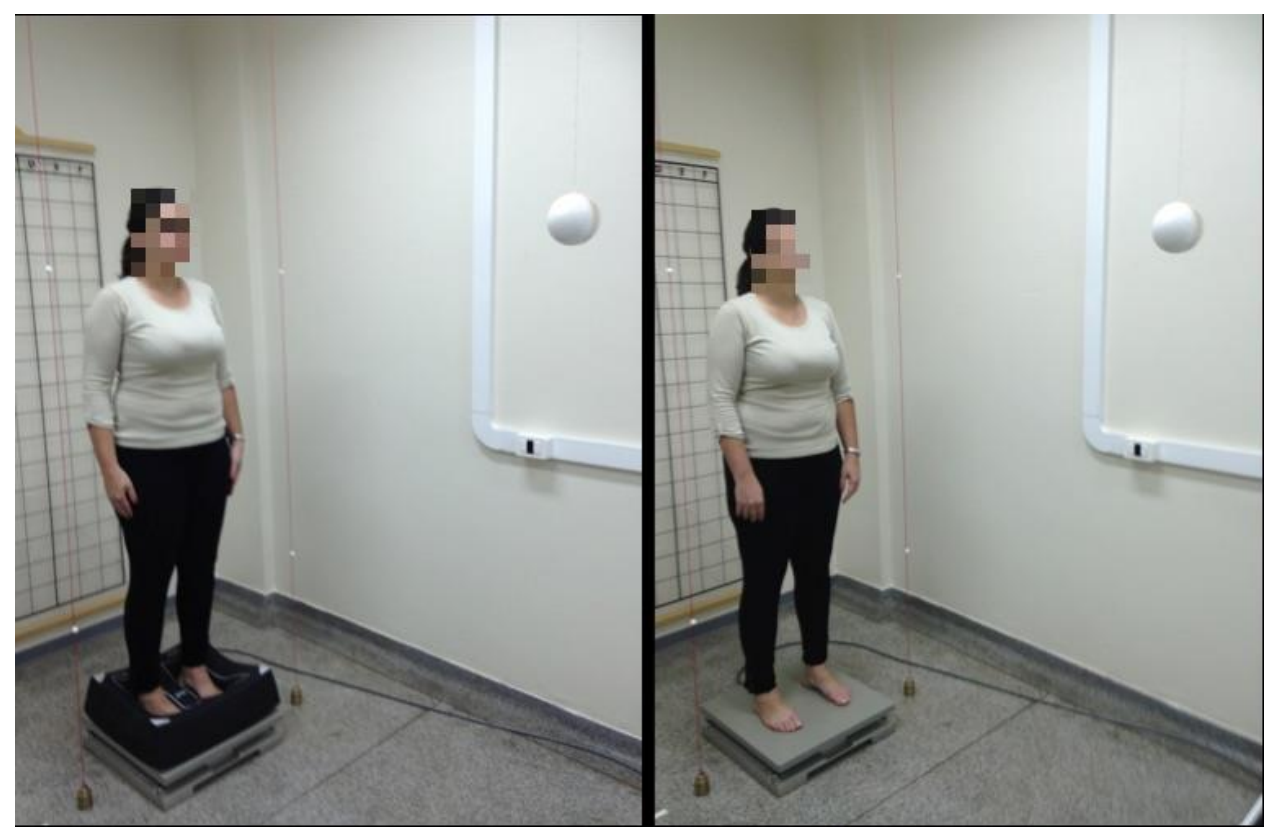

Figura 3. Teste modificado de integração sensorial do equilíbrio. Um alvo foi posicionado à uma distância de 2 metros do indivíduo, para fixação visual durante as condições com os olhos abertos.

Para a avaliação em superfície instável foi utilizada uma espuma com dimensões de 20x50x50 $\mathrm{cm}$ e densidade de $0,5 \mathrm{~kg} / \mathrm{cm}^{3}$. A largura da base de suporte foi definida em 3 níveis diferentes de acordo com a altura do voluntário, como sugerido pelo protocolo de avaliação do Balance Master System ${ }^{\circledR} .{ }^{81}$ A distância entre os pés do indivíduo sobre a plataforma e espuma variou de acordo com a sua altura, sendo: de 0,76 a 1,40m, a região lateral do calcâneo foi posicionada na linha $\mathrm{S}$ (short), com $20 \mathrm{~cm}$ entre os pés; de 1,41 a 1,65m, o pé foi posicionado na linha M (medium), com $25 \mathrm{~cm}$ entre os pés, e; de 1,66 a 2,03m, na linha T (tall), com $30 \mathrm{~cm}$ entre os pés (Figura 4).

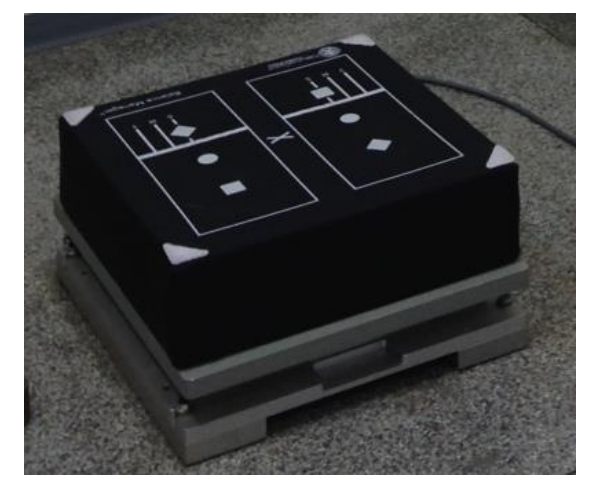

Figura 4. Uso da espuma sobre a plataforma de força para aumentar a perturbação durante o teste. Os maléolos mediais do voluntário foram centralizados na linha horizontal marcada na espuma. A largura da base de suporte foi definida de acordo com a altura do indivíduo nas linhas verticais marcadas na espuma. 
A realização destas quatro condições teve o objetivo de reduzir o input dos sistemas sensoriais disponíveis para o paciente na manutenção do equilíbrio estático. ${ }^{94}$

Este teste foi realizado em uma plataforma de força (AMTI - OR6-7-1000, frequência de coleta: $100 \mathrm{hz}$ ) pois o Balance Master $^{\circledR}$ não fornece a opção do teste com duração de 30 segundos, tempo recomendado para a avaliação do equilíbrio corporal estático. ${ }^{95}$

O ambiente de coleta estava livre de ruídos ou estímulos que atrapalhassem a concentração do indivíduo durante o teste. Um alvo foi posicionado à uma distância de 2 metros do indivíduo, para fixação visual durante as condições com os olhos abertos. O teste foi repetido três vezes em cada condição e a variável analisada foi a área de oscilação do centro de pressão (COP) $\left(\mathrm{cm}^{2}\right)$. Esta variável é resultante da média composta por $85 \%$ das trajetórias nas direções anteroposterior e mediolateral. ${ }^{81}$

\subsubsection{LIMITES DE ESTABILIDADE}

Na posição ortostática, a manutenção do equilíbrio pode ser analisada por meio do modelo do pêndulo invertido, pelo qual considera-se que a situação de equilíbrio é alcançada quando a projeção vertical do centro de massa estiver mantida dentro dos limites da base de

suporte, ${ }^{96-98}$ região marcada pelo limite de estabilidade (LOS). ${ }^{99}$ O LOS é a distância máxima que o centro de massa de uma pessoa pode ser deslocado intencionalmente sem alterar a base de suporte. A realização bem-sucedida dessa tarefa é produto da complexa interação de sistemas neurais com componentes musculoesqueléticos. ${ }^{100}$

Este teste quantifica as características de movimento do centro de massa associadas com a habilidade do indivíduo oscilar o corpo voluntariamente em oito direções no espaço. ${ }^{101}$ Consiste na exibição na tela do computador de um sinal representativo do centro de massa do indivíduo, além de um alvo central e oito alvos periféricos, aleatória e individualmente iluminados, dispostos de modo circular, nos sentidos anterior (A), anterior-direita (AD), direita (D), posterior-direita (PD), posterior $(\mathrm{P})$, posterior-esquerda (PE), esquerda (E) e anterior-esquerda (AE) (Figura 5). ${ }^{81}$

A tela do monitor foi posicionada em frente a linha dos olhos do indivíduo, que foi orientado a deslocar intencionalmente o seu COP sem mudar a base de suporte até a distância máxima de 8 direções ordenadas aleatoriamente por sorteio, após o feedback visual e sonoro do equipamento, durante 10 segundos em cada direção, em sua velocidade máxima. Foi realizada familiarização do paciente com o teste e em seguida duas repetições para obtenção 
de medidas confiáveis do LOS. ${ }^{102}$

A quantificação deste teste fornece uma representação importante do equilíbrio, pois sua diminuição pode comprometer a realização das atividades de vida diária. ${ }^{103}$ Os parâmetros analisados foram:

- Tempo de reação: intervalo de tempo entre o comando sonoro do equipamento para início do teste e o primeiro movimento de excursão executado pelo indivíduo;

- Velocidade: velocidade do movimento, mensurada em graus por segundo;

- Excursão máxima: representa a maior distância atingida durante a execução da tarefa;

- Excursão final: representa a distância em que o indivíduo foi capaz de realizar a excursão e mantê-la até o final do teste.

A excursão máxima e ponto final da excursão foram mensurados em percentual, sendo considerado $100 \%$ o limite de estabilidade máximo teórico, estimado pelo equipamento e normalizado de acordo com a altura do indivíduo. ${ }^{81}$

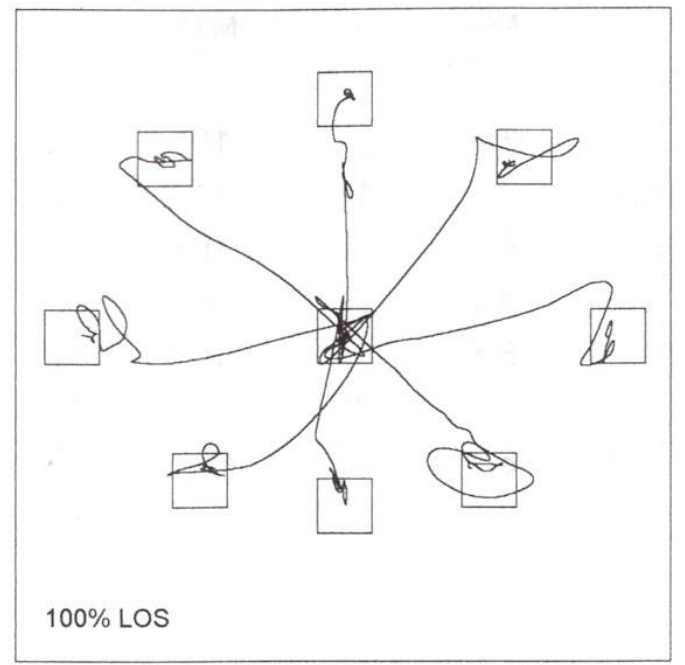

Figura 5. Representação da tela do teste Limites de Estabilidade no equipamento Balance Master System.

\subsubsection{TESTE DE CAMINHADA}

O teste de caminhada foi realizado no Balance Master, e a partir da passagem do voluntário sobre a plataforma, foi possível analisar os seguintes parâmetros da marcha (Figura 6):

- Comprimento dos passos;

- Largura dos passos;

- Velocidade da marcha. 


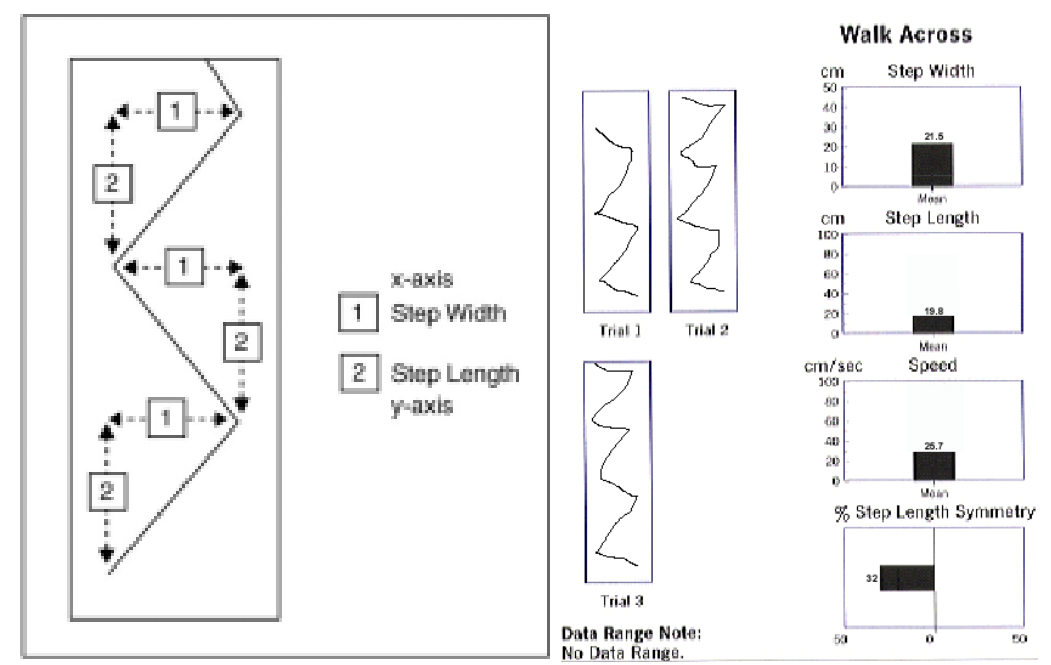

Figura 6. Representação do deslocamento durante o teste de caminhada. $\mathrm{O}$ número 1 representa a mensuração da largura do passo no eixo $\mathrm{X}$ e o número 2 representa a mensuração do comprimento do passo no eixo Y. Os gráficos indicam as médias destas medidas, além da velocidade de execução da tarefa.

Pacientes com disfunções de equilíbrio, realizam compensações aumentando sua base de apoio com maior largura do passo para realizar a fase de balanço com mais facilidade. Uma diminuição do comprimento do passo pode ser ocasionada pela dificuldade em avançar a perna durante o balanço, por incapacidade de manter a perna de suporte por um período suficiente para permitir uma maior oscilação da perna oposta ou mesmo voluntariamente, com objetivo de reduzir a velocidade da marcha por medo de cair, por exemplo. ${ }^{81}$

Além disso, a diminuição da velocidade de marcha apresenta correlação com a fragilidade e perda funcional, além de maior risco de queda. ${ }^{104}$

Neste teste o paciente foi orientado a caminhar em sua velocidade mais ágil sem correr ou trotar, de um metro antes até um metro depois da plataforma, realizando cerca de dois passos sobre o equipamento. O teste foi repetido três vezes para maior consistência das características dos voluntários.

\subsubsection{CAMINHADA TANDEM}

Este teste quantifica as características do movimento de caminhar ao longo de uma linha marcada no comprimento da plataforma do equipamento Balance Master. A capacidade de caminhar com os calcanhares próximos assim que acontece uma passada indica um bom controle postural. O paciente foi orientado a caminhar sobre a linha central da plataforma com 
a maior velocidade possível, após o comando do equipamento (Figura 7) e as variáveis fornecidas foram:

- Largura de passo $(\mathrm{cm})$ : representa o erro do paciente na execução da tarefa;

- Velocidade da marcha (cm/seg.).

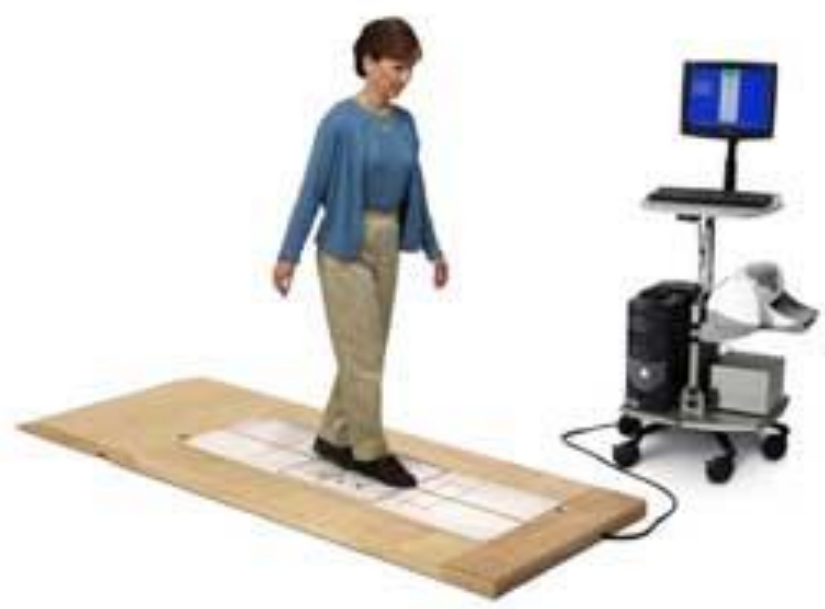

Figura 7. Caminhada Tandem.

\subsubsection{TESTE DE SUBIDA E DESCIDA DO DEGRAU}

Este teste consistiu na avaliação da habilidade do indivíduo em transpor um degrau de 20 centímetros de altura em sua maior velocidade, apoiando um dos pés no degrau e finalizando com ambos os pés posicionados à frente do degrau, alinhados (Figura 8). O teste foi realizado três vezes em cada perna e as variáveis obtidas para cada membro foram:

- Tempo movimento (segundos), tempo necessário para realizar a tarefa, se iniciando no deslocamento do peso para a perna que não vai apoiar no degrau e finalizando ao impacto deste mesmo membro na superfície da plataforma após o degrau;

- Índice de elevação (\% do peso corporal), que consiste no grau de impacto máximo exercido sobre o pé que apoia no degrau durante o movimento de subida;

- Índice de impacto, que consiste no nível de impacto exercido na aterrissagem (\% do peso corporal). ${ }^{81}$ 


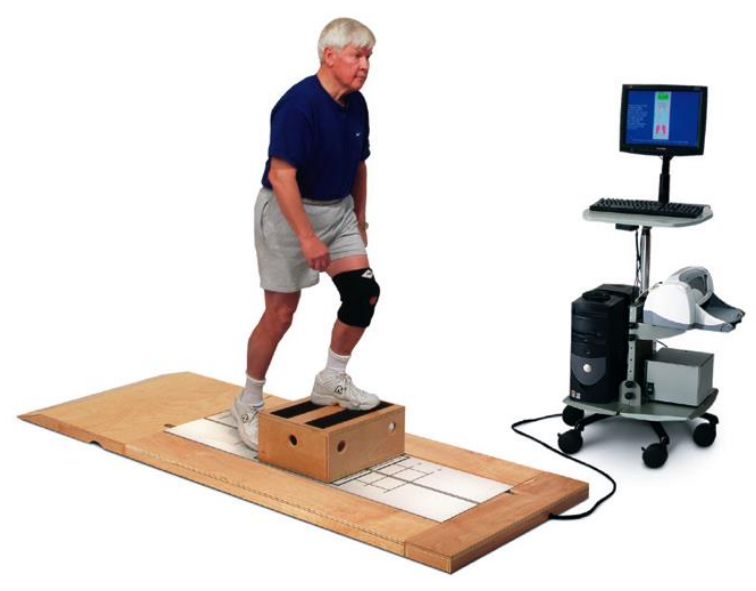

Figura 8. Teste de subida e descida do degrau.

O índice de elevação está relacionado à força concêntrica máxima de elevação exercida pela perna durante a subida do degrau. Um índice maior de elevação indica uma maior capacidade de produzir força concêntrica no quadríceps. O índice de impacto está relacionado à máxima força de impacto vertical na aterrisagem da perna na superfície da plataforma. Esta variável mensura o desempenho excêntrico da perna que está apoiada no degrau. Um alto índice de impacto é esperado se o indivíduo apresenta fraqueza muscular, devido a incapacidade de controlar a descida da perna até a plataforma de força. ${ }^{105}$

\subsubsection{TESTE SENTADO PARA EM PÉ}

Este teste quantifica as características do movimento em que o paciente parte da posição sentada para em pé. A partir da posição sentada, com $90^{\circ}$ de flexão de quadril, joelhos e tornozelos, os sujeitos foram orientados a se levantar o mais rápido possível após o sinal sonoro do equipamento, com os braços cruzados sobre o tronco sem apoiar no banco, nas pernas ou mesmo abduzir os ombros (Figura 9). O teste foi repetido três vezes e as variáveis analisadas foram:

- Tempo de movimento (segundos), tempo em que o paciente realizou a tarefa;

- Índice de elevação (\% do peso corporal): representa a produção de força dos membros inferiores para atingir a posição de pé completa;

- Velocidade de movimento do CG (graus/segundos), velocidade de execução do movimento. 
O teste sentado para em pé é amplamente utilizado na avaliação da funcionalidade pois se correlaciona com fraqueza de membros inferiores e se trata de uma habilidade funcional de extrema importância nas atividades da vida diária. ${ }^{106}$

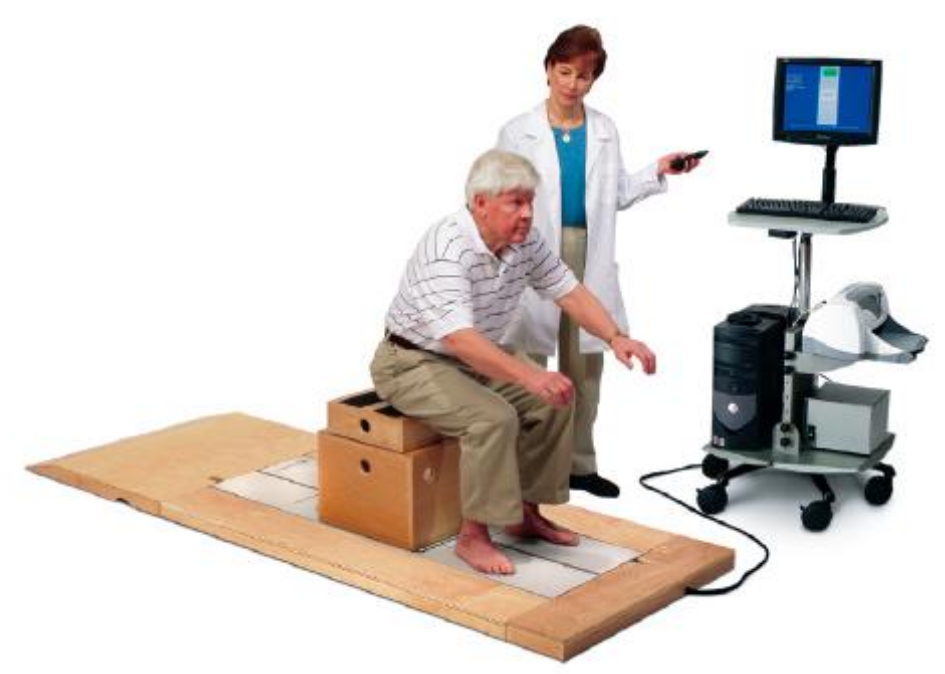

Figura 9. Teste sentado para em pé.

\subsection{QUESTIONÁRIOS}

\subsubsection{QUESTIONÁRIO INTERNACIONAL DE ATIVIDADE FíSICA - IPAQ (VERSÃO CURTA)}

Visto que o nível de aptidão física pode influenciar no equilíbrio, foi aplicado nos sujeitos desse estudo o Questionário Internacional de Atividade Física (IPAQ, versão curta) a fim de se estratificar a amostra e ponderar a análise dos dados. Este questionário permite estimar o tempo semanal gasto em atividades físicas classificando o paciente em sedentário, insuficientemente ativo, ativo e muito ativo ${ }^{107}$ (Anexo B). Foi proposto pela Organização Mundial de Saúde e validado em 12 países. A versão reduzida do questionário, utilizada neste estudo, apresenta sete questões, cujas informações avaliam diferentes dimensões de atividade física, como caminhadas e esforço físico entre as intensidades leve, moderada e vigorosa. ${ }^{108}$

A classificação dos indivíduos segue os critérios a seguir:

- Sedentário:

- Nenhuma atividade física por pelo menos 10 minutos contínuos em nenhum dia da semana; 
- Insuficientemente ativo:

- Atividade física por pelo menos 10 minutos contínuos em algum dia da semana sem atingir o critério para ser classificado como ativo;

- Ativo:

- Atividades vigorosas ao menos 3 dias por semana e por pelo menos 20 minutos em cada sessão;

- Atividade moderada ou caminhada ao menos 5 dias por semana e ao menos por 30 minutos ou;

- Qualquer atividade ao menos 5 dias por semana perfazendo no total pelo menos 150 minutos;

- Muito ativo:

- Atividades vigorosas ao menos 5 dias por semana por no mínimo 30 minutos;

- Atividades vigorosas ao menos 3 dias por semana, com 20 ou mais minutos por sessão, acrescidas de atividade moderada ou caminhada ao menos 5 dias por semana e com ao menos 30 minutos por sessão.

\subsubsection{DIZZINESS HANDICAP INVENTORY (DHI BRASILEIRO)}

O DHI Brasileiro é um questionário que avalia a autopercepção dos efeitos incapacitantes provocados pela tontura (Anexo C). É composto por 25 questões, das quais sete avaliam aspectos físicos, nove os aspectos emocionais, e nove os funcionais. Cada resposta recebe uma pontuação, sendo: Sim -4 pontos; Às vezes -2 pontos; e Não -0 pontos. ${ }^{109}$

A pontuação final é a soma de todas as respostas, graduadas em:

- 0 a 30 pontos: Leve deficiência;

- 31 a 60 pontos: Deficiência moderada;

- 61 a 100 pontos: Alta deficiência ${ }^{110}$

Este questionário foi aplicado apenas nos pacientes que apresentavam queixa de tontura, a fim de avaliar a manifestação e o impacto da mesma nas atividades de vida diária destes pacientes.

\subsubsection{ESCALA INTERNACIONAL DE EFICÁCIA DE QUEDAS (FES-1 BRASIL)}


O FES-I Brasil questionário possui 16 questões que avaliam a percepção pelo paciente da confiança no seu equilíbrio ao realizar as atividades do cotidiano (Anexo D). Por meio da resposta graduada em 4 níveis de preocupação com a possibilidade de quedas, é possível avaliar o medo de cair, fator que contribui para a ocorrência de quedas bem como pelo decréscimo na qualidade de vida. ${ }^{111,112}$

O teste apresenta elevados níveis de validade, confiabilidade e reprodutibilidade ${ }^{111} \mathrm{e}$ os scores variam de 16 a 64 pontos, que classificam o indivíduo em:

- Baixa preocupação com quedas: 16-19 pontos;

- Moderada preocupação com quedas: 20-27 pontos;

- Alta preocupação com quedas: $28-64$ pontos. ${ }^{112}$

Este questionário foi aplicado em todos os voluntários do estudo.

\subsection{ANÁLISE ESTATÍSTICA}

\subsubsection{CÁLCULO AMOSTRAL}

O cálculo amostral foi realizado a partir de um estudo piloto e foram consideradas as médias dos oito desfechos mais importantes nos 4 grupos e o maior desvio padrão entre eles. A análise foi realizada por meio da análise de variância, com nível de significância de $5 \%$ e poder do teste de $80 \%$. As comparações de interesse com relação ao grupo controle, foram obtidas por meio de contrastes ortogonais baseando-se em uma ANOVA.

De todas as oito variáveis de desfecho avaliadas neste estudo, as sete descritas a seguir contemplaram o número de 35 ou menos indivíduos para cada grupo, na comparação entre os grupos de migrânea e controles:

- Teste modificado de integração sensorial do equilíbrio;

- Limites de estabilidade;

- Teste de caminhada;

- Caminhada tandem;

- Teste sentado para em pé,

- DHI;

- FES. 


\subsubsection{ANÁLISE DOS DADOS}

Primeiramente foi realizada uma análise bruta dos dados a fim de se interpretar e testar a homogeneidade da amostra, buscando associações e fatores confundidores. Para está análise foi utilizado o teste ANOVA com contrastes ortogonais. Para as variáveis categóricas foi utilizado o Teste Exato de Fisher.

Após esta análise, os dados foram analisados novamente com o teste ANCOVA com contrastes ortogonais considerando os seguintes confundidores: idade, nível de atividade física, tempo de cefaleia, presença de tontura dentro e fora da crise, IMC e número de medicamentos profiláticos em uso $(0,1$ ou 2+). Estas covariáveis foram incluídas no modelo estatístico para eliminação de possíveis confundidores na análise da hipótese alternativa com o objetivo de demonstrar a relação entre os subtipos de migrânea e as variáveis testadas ponderadas por estes fatores. O nível de significância estatística adotado foi de $\alpha<0.05$ e os testes foram realizados no software SAS 9.2.

Além disso, foi calculado o tamanho de efeito (ES) para os testes de equilíbrio funcional com a finalidade de demonstrar o grau em que o fenômeno estudado está presente na população. A magnitude do ES, calculado por meio do $d$ de Cohen, é interpretada como um índice de relevância clínica sendo 0,2 considerado pequeno, 0,5 como moderado e >0,8 grande ES. Quanto maior este índice, maior a diferença entre grupos e maior a relevância clínica dos resultados. ${ }^{113}$

Também foi calculada a razão de prevalência (RP) a partir da prevalência de quedas no último ano em todos os grupos, com o objetivo de verificar a relação entre a presença de migrânea e possível associação com o risco de quedas. Todos os resultados foram reportados utilizando-se a média ou diferença média entre os grupos, complementadas com o respectivo Intervalo de Confiança 95\% (IC95\%). 


\section{Resultados}

\subsection{Amostra}

4.2 Teste modificado de integração sensorial do equilíbrio

4.3 Limites de estabilidade

4.4 Teste de caminhada e caminhada tandem

4.5 Teste de subida e descida do degrau

4.6 Teste de sentado para em pé

4.7 Tontura e DHI Brasileiro

4.8 Quedas e FES-I Brasil 


\section{RESULTADOS}

\subsection{Amostra}

O processo de coleta dos dados foi iniciado em junho de 2013 e finalizado em dezembro de 2014. Foram coletados 140 pacientes, cujas características demográficas são apresentadas na Tabela 2 .

Não foram observadas diferenças na idade e nível de atividade física entre os grupos, e não houve diferença na intensidade da dor de cabeça entre grupos de indivíduos com migrânea (grupos M, MA e MC) (p>0,05).

Como esperado, a ingestão de medicação foi menor no GC em relação a todos os grupos de migrânea $(\mathrm{p}<0,05)$. Os medicamentos prescritos em uso pelos pacientes foram, em ordem de maior frequência: topiramato, amitriptilina/nortriptilina, sertralina, atenolol/propranolol, ácido valpróico, clonazepam, pregabalina, fluoxetina, carbamazepina, clorpromazina, flunarizina, lamotrigina, diazepam, venlafaxina e alprazolam. Cerca de 10 pacientes em cada subgrupo de migrânea não estavam sob uso de nenhuma medicação e nenhum paciente ingeriu analgésicos ou anti-inflamatórios nas prévias 24 horas aos testes. Dois pacientes do grupo controle estavam sob diário de antidepressivos e três estavam em uso de medicação anti-hipertensiva. A maioria dos pacientes com migrânea se apresentaram com prescrição de diferentes tipos de medicações associadas em diferentes doses, por se tratar de um ambulatório terciário.

O IMC foi menor nos indivíduos controle e no grupo $\mathrm{M}$ em comparação com pacientes com MA $(\mathrm{p}<0,05)$. O grupo $\mathrm{M}$ apresentou menos anos de doença e menor tempo de duração da crise em comparação aos pacientes com MA e MC ( $\mathrm{p}<0,05)$. Pacientes com MC apresentaram maior número de crises de migrânea do que pacientes com $\mathrm{M}$ e MA (p<0,05), (Tabela 2).

Nenhum dos confundidores considerados na análise exerceu significante efeito sobre todas as variáveis avaliadas ( $p>0,05$ para idade, IMC, IPAQ, tempo de início dor de cabeça, presença de tontura e ingestão de medicamentos). Mesmo assim, os confundidores foram mantidos na análise devido a possibilidade de efeito sobre os níveis de significância apresentados. 
Tabela 2. Valores médios e desvio padrão das variáveis demográficas da amostra - média e IC 95\%.

\begin{tabular}{|c|c|c|c|c|}
\hline & $\mathrm{GC}(\mathrm{n}=35)$ & $M(n=35)$ & MA $(n=35)$ & $\mathrm{MC}(\mathrm{n}=35)$ \\
\hline Idade (anos) & $35,9(32,6$ a 39,2$)$ & $34,8(32,1$ a 37,5$)$ & $37,2(34,0$ a 40,5$)$ & $36,8(33,6$ a 40,0$)$ \\
\hline $\mathrm{IMC}(\mathrm{kg} / \mathrm{cm} 2)$ & $23,8(22,6 \text { a } 25,1)^{*}$ & $24,1(22,6 \text { a } 25,5)^{\dagger}$ & $26,7(25,0$ a 28,2$)$ & $25,9(24,4$ a 27,4$)$ \\
\hline Tempo de Cefaleia (anos) & - & $14,9(12,0 \text { a } 17,9)^{*}$ & $19,7(15,7$ a 23,1$)$ & $19,1(15,9$ a 22,3$)$ \\
\hline Frequência de crises (dias/mês) & - & $5,4(4,5$ a 6,3$)$ & $5,0(3,9$ a 6,1$)$ & $19,6(16,3 \text { a } 23,0)^{\S}$ \\
\hline Duração das crises (horas) & - & $13,8(5,9 \text { a } 21,6)^{*}$ & $29,6(18,2$ a 41,0$)$ & $26,1(17,1$ a 45,4$)$ \\
\hline Intensidade de dor (EVN) & - & $7,5(7,3$ a 7,6$)$ & $7,8(7,5$ a 8,0$)$ & $8,5(8,0$ a 8,6$)$ \\
\hline Número de medicações ingeridas diariamente & $0,37(0,1 \text { a } 0,6)^{\|}$ & $2,17(1,6$ a 2,7$)$ & $3,17(2,7$ a 3,6$)$ & $2,97(2,5$ a 3,4$)$ \\
\hline \multirow{4}{*}{ Insuficientemente ativo } & $0 \%$ & $0 \%$ & $0 \%$ & $12,4 \%$ \\
\hline & $29 \%$ & $55,6 \%$ & $55,6 \%$ & $31,3 \%$ \\
\hline & $52 \%$ & $38,9 \%$ & $44,4 \%$ & $56,3 \%$ \\
\hline & $19 \%$ & $5,6 \%$ & $0 \%$ & $0 \%$ \\
\hline
\end{tabular}

IMC: índice de massa corpórea, EVN: escala visual numérica, GC: grupo controle, M: migrânea sem aura, MA: migrânea com aura grupo, MC: migrânea crônica. $p<0,05:{ }^{*} \mathrm{GC}$ versus $\mathrm{MA}$ and $\mathrm{MC},{ }^{\dagger} \mathrm{M}$ versus $\mathrm{MA},{ }^{\dagger} \mathrm{M}$ versus $\mathrm{MA}$ e $\mathrm{MC},{ }^{\S} \mathrm{MC}$ versus $\mathrm{M}$ e MA, ${ }_{\mathrm{GC}}$ versus $\mathrm{M}$, MA e MC. 


\subsection{TESTE MODIFICADO DE INTEGRAÇÃO SENSORIAL DO EQUILÍBRIO}

Não houve diferença na área de deslocamento para a condição OAest entre os grupos GC (1,2 $\mathrm{cm}^{2}$ IC 95\% 1,05 a 1,34), M (1,52 $\mathrm{cm}^{2}$ IC 95\% 1,26 a 1,77), MA (2,47 $\mathrm{cm}^{2}$ IC 95\% 1,97 a 2,97) e MC (3,23 $\mathrm{cm}^{2}$ IC 95\% 2,21 a 4,24) (p>0,05). No entanto, os resultados para a condição OFest exibiram valores de área de deslocamento superiores para MA $\left(4,49 \mathrm{~cm}^{2}\right.$ IC $95 \%$ 3,21 a 5,77) e MC (4,53 $\mathrm{cm}^{2}$ IC $95 \% 3,03$ a 6,04), em comparação ao GC $\left(1,53 \mathrm{~cm}^{2}\right.$ IC $95 \% 1,31$ a 1,74) $(\mathrm{p}=0,02)$. O grupo M $\left(2,1 \mathrm{~cm}^{2} \mathrm{IC} 95 \% 1,61\right.$ a 2,59) não apresentou nenhuma diferença em relação aos outros grupos nesta condição ( $p>0,06)$

Para a condição OAinst, o GC $\left(5,09 \mathrm{~cm}^{2}\right.$ IC $95 \%$ 4,63 a 5,56) e grupo M $\left(5,58 \mathrm{~cm}^{2}\right.$ IC 95\% 5,03 a 6,14) apresentaram valores de área de deslocamento menores do que indivíduos com MA $\left(8,75 \mathrm{~cm}^{2}\right.$ IC 95\% 7,31 a 10,18) e MC $\left(8,82 \mathrm{~cm}^{2}\right.$ IC 95\% 7,66 a 9,97) (p<0,02). As mesmas diferenças entre os grupos reportados para a condição OAinst também foram observados para a condição OFinst (GC: $14,82 \mathrm{~cm}^{2}$ IC 95\% 13,72 a 15,92; M: $17,27 \mathrm{~cm}^{2}$ IC 95\% 15,39 a 19,14; MA: 21,87 $\mathrm{cm}^{2}$ IC 95\% 19,09 a 24,66; MC: 22,44 $\mathrm{cm}^{2}$ IC 95\% 19,92 a 24,95), mas com uma magnitude de diferença maiores entre os grupos ( $p<0,0001)$ (Figura 10).

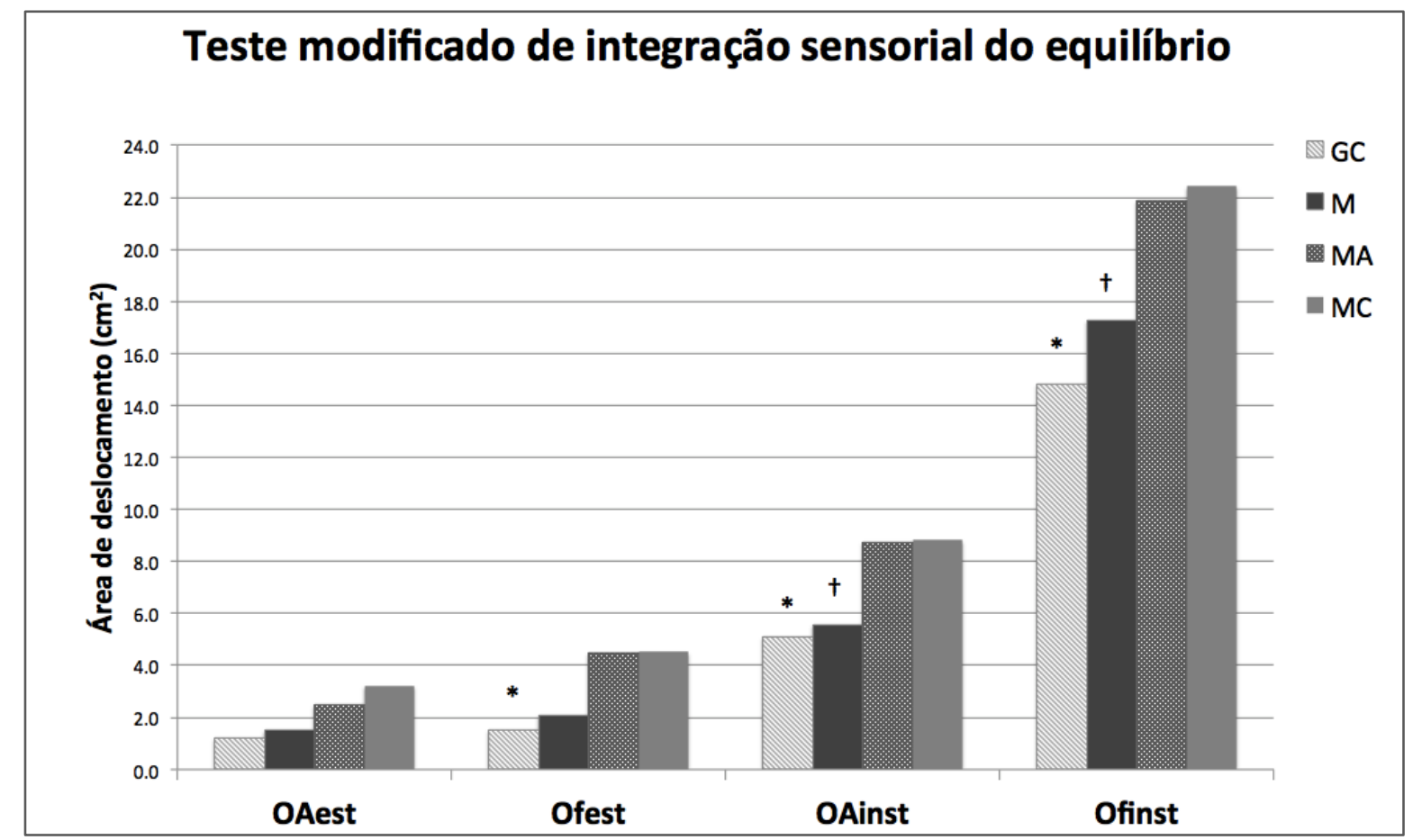

Figura 10. Teste modificado de integração sensorial do equilíbrio. GC: grupo controle, M: migrânea sem aura, MA: migrânea com aura, MC: migrânea crônica, OAest: superfície estável com olhos abertos, OFest: superfície estável com olhos fechados, OAinst: superfície instável com olhos abertos, OFinst: superfície instável com olhos fechados. ${ }^{*} \mathrm{p}<0,02$ GC versus $\mathrm{MA}$ e MC. ${ }^{\dagger} \mathrm{p}<0,02 \mathrm{M}$ versus MA e MC. 
As diferenças entre o GC versus grupo MA e MC no teste modificado de integração sensorial do equilíbrio, revelaram ES moderados para as condições OAest (MA: 0,67, MC 0,54, $p<0,05$ ), OFest (MA: 0,63, MC: 0,54, $p<0,05$ ), OAinst (MA: 0,66, MC: 0,82, $p<0,05$ ) e OFinst (MA: 0,64, MC: 0,76, $p<0,05)$.

Além disso foram verificados moderados ES entre os grupos M e MA nas condições OFest (MA: 0,48, $p<0,05$ ) e OAinst (MA: 0,56, $p<0,05$ ); e M versus MC na condição OAinst (MC: 0,69, $p<0,05)$ (Tabela 3).

Tabela 3. Tamanhos de efeito e IC $95 \%$ das diferenças entre controles (GC), grupo de migrânea crônica (MC), migrânea com aura (MA) e sem aura (M) no teste modificado de integração sensorial do equilíbrio.

\begin{tabular}{ccccc}
\hline \hline & OAest $\left(\mathrm{cm}^{2}\right)$ & OFest $\left(\mathrm{cm}^{2}\right)$ & OAinst $\left(\mathrm{cm}^{2}\right)$ & OFinst $\left(\mathrm{cm}^{2}\right)$ \\
\hline GC versus $\mathrm{M}$ & 0,30 & 0,29 & 0,18 & 0,31 \\
& $(-0,18$ a 0,76$)$ & $(-0,18$ a 0,76$)$ & $(-0,29$ a 0.65$)$ & $(-0,17$ a 0.78$)$ \\
GC versus MA & $0,67^{*}$ & $0,63^{*}$ & $0,66^{*}$ & $0,64^{*}$ \\
& $(0,18$ a 1,14$)$ & $(0,14$ a 1,10$)$ & $(0,18$ a 1,14$)$ & $(0,16$ a 1,12$)$ \\
GC versus MC & $0,54^{*}$ & $0,54^{*}$ & $0,82^{*}$ & $0,76^{*}$ \\
M versus MA & $(0,06$ a 1,01$)$ & $(0,06$ a 1,01$)$ & $(0,32$ a 1,30$)$ & $(0,27$ a 1,24$)$ \\
& 0,46 & $0,48^{*}$ & $0,56^{*}$ & 0,37 \\
M versus MC & $(-0,02$ a 0,95$)$ & $(0,00$ a 0,94$)$ & $(0,08$ a 1,04$)$ & $(-0,10$ a 0,84$)$ \\
& 0,45 & 0,42 & $0,69^{*}$ & 0,45 \\
\hline
\end{tabular}

*Tamanhos de efeito médios e grandes com nível de significância <0,05. OAest: superfície estável com olhos abertos, OFest: superfície estável com olhos fechados, OAinst: superfície instável com olhos abertos, OFinst: superfície instável com olhos fechados. 


\subsection{LIMITES DE ESTABILIDADE}

Indivíduos do GC exibiram em geral valores de tempo de reação menores do que os indivíduos de todos os grupos de migrânea em todas as direções do movimento. Para movimentos na direção A, foram observados menores valores de tempo de reação no CG em comparação com pacientes do grupo MA $(\mathrm{p}<0,02)$. Para movimentos nas direções $\mathrm{AD}, \mathrm{D}$, PD, PE e E, observou-se diferentes valores de tempo de reação do GC em comparação aos grupos M, MA e MC ( $\mathrm{p}<0,03)$. Para movimentos na direção $\mathrm{P}$, o GC apresentou valores de tempo de reação menores em comparação ao grupo $\mathrm{M}(\mathrm{p}<0,03)$. Para movimentos na direção AE, o GC foi diferente em comparação a pacientes do grupo $M(p<0,02)$ e $M A(p<0,03)$ (Tabela 4).

Indivíduos com migrânea apresentaram menores valores de velocidade de movimento comparados ao GC. Para movimentos nas direções A, D, PD, P, E e AE, indivíduos controle foram mais rápidos do que os grupos $\mathrm{M}, \mathrm{MA}$ e $\mathrm{MC}(\mathrm{p}<0,04)$. Para movimentos na direção $\mathrm{E}$, também foram observadas diferenças entre $\mathrm{M}$ e MA $(\mathrm{p}=0,04)$. Para movimentos na direção $\mathrm{AD}$, indivíduos controle apresentaram maiores valores de velocidade dos movimentos do que MA $(p=0,01)$ e M $(p<0,02)$. Para movimentos na direção PE, o GC apresentou diferentes valores de velocidade de movimento em comparação com indivíduos com MC ( $\mathrm{p}=0,02)$ e MA $(\mathrm{p}=0,01)$ (Tabela 5).

Indivíduos do GC apresentaram excursão final maiores do que indivíduos com migrânea. Para movimentos nas direções AD, D, PD, P e E, o GC apresentou valores de excursão final maiores em relação aos indivíduos do grupo $M$, MA e MC (p<0,03). Para movimentos na direção A, o GC apresentou maior excursão final em comparação com pacientes MA $(p=0,01)$ e $M(p<0,02)$. Para os movimentos nas direções PE e AE, foram observadas diferenças entre o GC e pacientes com MA $(\mathrm{p}=0,01)$ e GC comparado a MC $(\mathrm{p}<0,02)$ (Tabela 6).

Todos os grupos de migrânea apresentaram menores valores de excursão máxima em todas as oito direções testadas durante os testes LoS comparados aos indivíduos controle $(\mathrm{p}<0,01)$

(Tabela

7). 
Tabela 4. Tempo de reação do teste Limites de Estabilidade (segundos) - média (IC 95\%).

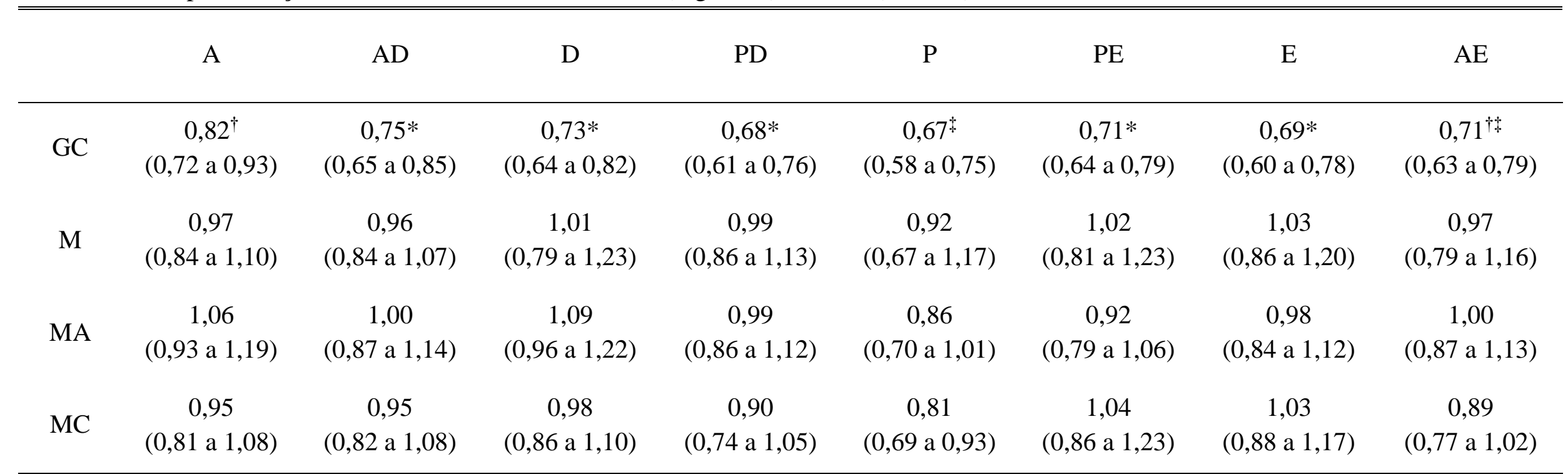

A: anterior, AD: anterior direita, D: direita, PD: posterior direita, P: posterior, PE: posterior esquerda, E: esquerda, AE: anterior esquerda. GC: grupo controle, M: migrânea sem aura, MA: migrânea com aura, MC: migrânea crônica. ${ }^{*} \mathrm{GC}$ versus $\mathrm{M}, \mathrm{MA}$ and $\mathrm{MC}, p<0,03$; ${ }^{\ddagger} \mathrm{GC}$ versus $\mathrm{M}, p<0,03$; ${ }^{\dagger} \mathrm{GC}$ versus $\mathrm{MA}$, $p<0,02$. 
Tabela 5. Velocidade de movimento do teste Limites de Estabilidade (graus/segundo) - média (IC 95\%).

\begin{tabular}{|c|c|c|c|c|c|c|c|c|}
\hline $\mathrm{GC}$ & $\begin{array}{c}5,04^{*} \\
(4,27 \text { a } 5,80)\end{array}$ & $\begin{array}{c}4,78^{\dagger \dagger} \\
(4,20 \text { a } 5,36)\end{array}$ & $\begin{array}{c}5,54^{*} \\
(4,93 \text { a } 6,14)\end{array}$ & $\begin{array}{c}4,57 * \\
(4,10 \text { a } 5,04)\end{array}$ & $\begin{array}{c}3,23 * \\
(2,88 \text { a } 3,59)\end{array}$ & $\begin{array}{c}4,08^{\| \ddagger} \\
(3,51 \text { a } 4,65)\end{array}$ & $\begin{array}{c}5,51 * \S \\
(4,75 \text { a } 6,26)\end{array}$ & $\begin{array}{c}5,17 * \\
(4,52 \text { a } 5,81)\end{array}$ \\
\hline $\mathrm{M}$ & $\begin{array}{c}3,74 \\
(3,18 \text { a } 4,29)\end{array}$ & $\begin{array}{c}3,94 \\
(3,40 \text { a } 4,49)\end{array}$ & $\begin{array}{c}3,80 \\
(3,31 \text { a } 4,29)\end{array}$ & $\begin{array}{c}3,33 \\
(2,81 \text { a } 3,84)\end{array}$ & $\begin{array}{c}2,56 \\
(2,07 \text { a } 3,05)\end{array}$ & $\begin{array}{c}3,53 \\
(3,01 \text { a } 4,05)\end{array}$ & $\begin{array}{c}4,52^{\S} \\
(3,80 \text { a } 5,24)\end{array}$ & $\begin{array}{c}4,35 \\
(3,69 \text { a } 5,01)\end{array}$ \\
\hline $\mathrm{MC}$ & $\begin{array}{c}3,62 \\
(3,01 \text { a } 4,23)\end{array}$ & $\begin{array}{c}4,02 \\
(3,40 \text { a } 4,64)\end{array}$ & $\begin{array}{c}3,78 \\
(3,20 \text { a } 4,35)\end{array}$ & $\begin{array}{c}3,26 \\
(2,71 \text { a } 3,81)\end{array}$ & $\begin{array}{c}2,12 \\
(1,74 \text { a } 2,51)\end{array}$ & $\begin{array}{c}3,15 \\
(2,73 \text { a } 3,57)\end{array}$ & $\begin{array}{c}4,00 \\
(3,43 \text { a } 4,58)\end{array}$ & $\begin{array}{c}3,81 \\
(3,26 \text { a } 4,36)\end{array}$ \\
\hline
\end{tabular}

A: anterior, AD: anterior direita, D: direita, PD: posterior direita, P: posterior, PE: posterior esquerda, E: esquerda, AE: anterior esquerda. GC: grupo controle, M: migrânea sem aura, MA: migrânea com aura, MC: migrânea crônica. * ${ }^{*} \mathrm{GC}$ versus $\mathrm{M}$, MA e MC, $p<0,04 ;{ }^{\dagger} \mathrm{GC}$ versus $\mathrm{M}$, $p<0,02 ;{ }^{*} \mathrm{GC}$ versus MA, $p=0,01 ;{ }^{\|}$CG versus $\mathrm{MC}, p=0,02 ;{ }^{\S} \mathrm{M}$ versus $\mathrm{MA}, p=0,04$. 
Tabela 6. Excursão final no teste Limites de Estabilidade (\% da máxima excursão estimada) - média (IC 95\%).

\begin{tabular}{|c|c|c|c|c|c|c|c|c|}
\hline $\mathrm{GC}$ & $\begin{array}{c}86,8^{\dagger+} \\
(81,1 \text { a } 92,6)\end{array}$ & $\begin{array}{c}99,6^{*} \\
(94,8 \text { a } 104,3)\end{array}$ & $\begin{array}{c}82,3^{*} \\
(76,4 \text { a } 88,2)\end{array}$ & $\begin{array}{c}86,2^{*} \\
(80,3 \text { a } 92,1)\end{array}$ & $\begin{array}{c}61,7^{*} \\
(56,7 \text { a } 66,6)\end{array}$ & $\begin{array}{c}79,0^{\S \ddagger} \\
(72,3 \text { a } 85,8)\end{array}$ & $\begin{array}{c}81,3^{*} \\
(77,1 \text { a } 85,5)\end{array}$ & $\begin{array}{c}94,7^{8 \dagger} \\
(89,9 \text { a } 99,5)\end{array}$ \\
\hline $\mathrm{M}$ & $\begin{array}{c}77,6 \\
(71,4 \text { a } 83,8)\end{array}$ & $\begin{array}{c}86,2 \\
(79,3 \text { a } 93,0)\end{array}$ & $\begin{array}{c}72,4 \\
(65,4 \text { a } 79,3)\end{array}$ & $\begin{array}{c}71,9 \\
(66,1 \text { a } 77,6)\end{array}$ & $\begin{array}{c}49,4 \\
(44,6 \text { a } 54,3)\end{array}$ & $\begin{array}{c}71,7 \\
(64,9 \text { a } 78,5)\end{array}$ & $\begin{array}{c}74,5 \\
(70,0 \text { a } 78,9)\end{array}$ & $\begin{array}{c}89,9 \\
(85,0 \text { a } 94,7)\end{array}$ \\
\hline $\mathrm{MC}$ & $\begin{array}{c}78,0 \\
(72,3 \text { a } 83,7)\end{array}$ & $\begin{array}{c}82,2 \\
(73,6 \text { a } 90,8)\end{array}$ & $\begin{array}{c}69,1 \\
(62,4 \text { a } 75,9)\end{array}$ & $\begin{array}{c}69,5 \\
(62,0 \text { a } 77,0)\end{array}$ & $\begin{array}{c}46,3 \\
(41,2 \text { a } 51,4)\end{array}$ & $\begin{array}{c}64,6 \\
(57,1 \text { a } 72,0)\end{array}$ & $\begin{array}{c}71,3 \\
(65,9 \text { a } 76,7)\end{array}$ & $\begin{array}{c}82,2 \\
(75,5 \text { a } 89,0)\end{array}$ \\
\hline
\end{tabular}

A: anterior, AD: anterior direita, D: direita, PD: posterior direita, P: posterior, PE: posterior esquerda, E: esquerda, AE: anterior esquerda, GC: grupo controle, M: migrânea sem aura, MA: migrânea com aura, MC: migrânea crônica. * ${ }^{*} \mathrm{GC}$ versus $\mathrm{M}, \mathrm{MA}$ and $\mathrm{MC}, p<0,03 ;{ }^{\dagger} \mathrm{GC}$ versus $\mathrm{M}, p<0,02 ;{ }^{*} \mathrm{GC}$ versus $\mathrm{MA}, p=0,01 ;{ }^{\S} \mathrm{GC}$ versus $\mathrm{MC}, \mathrm{p}<0,02$. 
Tabela 7. Excursão Máxima no teste Limites de Estabilidade (\% da máxima excursão estimada) - média (IC 95\%).

\begin{tabular}{|c|c|c|c|c|c|c|c|c|}
\hline $\mathrm{GC}$ & $\begin{array}{c}97,5^{*} \\
(93,3 \text { a } 101,8)\end{array}$ & $\begin{array}{c}103,4^{*} \\
(99,2 \text { a } 107,6)\end{array}$ & $\begin{array}{c}95,4^{*} \\
(92,0 \text { a } 98,8)\end{array}$ & $\begin{array}{c}96,7^{*} \\
(91,7 \text { a } 101,7)\end{array}$ & $\begin{array}{c}74,7 * \\
(70,1 \text { a } 79,3)\end{array}$ & $\begin{array}{c}89,6^{*} \\
(84,6 \text { a } 94,6)\end{array}$ & $\begin{array}{c}91,7 * \\
(88,2 \text { a } 95,2)\end{array}$ & $\begin{array}{c}101,7 * \\
(97,8 \text { a } 105,9)\end{array}$ \\
\hline $\mathrm{M}$ & $\begin{array}{c}87,6 \\
(83,3 \text { a } 91,9)\end{array}$ & $\begin{array}{c}90,3 \\
(83,1 \text { a } 97,6)\end{array}$ & $\begin{array}{c}80,3 \\
(73,9 \text { a } 86,8)\end{array}$ & $\begin{array}{c}81,3 \\
(74,6 \text { a } 87,9)\end{array}$ & $\begin{array}{c}61,8 \\
(56,4 \text { a } 67,2)\end{array}$ & $\begin{array}{c}80,4 \\
(74,1 \text { a } 86,7)\end{array}$ & $\begin{array}{c}81,3 \\
(75,4 \text { a } 87,3)\end{array}$ & $\begin{array}{c}94,3 \\
(90,1 \text { a } 98,6)\end{array}$ \\
\hline $\mathrm{MC}$ & $\begin{array}{c}88,6 \\
(84,5 \text { a } 92,6)\end{array}$ & $\begin{array}{c}94,1 \\
(89,0 \text { a } 99,1)\end{array}$ & $\begin{array}{c}81,6 \\
(77,9 \text { a } 85,2)\end{array}$ & $\begin{array}{c}80,6 \\
(75,1 \text { a } 86,0)\end{array}$ & $\begin{array}{c}57,6 \\
(52,2 \text { a } 63,0)\end{array}$ & $\begin{array}{c}76,0 \\
(71,1 \text { a } 80,9)\end{array}$ & $\begin{array}{c}81,0 \\
(76,9 \text { a } 85,1)\end{array}$ & $\begin{array}{c}93,1 \\
(89,1 \text { a } 97,1)\end{array}$ \\
\hline
\end{tabular}

A: anterior, AD: anterior direita, D: direita, PD: posterior direita, P: posterior, PE: posterior esquerda, E: esquerda, AE: anterior esquerda. GC: grupo controle, M: migrânea sem aura, MA: migrânea com aura, MC: migrânea crônica. * $\mathrm{GC}$ versus $\mathrm{M}, \mathrm{MA}$ e $\mathrm{MC}, p<0,01$. 


\section{Tamanho de Efeito (ES)}

No tempo de reação do teste LOS, o tamanho de efeito foi moderado na comparação entre GC versus $\mathrm{M}$ e $\mathrm{MC}(\mathrm{M}: 0,64, \mathrm{MC}: 0,65, p<0,05)$ e grande para comparação entre GC versus MA (MA: 0,81, $p<0,05)$. Na velocidade de movimento deste mesmo teste foram verificados moderados a grandes ES na comparação do GC versus grupos de migrânea (M: 0,61, MA: -0,93, MC: -0,77, p<0,05). Na variável excursão máxima também foram observados ES moderados e grandes entre o GC versus grupos de migrânea (M: -0,60, MA: 1,51, MC: $-0,77, p<0,05)$ e entre M versus MA (MA: -0,87, $p<0,05)$. Na variável excursão final, foram verificados grandes tamanhos de efeito nas comparações entre GC versus grupos de migrânea (M: -1,57, MA: -1,19, MC: -0,96, $p<0,05)$ e entre M versus MA e MC (MA: 0,60, MC: 0,72, $p<0,05)$ (Tabela 8).

Tabela 8. Tamanhos de efeito e IC $95 \%$ das diferenças entre controles (GC), grupo de migrânea crônica (MC), migrânea com aura (MA) e sem aura (M) no teste limites de estabilidade.

\begin{tabular}{ccccc}
\hline \hline & $\begin{array}{c}\text { Tempo de } \\
\text { reação (seg.) }\end{array}$ & $\begin{array}{c}\text { Velocidade de } \\
\text { movimento }(\% \text { seg. })\end{array}$ & $\begin{array}{c}\text { Excursão } \\
\text { máxima }(\%)\end{array}$ & $\begin{array}{c}\text { Excursão final } \\
(\%)\end{array}$ \\
\hline GC versus $\mathrm{M}$ & $0,64^{*}$ & $-0,61^{*}$ & $-0,60$ & $-1,57$ \\
& $(0,16 \mathrm{a} 1,12)$ & $(-1,08 \mathrm{a}-0,12)$ & $(-1,07 \mathrm{a}-0,11)^{*}$ & $(-2,09 \mathrm{a}-1,02)^{*}$ \\
GC versus $\mathrm{MA}$ & $0,81^{*}$ & $-0,93^{*}$ & $-1,51$ & $-1,19$ \\
& $(0,32 \mathrm{a} 1,29)$ & $(-1,41 \mathrm{a}-0,42)$ & $(-2,02 \mathrm{a}-0,96)^{*}$ & $(-1,68 \mathrm{a}-0,67)^{*}$ \\
GC versus $\mathrm{MC}$ & $0,65^{*}$ & $-0,77$ & $-0,77$ & $-0,96$ \\
M versus $\mathrm{MA}$ & $(0,16 \mathrm{a} 1,13)$ & $(-1,25 \mathrm{a}-0,28)^{*}$ & $(-1,25 \mathrm{a}-0,28)^{*}$ & $(-1,44 \mathrm{a}-0,45)^{*}$ \\
& 0,02 & $-0,30$ & $-0,87$ & 0,60 \\
M versus $\mathrm{MC}$ & $(-0,45 \mathrm{a} 0,49)$ & $(-0,77 \mathrm{a} 0,17)$ & $(-1,35 \mathrm{a}-0,37)^{*}$ & $(0,11 \mathrm{a} 1,07)^{*}$ \\
& $-0,09$ & $-0,16$ & $-0,21$ & 0,72 \\
\hline
\end{tabular}

*Tamanhos de efeito médios e grandes com nível de significância <0,05.

**Foi utilizado para cálculo a média das oito direções do teste limites de estabilidade.

\subsection{TESTE DE CAMINHADA E CAMINHADA TANDEM}

No teste de caminhada, o GC realizou a tarefa em maior velocidade que pacientes $M$, MA e MC ( $\mathrm{p}<0,0001)$. O GC também apresentou maior comprimento de passo em relação ao grupo $\mathrm{M}(\mathrm{p}=0,0004)$, MA ( $\mathrm{p}=0,0009)$ e $\mathrm{MC}(\mathrm{p}=0,0003)$. Além disso, a largura do passo foi 
diferente entre $\mathrm{GC}$ versus MA ( $\mathrm{p}=0,005)$ e $\mathrm{CG}$ versus $\mathrm{MC}(\mathrm{p}=0,03)$. Não houve evidência da diferença entre subgrupos de migrânea neste teste (Tabela 9).

O teste de caminhada tandem também revelou diferenças na velocidade entre o GC e todos os pacientes migranosos $(\mathrm{p}<0,0001)$. A largura do passo na caminhada tandem foi menor no GC em contraste com o grupo M (p=0,006), MA (p=0,0005) e MC (p=0,03). Os pacientes com migrânea não apresentaram diferenças entre si neste teste (Tabela 9).

Tabela 9. Média e IC 95\% nas variáveis dos testes de caminhada e caminhada tandem em controles (GC), migranosos crônicos (MC), migranosos com aura (MA) e sem aura (M).

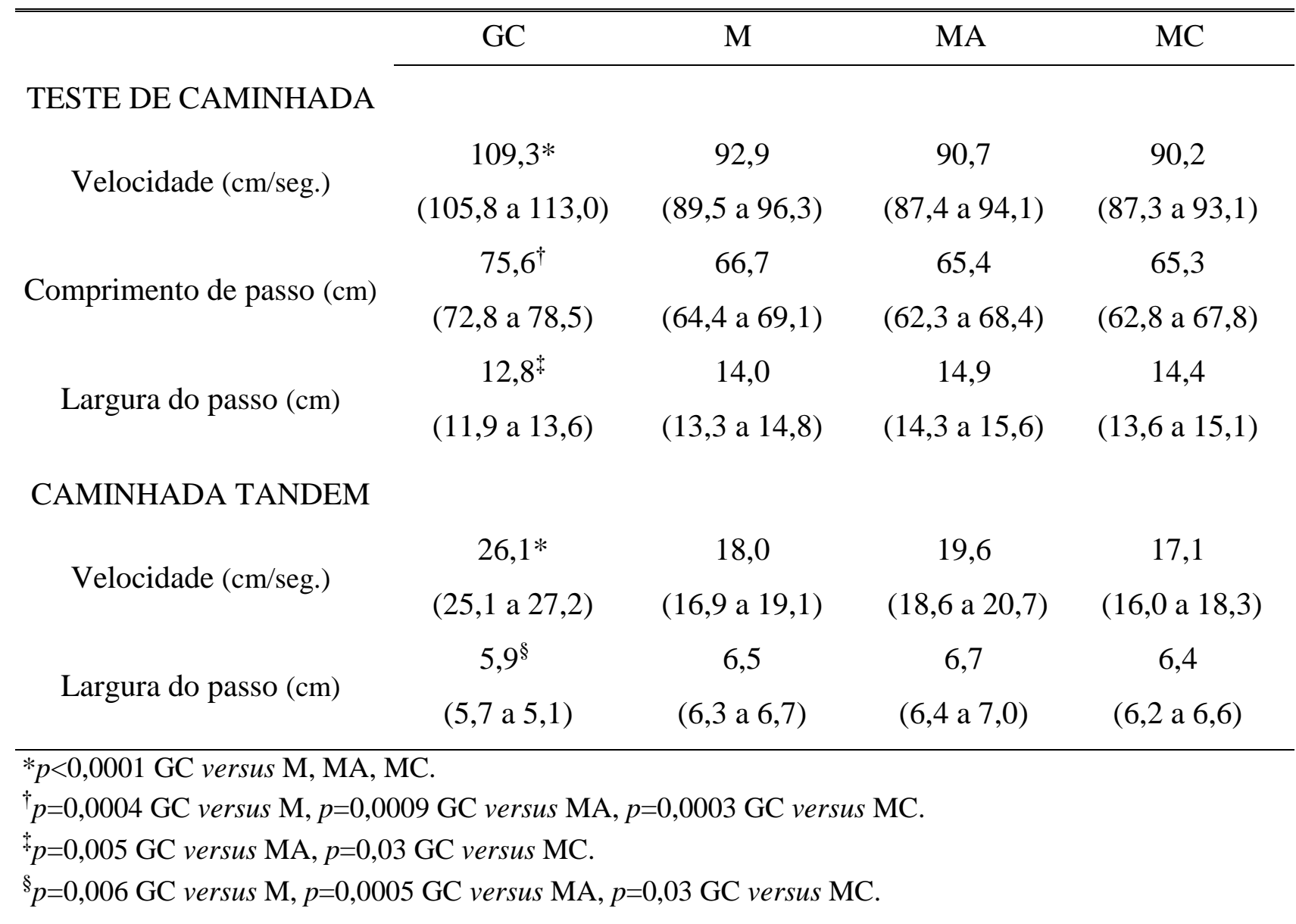

Tamanho de Efeito (ES)

Para a velocidade no teste de caminhada, as diferenças entre $\mathrm{CG}$ versus grupos de migrânea apresentaram ES grandes (M: -0.90, MA: -1,03 e MC: -1.12, p<0,05). As diferenças entre CG versus grupos de migrânea no comprimento do passo do teste de caminhada tiveram ES moderados (M: -0.66, MA: -0,68 e MC: -0.75, p<0,05). Para a largura passo neste mesmo 
teste, um ES moderado de 0,54 $(p<0,05)$ foi encontrado apenas entre CG contra MA (Tabela $10)$.

No teste de caminhada tandem, os ES das diferenças entre CG versus grupos de migrânea na variável velocidade foram considerados grandes (M: -1,44, MA: -1,16 e MC: $1,55, p<0,05)$. Para a largura do passo neste teste, as diferenças entre CG versus M e MA apresentaram moderados ES (M: 0,56 e MA: 0,57, com $p<0,05)$ (Tabela 10).

Tabela 10. Tamanhos de efeito e IC 95\% das diferenças entre controles (GC), grupo de migrânea crônica (MC), migrânea com aura (MA) e sem aura (M) nos testes de caminhada e caminhada tandem.

\begin{tabular}{|c|c|c|c|}
\hline $\begin{array}{c}\text { TESTE DE } \\
\text { CAMINHADA }\end{array}$ & Velocidade (cm/seg.) & Largura do passo $(\mathrm{cm})$ & $\begin{array}{l}\text { Comprimento do } \\
\text { passo }(\mathrm{cm})\end{array}$ \\
\hline GC versus $\mathrm{M}$ & $-0,90(-1,38 \text { a }-0,40)^{*}$ & $0,29(-0,18$ a 0,76$)$ & $-0,66(-1,14 \text { a }-0,18)^{*}$ \\
\hline GC versus MA & $-1,03(-1,51 \text { a }-0,52)^{*}$ & $0,54(0,06 \text { a } 1,01)^{*}$ & $-0,68(-1,15 \text { a }-0,19)^{*}$ \\
\hline GC versus $\mathrm{MC}$ & $-1,12(-1,61 \text { a }-0,6)^{*}$ & $0,38(-0,09$ a 0,85$)$ & $-0,75(-1,23 \text { a }-0,26)^{*}$ \\
\hline M versus MA & $-0,12(-0,59$ a 0,35$)$ & $0,25(-0,22$ a 0,72$)$ & $-0,09(-0,56$ a 0,37$)$ \\
\hline $\mathrm{M}$ versus $\mathrm{MC}$ & $-0,16(-0,63$ a 0,31$)$ & $0,10(-0,37$ a 0,56$)$ & $-0,11(-0,58$ a 0,36$)$ \\
\hline \multicolumn{4}{|l|}{$\begin{array}{l}\text { CAMINHADA } \\
\text { TANDEM }\end{array}$} \\
\hline GC versus $\mathrm{M}$ & $-1,44(-1,95 \text { a }-0,90)^{*}$ & $0,56(0,07 \text { a } 1,03)^{*}$ & \\
\hline GC versus MA & $-1,16(-1,66 \text { a }-0,65)^{*}$ & $0,57(0,09 \text { a } 1,04)^{*}$ & \\
\hline GC versus $\mathrm{MC}$ & $-1,55(-2,07 \mathrm{a}-1,00)^{*}$ & $0,43(-0,05$ a 0,90$)$ & \\
\hline M versus MA & $0,30(-0,18$ a 0,76$)$ & $0,12(-0,35$ a 0,58$)$ & \\
\hline $\mathrm{M}$ versus $\mathrm{MC}$ & $-0,14(-0,61$ a 0,33$)$ & $-0,10(-0,57$ a 0,37$)$ & \\
\hline
\end{tabular}

*Tamanhos de efeito médios e grandes com nível de significância <0,05.

\subsection{TESTE DE SUBIDA E DESCIDA DO DEGRAU}

No teste de subida e descida, foram observadas diferenças no tempo de execução de ambas as pernas esquerda e direita entre $\mathrm{CG}$ versus $\mathrm{M}(\mathrm{p}=0,0006)$, grupo MA e MC ( $\mathrm{p}<0,0001)$. O índice de elevação foi maior em ambas as pernas do GC em comparação com M ( $p<0,02)$, MA e MC ( $<<0,0001)$. Ainda quanto ao índice de elevação de ambas as pernas, 
houve evidência de diferença entre M e MA (p<0,01). O índice de impacto também foi maior em ambas as pernas do GC em contraste com o grupo $\mathrm{M}(\mathrm{p}=0,005)$, grupos MA e MC ( $\mathrm{p}<0,0001)$. Os demais grupos de migrânea não apresentaram diferenças entre si neste teste (Tabela 11).

Tabela 11. Média e IC 95\% nas variáveis do teste de subida e descida do degrau em controles (GC), migranosos crônicos (MC), migranosos com aura (MA) e sem aura (M).

\begin{tabular}{|c|c|c|c|c|c|c|}
\hline & \multicolumn{2}{|c|}{ Tempo de movimento (seg.) } & \multicolumn{2}{|c|}{$\begin{array}{l}\text { Índice de elevação } \\
\text { (\% peso corporal) }\end{array}$} & \multicolumn{2}{|c|}{$\begin{array}{l}\text { Índice de impacto } \\
\text { (\% peso corporal) }\end{array}$} \\
\hline & Esquerda & Direita & Esquerda & Direita & Esquerda & Direita \\
\hline $\mathrm{GC}$ & $\begin{array}{c}1,3^{*} \\
(1,3 \text { a } 1,4)\end{array}$ & $\begin{array}{c}1,3^{*} \\
(1,3 \text { a } 1,4)\end{array}$ & $\begin{array}{c}48,2^{\dagger} \\
(45,9 \text { a } 50,6)\end{array}$ & $\begin{array}{c}52,6^{\dagger} \\
(50,1 \text { a } 55,0)\end{array}$ & $\begin{array}{c}76,1^{\S} \\
(69,3 \text { a } 82,9)\end{array}$ & $\begin{array}{c}82,1^{\S} \\
(76,0 \text { a } 88,1)\end{array}$ \\
\hline M & $\begin{array}{c}1,6 \\
(1,5 \text { a } 1,6)\end{array}$ & $\begin{array}{c}1,6 \\
(1,5 \text { a } 1,6)\end{array}$ & $\begin{array}{c}43,0^{\ddagger} \\
(40,2 \text { a } 45,8)\end{array}$ & $\begin{array}{c}45,5^{*} \\
(42,7 \text { a } 48,2)\end{array}$ & $\begin{array}{c}61,91 \\
(56,2 \text { a } 67,6)\end{array}$ & $\begin{array}{c}56,7 \\
(51,3 \text { a } 62,1)\end{array}$ \\
\hline MA & $\begin{array}{c}1,7 \\
(1,61 \text { a } 1,8)\end{array}$ & $\begin{array}{c}1,7 \\
(1,6 \text { a } 1,8)\end{array}$ & $\begin{array}{c}36,5 \\
(34,1 \text { a } 38,9)\end{array}$ & $\begin{array}{c}38,6 \\
(36,4 \text { a } 40,8)\end{array}$ & $\begin{array}{c}50,9 \\
(47,3 \text { a } 54,6)\end{array}$ & $\begin{array}{c}55,3 \\
(51,3 \text { a } 59,3)\end{array}$ \\
\hline $\mathrm{MC}$ & $\begin{array}{c}1,7 \\
(1,6 \text { a } 1,8)\end{array}$ & $\begin{array}{c}1,7 \\
(1,6 \text { a } 1,8)\end{array}$ & $\begin{array}{c}38,8 \\
(36,7 \text { a } 40,9)\end{array}$ & $\begin{array}{c}40,7 \\
(38,7 \text { a } 42,7)\end{array}$ & $\begin{array}{c}55,8 \\
(51,7 \text { a } 59,9)\end{array}$ & $\begin{array}{c}56,9 \\
(53,4 \text { a } 60,4)\end{array}$ \\
\hline $\begin{array}{l}* p=0 \\
{ }^{\dagger} p=0, \\
{ }^{\dagger} p<0, \\
{ }^{\ddagger} p=0,\end{array}$ & $\begin{array}{l}06 \text { GC versu } \\
\text { GC versus } \mathrm{M} \\
\text { M versus } \mathrm{M} A \\
\text { GC versus } \mathrm{A}\end{array}$ & $\begin{array}{l}0<0,0001 \mathrm{GC} \\
0001 \mathrm{GC} v e\end{array}$ & $\begin{array}{l}\text { ersus MA e MC } \\
\text { is MA e MC. } \\
\text { sus MA e MC. }\end{array}$ & & & \\
\hline
\end{tabular}

Tamanho de Efeito (ES)

No teste subida e descida do degrau, foram observados grandes ES para as diferenças no tempo de movimento entre CG versus $\mathrm{MA}$ e $\mathrm{MC}$ no membro inferior esquerdo (MA: -0,95 e MC: $-0,82, p<0,05$ ) e direito (MA: $-1,16$ e MC: -1,02, $p<0,05$ ). Foram também encontrados ES moderados entre CG versus $\mathrm{M}$, e entre $\mathrm{M}$ versus MA apenas para o tempo de movimento da perna direita $(-0,53, p<0,05)$. No índice de elevação, as diferenças entre CG versus grupos de migrânea tiveram ES grandes para o membro inferior esquerdo (M: 0,82, MA: 0,91 e MC: 1,05, $p<0,05$ ) e direito (M: 0,98, MA: 1,07 e MC: 1,05, $p<0,05$ ). Para a variável índice de impacto, ES moderados e grandes foram encontrados entre CG versus MA e MC no membro inferior esquerdo (MA: -0,89 e MC: $-0,70, p<0,05$ ) e direito (MA: -1,01 e MC: $-0,98, p$ 
$<0,05)$. Para a perna direita, um índice de impacto com ES grande também foi encontrado para a diferença entre o GC versus $\mathrm{M}(-0,85, \mathrm{p}<0,05)$ (Tabela 12).

Tabela 12. Tamanhos de efeito e IC $95 \%$ das diferenças entre controles (GC), grupo de migrânea crônica (MC), migrânea com aura (MA) e sem aura (M) no teste subida e descida do degrau.

\begin{tabular}{|c|c|c|c|c|c|c|}
\hline & $\begin{array}{c}\text { Tempo de } \\
\text { movimento } \\
\text { (seg.) E }\end{array}$ & $\begin{array}{c}\text { Tempo de } \\
\text { movimento } \\
\text { (seg.) D }\end{array}$ & $\begin{array}{l}\text { Índice de } \\
\text { elevação E } \\
\text { (\% do PC) }\end{array}$ & $\begin{array}{l}\text { Índice de } \\
\text { elevação D } \\
\text { (\% do PC) }\end{array}$ & $\begin{array}{l}\text { Indice de } \\
\text { impacto E } \\
(\% \text { do PC) }\end{array}$ & $\begin{array}{l}\text { Indice de } \\
\text { impacto D } \\
(\% \text { do } P C)\end{array}$ \\
\hline $\begin{array}{c}\text { GC versus } \\
\text { M }\end{array}$ & $\begin{array}{c}-0,39 \\
(-0,86 \text { a } 0,09)\end{array}$ & $\begin{array}{c}-0,53^{*} \\
(-1,00 \mathrm{a}-0,04)\end{array}$ & $\begin{array}{c}0,82^{*} \\
(0,32 \text { a } 1,29)\end{array}$ & $\begin{array}{c}0,98^{*} \\
(0,47 \text { a } 1,46)\end{array}$ & $\begin{array}{c}-0,44 \\
(-0,91 \text { a } 0,04)\end{array}$ & $\begin{array}{c}-0,85^{*} \\
(-1,33 \text { a }-0,36)\end{array}$ \\
\hline $\begin{array}{c}\text { GC versus } \\
\text { MA }\end{array}$ & $\begin{array}{c}-0,95^{*} \\
(-1,44 \text { a }-0,45)\end{array}$ & $\begin{array}{c}-1,16^{*} \\
(-1,66 \mathrm{a}-0,64)\end{array}$ & $\begin{array}{c}0,91 * \\
(0,41 \text { a } 1,39)\end{array}$ & $\begin{array}{c}1,07 * \\
(0,56 \text { a } 1,56)\end{array}$ & $\begin{array}{c}-0,89^{*} \\
(-1,37 \text { a }-0,39)\end{array}$ & $\begin{array}{c}-1,01^{*} \\
(-1,49 \text { a }-0,50)\end{array}$ \\
\hline $\begin{array}{c}\text { GC versus } \\
\text { MC }\end{array}$ & $\begin{array}{c}-0,82 * \\
(-1,30 \text { a }-0,32)\end{array}$ & $\begin{array}{c}-1,02 * \\
(-1,51 \mathrm{a}-0,52)\end{array}$ & $\begin{array}{c}1,05^{*} \\
(0,54 \text { a } 1,54)\end{array}$ & $\begin{array}{c}1,05^{*} \\
(0,54 \text { a } 1,54)\end{array}$ & $\begin{array}{c}-0,70^{*} \\
(-1,17 \mathrm{a}-0,21)\end{array}$ & $\begin{array}{c}-0,98^{*} \\
(-1,47 \mathrm{a}-0,48)\end{array}$ \\
\hline $\begin{array}{c}\text { M versus } \\
\text { MA }\end{array}$ & $\begin{array}{c}-0,48 \\
(-0,95 \text { a } 0,0)\end{array}$ & $\begin{array}{c}-0,53^{*} \\
(-1,01 \mathrm{a}-0,05)\end{array}$ & $\begin{array}{c}0,26 \\
(-0,21 \text { a } 0,73)\end{array}$ & $\begin{array}{c}0,06 \\
(-0,41 \text { a } 0,53)\end{array}$ & $\begin{array}{c}-0,44 \\
(-0,91 \text { a } 0,04)\end{array}$ & $\begin{array}{c}-0,06 \\
(-0,53 \text { a } 0,41)\end{array}$ \\
\hline $\begin{array}{l}\text { M versus } \\
\text { MC }\end{array}$ & $\begin{array}{c}-0,33 \\
(-0,79 \text { a } 0,15)\end{array}$ & $\begin{array}{c}-0,38 \\
(-0,85 \text { a } 0,10)\end{array}$ & $\begin{array}{c}0,27 \\
(-0,20 \text { a } 0,74)\end{array}$ & $\begin{array}{c}0,16 \\
(-0,31 \text { a } 0,63)\end{array}$ & $\begin{array}{c}-0,24 \\
(-0,71 \text { a } 0,23)\end{array}$ & $\begin{array}{c}0,01 \\
(-0,46 \text { a } 0,48)\end{array}$ \\
\hline
\end{tabular}

*Tamanhos de efeito médios e grandes com nível de significância <0,05. D: direito, E: esquerdo.

\subsection{TESTE DE SENTADO PARA EM PÉ}

No teste de sentado para em pé, foi observada diferença entre o GC em comparação aos grupos M, MA e MC na variável de transferência de peso e índice de elevação $(\mathrm{p}<0,002)$. Não foram observadas diferenças entre os grupos na variável velocidade do CG (Tabela 13).

Tabela 13. Média e IC $95 \%$ nas variáveis do teste sentado para em pé em controles (GC), migranosos crônicos (MC), migranosos com aura (MA) e sem aura (M).

\begin{tabular}{cccc}
\hline \hline & $\begin{array}{c}\text { Transferência de peso } \\
(\text { seg. })\end{array}$ & $\begin{array}{c}\text { Índice de elevação } \\
(\% \text { peso corporal })\end{array}$ & $\begin{array}{c}\text { Velocidade do CG } \\
\text { (graus/seg) }\end{array}$ \\
\hline GC & $0,4(0,4 \text { a } 0,4)^{*}$ & $24,7(23,4 \text { a } 26,0)^{\dagger}$ & $3,9(3,8$ a 4,2$)$ \\
M & $0,6(0,5$ a 0,6$)$ & $20,2(18,9$ a 21,5$)$ & $3,5(3,2$ a 3,8$)$ \\
MA & $0,6(0,5$ a 0,6$)$ & $18,4(17,0$ a 19,7$)$ & $3,7(3,4$ a 4,1$)$ \\
MC & $0,5(0,5$ a 0,6$)$ & $19,9(18,7$ a 21,2$)$ & $3,7(3,4$ a 4,0$)$
\end{tabular}

CG: centro de gravidade

$* p=0,0004$ GC versus $\mathrm{M}, p<0,0001 \mathrm{GC}$ versus MA, $p=0,002 \mathrm{CG}$ versus $\mathrm{MC}$.

${ }^{\dagger} p=0,002$ GC versus $\mathrm{M}, p=0,0006 \mathrm{CG}$ versus $\mathrm{MA}, p=0,01 \mathrm{CG}$ versus $\mathrm{MC}$. 


\section{Tamanho de Efeito (ES)}

No teste sentado para em pé, foram observados os ES moderados entre CG versus grupos de migrânea (M: 0,63, MA: 0,62 e MC: 0,50, p<0,05). As diferenças no índice de elevação demonstraram ES moderado e grande entre CG versus M e MA (-0,66 e -0,93, respectivamente, $p<0,05$ ) (Tabela 14$)$.

Tabela 14. Tamanhos de efeito e IC 95\% das diferenças entre controles (GC), grupo de migrânea crônica (MC), migrânea com aura (MA) e sem aura (M) no teste sentado para em pé.

\begin{tabular}{cccc}
\hline \hline & $\begin{array}{c}\text { Transferência de peso } \\
(\text { seg. })\end{array}$ & $\begin{array}{c}\text { Índice de elevação } \\
(\% \text { do PC })\end{array}$ & $\begin{array}{c}\text { Velocidade do CG } \\
(\% \text { seg. })\end{array}$ \\
\hline GC versus $\mathrm{M}$ & $0,63(0,14 \text { a } 1,10)^{*}$ & $-0,66(-1,13 \text { a }-0,17)^{*}$ & $-0,32(-0,79$ a 0,15$)$ \\
GC versus MA & $0,62(0,13 \text { a } 1,09)^{*}$ & $-0,93(-1,41 \text { a }-0,43)^{*}$ & $-0,13(-0,60$ a 0,34$)$ \\
GC versus MC & $0,50(0,20 \text { a } 0,97)^{*}$ & $-0,72(-1,19$ a 0,23$)$ & $-0,17(-0,64$ a 0,30$)$ \\
M versus MA & $0(-0,47$ a 0,47$)$ & $-0,27(-0,74$ a 0,20$)$ & $0,18(-0,29$ a 0,65$)$ \\
M versus MC & $-0,12(-0,59$ a 0,35$)$ & $-0,04(-0,51$ a 0,43$)$ & $0,15(-0,32$ a 0,62$)$
\end{tabular}

*Tamanhos de efeito médios e grandes com nível de significância <0,05. PC: peso corporal

\subsection{TONTURA E DHI BRASILEIRO}

Não foram observadas diferenças quanto à presença de tonturas dentro da crise entre grupos de indivíduos com migrânea (grupos M, MA e MC) (p>0,05). A presença de tontura fora da crise foi menor no GC em relação a todos os grupos de migrânea $(p<0,0001)$. Os pacientes do grupo $M$ também relataram tontura fora da crise em menor frequência comparados a pacientes do grupo MA e MC (p <0,0001).

O GC apresentou menor score no DHI Brasileiro em comparação a todos os pacientes com migrânea $(\mathrm{p}<0,0001)$. Foi encontrada também diferença entre o $\mathrm{M}$ versus $\mathrm{MA}$ e MC neste mesmo score $(\mathrm{p}<0,0001)$. De acordo com os scores de corte, indivíduos do GC e M apresentaram leve deficiência devido à tontura, enquanto indivíduos do grupo MA e MC apresentaram deficiência moderada de acordo com o DHI (Tabela 15). 
Dentro do score total do DHI Brasileiro, foram observados maiores níveis de autopercepção de incapacidade dentro dos aspectos funcionais, seguido de aspectos físicos e por fim os aspectos emocionais, com diferença observada entre os grupos $(p<0,05)$ (Figura 11).

Tabela 15. Média e desvio padrão da pontuação do DHI e prevalência de tontura dentro e fora das crises de migrânea.

\begin{tabular}{ccccc}
\hline \hline & GC & M & MA & MC \\
\cline { 2 - 5 } Tontura dentro da crise & - & $43 \%$ & $43 \%$ & $49 \%$ \\
Tontura fora da crise & $9 \%^{*}$ & $29 \%^{\dagger}$ & $51 \%$ & $40 \%$ \\
DHI Brasileiro (pontos) & $4,6^{*}$ & $19,5^{\dagger}$ & 44,7 & 41,4 \\
& $(-0,1$ a 9,3$)$ & $(12,7$ a 26,2$)$ & $(36$ a 53,3) & $(33$ a 49,7) \\
\hline
\end{tabular}

DHI: Dizziness Handicap Inventory, ${ }^{*} p<0.0001$ : GC versus M, MA e MC; ${ }^{\dagger} p<0.0001$ : M versus MA e MC.

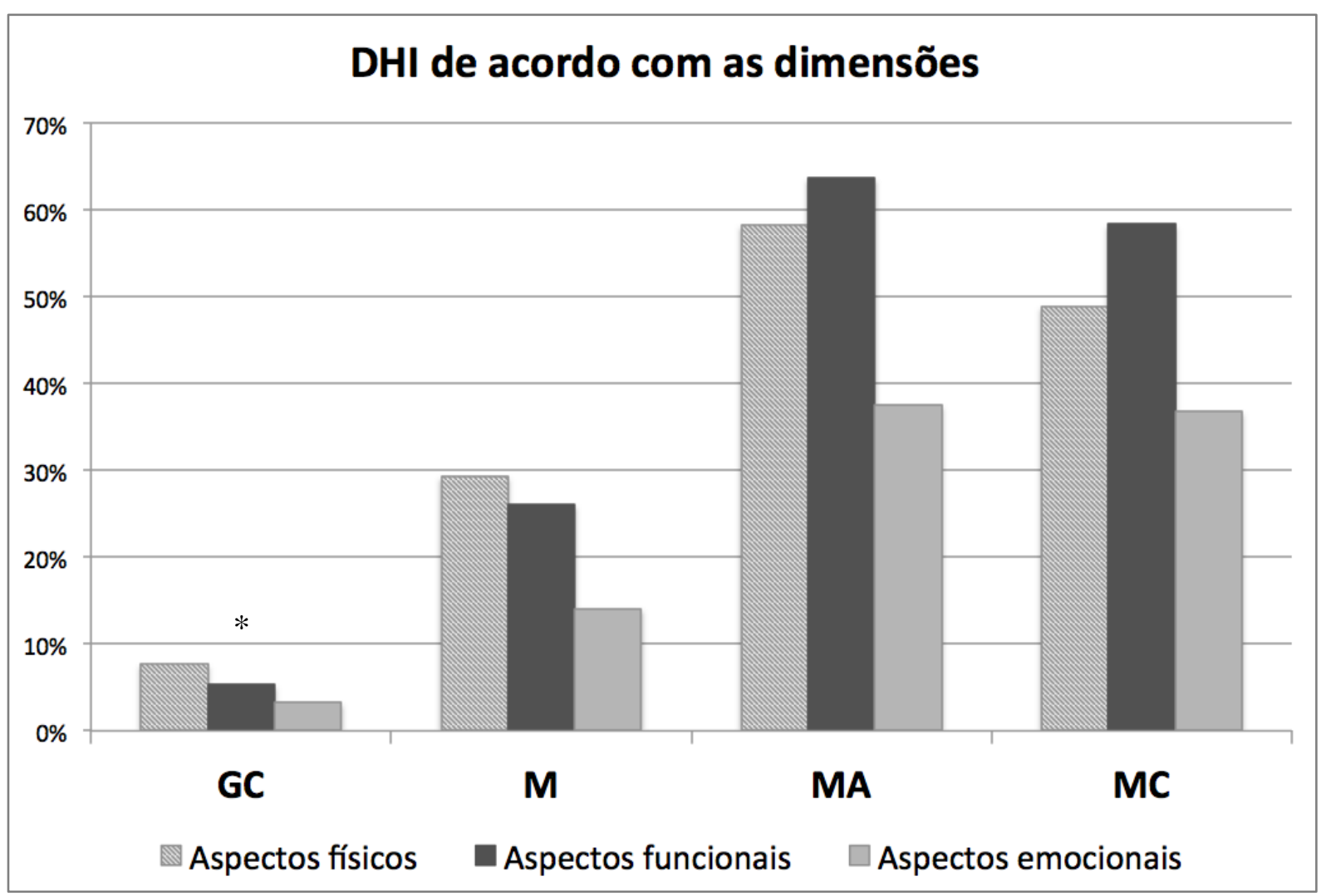

Figura 11. Níveis de autopercepção de incapacidade de acordo com as dimensões físicas, funcionais e emocionais do questionário DHI Brasileiro. GC: grupo controle, M: migrânea sem aura, MA: migrânea com aura, MC: migrânea crônica. *Teste exato de Fisher, $p<0.05$. 


\subsection{QUEDAS E FES-I BRASIL}

Foi observada diferença entre os grupos nas variáveis autorrelato de história de quedas e de desequilíbrio, sendo verificada maior frequência nos grupos MA e MC ( $p<0,0001)$. Dentre os migranosos com autorrelato de quedas, foi verificado maior número de quedas no último ano nos grupos MA e MC em relação ao grupo GC ( $p<0,009)$ (Tabela 16). Nenhum dos pacientes relataram lesões graves devido às quedas, como fraturas ou concussões. As queixas mais comuns após a ocorrência de quedas foram: arranhões, hematomas, entorses de tornozelo ou dor de curta duração nas costas, mão e/ou cabeça.

A razão de prevalência (RP) de quedas em pacientes do grupo $M$ foi de 2,75 vezes (IC 95\%: 0,9 a 7,8) em relação ao GC ( $p>0,05)$. Os pacientes com MA apresentaram uma RP de 7,2 vezes (IC 95\%: 2,8 a 18,4) em relação ao GC ( $p<0,05)$, e de 2,6 vezes (IC 95\%: 1,6 a 4,4) em relação aos pacientes M ( $p<0,05)$. Os pacientes com MC apresentaram uma RP de 4,5 (IC 95\%: 1,7-12,0) vezes em referência ao GC $(p<0,05)$ e de 1,6 (IC 95\%: 0.9 a 2.9) em relação ao grupo $\mathrm{M}(p>0,05)$ (Tabela 16).

O GC apresentou menor score no questionário FES-I Brasil em comparação a todos os grupos de migrânea e o grupo $\mathrm{M}$ obteve menor score comparado aos grupos MA e MC (M: 26,2 IC 95\%: 23,8 a 28,7; MA: 31 IC 95\%: 28,1 a 33,9; MC: 32,2 IC 95\%: 29,1 a 35,2; p <0,05). De acordo com a pontuação de corte, o GC e M apresentaram moderada preocupação com quedas, enquanto o grupo M e MA apresentaram alta preocupação com quedas (Tabela 16). 
Tabela 16. Prevalência e número de quedas no último ano (média e DP), razão de prevalência de quedas (RP e IC 95\%) e pontuação no questionário FES-I (score e IC 95\%) dos grupos migrânea crônica (MC), migrânea com aura (MA), sem aura (M) e grupo controle (GC).

\begin{tabular}{|c|c|c|c|c|}
\hline & GC & $\mathrm{M}$ & MA & $\mathrm{MC}$ \\
\hline História de quedas & $11 \% *$ & $31 \%$ & $82 \%$ & $51 \%$ \\
\hline $\begin{array}{l}\text { Autorrelato de } \\
\text { desequilíbrio }\end{array}$ & $6 \% *$ & $63 \%$ & $86 \%$ & $63 \%$ \\
\hline Lesão devido à queda & $8,6 \% *$ & $37,1 \%$ & $65,7 \%$ & $40 \%$ \\
\hline Quedas (n último ano) & $1(0)^{\dagger}$ & $\begin{array}{c}1,7 \\
(1,1 \text { a } 2,15)\end{array}$ & $\begin{array}{c}2,7 \\
(1,8 \text { a } 3,5)\end{array}$ & $\begin{array}{c}2,7 \\
(1,8 \text { a } 3,5)\end{array}$ \\
\hline FES-I (pontos) & $\begin{array}{c}20^{*} \\
(18,7 \text { a } 21,3)\end{array}$ & $\begin{array}{c}26,2^{\S} \\
(23,8 \text { a } 28,7)\end{array}$ & $\begin{array}{c}31 \\
(28,1 \text { a } 33,9)\end{array}$ & $\begin{array}{c}32,2 \\
(29,1 \text { a } 35,2)\end{array}$ \\
\hline \multicolumn{5}{|l|}{ Razão de prevalência } \\
\hline Ref.: GC & - & $\begin{array}{c}2.75 \\
(0.9 \text { a } 7.8)\end{array}$ & $\begin{array}{c}7.2 * * \\
(2.8 \text { a } 18.4)\end{array}$ & $\begin{array}{c}4.5 * * \\
(1.7 \text { a } 12.0)\end{array}$ \\
\hline Ref.: M & $\begin{array}{c}2.75 \\
(0.9 \text { a } 7.8)\end{array}$ & - & $\begin{array}{c}2.6^{* * *} \\
(1.6 \text { a } 4.4)\end{array}$ & $\begin{array}{c}1.6 \\
(0.9 \text { a } 2.9)\end{array}$ \\
\hline
\end{tabular}

FES-I: Escala de Eficácia de Quedas. ${ }^{*} p<0,0001$ teste exato de Fisher.

${ }^{\dagger} p<0,009$, GC versus MA e MC;

${ }^{\ddagger} p<0,0002$, GC versus M, MA e MC;

$\S_{p}<0,007, \mathrm{M}$ versus MA MC;

** $p<0.002$ : diferenças na razão de prevalência. Ref.: referência. 


\section{Discussão}

5.1 Sumário

5.2 Discussão dos resultados

5.3 Limitações e forças do estudo 


\section{DISCUSSÃO}

\subsection{SUMÁRIO}

Baseado nos resultados apresentados, podemos afirmar que a hipótese de maior comprometimento funcional em pacientes com migrânea com aura e migrânea crônica foi parcialmente confirmada. Estes dois grupos de pacientes demonstraram maior área de oscilação no teste modificado de integração sensorial do equilíbrio em duas situações de teste em comparação a migranosos sem aura; e em três condições do teste, comparados aos controles, dentre as quatro condições de exame aplicadas. Nos demais testes funcionais avaliados, a aura influenciou apenas uma variável do teste de subida e descida no degrau. Além disso, estes resultados revelaram um expressivo aumento no autorrelato de história de quedas, presença de desequilíbrio e lesões devido às quedas em pacientes com aura, seguido de pacientes com migrânea crônica e migrânea sem aura, comparado aos controles. Estes resultados refletiram um aumento no risco de prevalência de quedas de migranosos crônicos e com aura em relação a controles, e também em migranosos com aura em relação aos sem aura. Ficaram também evidentes os maiores níveis de preocupação com quedas e maior incapacidade relacionada à tontura nestes dois grupos de pacientes.

No entanto, a diferença entre migranosos com aura e com migrânea crônica não refletiu no desempenho das atividades funcionais de caminhada, caminhada tandem, subida e descida do degrau, sentado para em pé e limites de estabilidade. Nestas atividades, todos os grupos de migranosos, incluído o grupo sem aura, apresentaram decréscimo da performance quando comparados ao grupo controle. Esta diferença entre controles e migranosos revelaram tamanho de efeitos moderados a altos, independente do subgrupo de migrânea. Além disso, é importante destacar que mesmo não sendo na mesma magnitude comparado aos pacientes com aura e crônicos, os migranosos sem aura relataram maior história de quedas, desequilíbrio, lesões devido à queda, apresentaram maiores scores na preocupação com quedas e incapacidade relacionada à tontura, quando comparados aos controles. 


\subsection{DisCUSSÃO DOS RESULTADOS}

Diante destes resultados, podemos especular que a influência da aura e da cronicidade no equilíbrio é mais evidente em protocolos de avaliação mais sensíveis ou minuciosos, como a avaliação do equilíbrio em tarefas que desafiam múltiplos sistemas de controle postural. Como exemplo no teste de integração sensorial, que comparado às atividades funcionais, podem apresentar menores possibilidades de adaptação e compensação durante os movimentos. Assim, verificamos que a presença da doença está relacionada a redução do equilíbrio funcional e quedas, em graus diferentes de acordo com os subgrupos de pacientes.

A maior parte dos estudos de avaliação do controle postural semi-estático também demonstraram alterações em migranosos, mas o contraste com este estudo deve ser cuidadoso devido às variações de protocolos de teste, características da população e poder amostral. Alguns estudos utilizaram outras condições desafiadoras como alterações no posicionamento da cabeça, ${ }^{3,9,11}$ estímulos de vibração nos músculos da perna, ${ }^{7}$ estimulação optocinética, ${ }^{6,10,11}$ ou estimulação vestibular galvânica. ${ }^{12}$ Estes estudos também não permitem o contraste de diferentes subgrupos de migrânea pois alguns deles avaliaram tipos diferentes de cefaleias ${ }^{8,12}$ ou não agruparam os pacientes de acordo com o diagnóstico da ICHD, ${ }^{2,3,8}$ mas de acordo com a presença ou não de tontura. ${ }^{5,6,9,10,13}$

A presença de tontura é muito comum em migranosos. Cerca de $38 \%$ dos pacientes relatam este sintoma ${ }^{64}$ e $58 \%$ dos migranosos apresentam evidência laboratorial de disfunção no funcionamento do sistema vestibular, independente de relatar tontura ou não. ${ }^{59,65}$ Porém, a influência da tontura no controle postural de migranosos permanece controversa. $5,6,9,10,13$

Nossos resultados demonstraram alta prevalência de tontura no período dentro da crise em migranosos sem aura (43\%), com aura (43\%) e com migrânea crônica (49\%), sem diferença entre os grupos, concordando com Furman et al, ${ }^{6}$ Ongun et al ${ }^{9}$ e Panichi et al. ${ }^{10}$ No período fora da crise, a tontura foi prevalente em $29 \%$ em migranosos sem aura, $51 \%$ em pacientes com aura e $40 \%$ em migranosos crônicos, com diferença entre controles versus migranosos e migranosos sem aura versus com aura. Por meio do DHI Brasileiro, foi demonstrado que o sintoma de tontura está relacionado de maneira significante à incapacidade percebida, em diferentes graus de acordo com os subgrupos de migrânea, influenciando especialmente as dimensões físicas e funcionais.

Em contraste com os testes de equilíbrio, podemos observar que a análise ponderada dos dados não revelou nenhuma influência da tontura dentro e fora da crise nas variáveis 
avaliadas. O que sugere que a presença da migrânea, independente do autorrelato da tontura, apresenta influência no controle postural. Porém, de acordo com a autopercepção do paciente, mesmo que sobreposta ao quadro de migrânea, a tontura está relacionada com maior percepção de incapacidade funcional e física.

Na maioria dos testes de equilíbrio avaliados neste estudo, pode ser observado que a magnitude e frequência da diferença entre os grupos é maior de acordo com a presença de aura e cronicidade. Outros estudos que avaliaram o teste modificado de integração sensorial do equilíbrio observaram o mesmo padrão em migranosos, mas comparado com controles ${ }^{2}$ ou em contraste com e sem autorrelato de vertigem. ${ }^{5,10}$

Akdal et $a l^{3}$ avaliaram migranosos por meio do teste modificado de integração sensorial, limites de estabilidade e marcha tandem e foram encontradas diferenças entre migranosos e controles nas condições de superfície estável e instável com olhos abertos e instável com os olhos fechados, enquanto nosso estudo não demonstrou diferenças entre migranosos sem aura e controles nestas mesmas condições. No teste de limites de estabilidade foi observado menor tempo de reação e excursão máxima e no teste de marcha tandem foi verificado maior largura de passo e menor velocidade em migranosos comparado a controles, ${ }^{3}$ corroborando com os nossos resultados. É importante destacar que Akdal et $a l^{3}$ incluíram pacientes com e sem aura no mesmo grupo, podendo justificar as diferenças encontradas entre os resultados no teste de integração sensorial do equilíbrio.

Estudos prévios demonstraram alterações na velocidade da marcha em migranosos comparado a controles, ${ }^{3,4,66}$ sem diferenças no teste Timed up and go de acordo com a presença de aura. ${ }^{4}$ A diminuição da velocidade da marcha e aumento da largura de passo está diretamente relacionado com a fragilidade, deterioramento do controle postural, redução da funcionalidade e risco de quedas em idosos. ${ }^{104}$

Menores índices de elevação no teste de sentado para em pé sugerem pobre controle motor e diminuição de força de membros inferiores. ${ }^{81}$ Além disso, a redução no desempenho na tarefa de subir e descer degraus está relacionada em pacientes com alto risco de queda. ${ }^{114}$ Estas alterações encontradas nos testes funcionais sugeriram que pacientes com migrânea podem estar expostos a um maior risco de quedas e subsequente incapacidade funcional.

Esta hipótese se correlaciona diretamente com o maior risco de prevalência de quedas verificado em pacientes com migrânea com aura em relação aos sem aura e controles, e em migranosos crônicos em relação aos controles. 
É importante destacar que $82 \%$ dos migranosos com aura, $51 \%$ dos migranosos crônicos e $31 \%$ dos migranosos sem aura relataram pelo menos um evento de queda no último ano e esta prevalência é maior comparada com idosos aos 65 anos de idade e semelhante a idosos de 80 anos. ${ }^{115}$ Como as quedas em migranosos não estão associadas à lesões graves e não apresentam o mesmo impacto no dia a dia quando comparados aos idosos, podemos sugerir que esta evidência indica um deterioramento precoce nos sistema que controlam o equilíbrio em migranosos. Além disso, foi demonstrada uma consequência deste deterioramento, a queda, na qual é frequentemente subestimada no exame clínico destes pacientes.

A presença de quedas em pacientes com migrânea pode ser subestimada por vários motivos. Em primeiro lugar, a população migranosa apresenta idade média em torno de 22 a $55 \operatorname{anos}^{36}$ e não está provavelmente sob risco de lesões graves relacionadas às quedas, pela ausência de doenças como osteoporose, osteoartrite, déficits cognitivos ou redução de reflexos protetores. ${ }^{116,117}$ Já que as quedas nesta faixa etária não levam a nenhuma lesão importante, os pacientes podem ignorar e omitir a sua ocorrência. O cenário oposto é observado em idosos, onde a presença de quedas ocupa a segunda posição de mortalidade e morbidade por causas externas, devido ao alto risco de lesões nesta população. ${ }^{87}$

Outras razões para subestimação das quedas nesta população incluem a baixa frequência anual encontrada e o fato da dor de cabeça já representar uma condição muito incapacitante por si só. Assim, talvez todos os esforços sejam no sentido do manejo da dor e não do equilíbrio e controle postural.

No entanto, já que as consequências das quedas são redução da mobilidade, autoconfiança, com consequente redução na qualidade de vida e deterioração progressiva do equilíbrio, ${ }^{88}$ atenção especial deve ser atribuída para os pacientes que apresentam aura e migrânea crônica. Este aspecto é reforçado pelos achados de altos índices de preocupação com quedas, detectado pelo questionário FES-1 Brasil, nestes dois grupos de pacientes. O medo de cair aumenta o risco de ocorrência futura de quedas, já que ele pode estar relacionado a restrição física, redução na qualidade de vida, incapacidade e sintomas depressivos. $^{112}$

Assim, nossos dados suportam a evidência de anormalidades no controle do equilíbrio em pacientes com diferentes subtipos de migrânea no desempenho de atividades estáticas e dinâmicas, que mimetizam atividades de vida diária. Além disso, fica evidente a consequência funcional destas alterações de equilíbrio: a presença de quedas. 
Como a idade média da amostra deste estudo foi em torno de 36 anos de idade e existe evidência de progressão destas alterações ao longo de um ano, ${ }^{9}$ é fundamental destacar a evidência de deterioração funcional precoce nesta população. A mesma pode ter um impacto significativo em suas vidas, juntamente com a diminuição da qualidade de vida já conhecida devido à presença da dor. Assim, esforços para a investigação clínica do comprometimento do equilíbrio e planejamento de intervenções terapêuticas adequadas podem ser de extrema importância. Neste contexto, a fisioterapia pode ter um papel importante na reabilitação deste grupo de pacientes.

\subsection{LIMITAÇÕES E FORÇAS DO ESTUDO}

Este estudo apresenta algumas limitações. Em primeiro lugar, não é possível realizar suposições sobre a etiologia das alterações de equilíbrio, já que os testes clínicos aplicados não são capazes de distinguir alterações de origem central ou periférica. Estudos futuros utilizando testes clínicos mais precisos como o Balance Master Equitest ${ }^{\circledR}$, ou correlacionando os achados com testes otoneurológicos e exames de neuroimagem podem contribuir para o avanço no conhecimento da etiologia destas alterações em pacientes com migrânea.

Em segundo lugar, a generalização dos resultados é apenas viável na mesma população em estudo, que não inclui os indivíduos do sexo masculino. De acordo com a maior prevalência da migrânea em mulheres, não foi viável a inclusão de homens no estudo devido à dificuldade da presença destes indivíduos no ambulatório de triagem.

Em terceiro lugar, não podemos absolutamente atestar a falta de diferenças entre os pacientes com migrânea com aura e migrânea crônica em comparação com pacientes com migrânea sem aura nos testes funcionais. Observou-se um padrão de alterações maior nesses pacientes, que poderia ter sido evidenciada na avaliação de pacientes com maior idade, onde talvez a disfunção estaria exacerbada, devido à somação com a deterioração dos sistemas de controle postural ocasionados pelo processo de envelhecimento.

Uma vez que as características originais da migrânea podem se modificar devido ao processo de cronificação e o sintoma de aura pode desaparecer, a quarta limitação está relacionada ao diagnóstico prévio ao processo de cronificação da migrânea. Talvez o grupo de migrânea crônica possa ser parcialmente constituído por pacientes que exibiram aura no passado, influenciando os achados neste grupo. Além disso, os pacientes com migrânea deste estudo são provenientes de um setor terciário, fator que pode superestimar os resultados. 
Devido ao desenho transversal do estudo, não é possível realizar suposições sobre a causa-efeito das conclusões deste estudo, tampouco concluir que a migrânea aumenta o risco de quedas. Com a análise do risco de prevalência, é possível sugerir que a migrânea está associada ao risco de quedas, já que o mesmo é multifatorial e o presente estudo não avaliou outros fatores como alterações visuais, fraqueza de membros inferiores ou riscos ambientais. Futuros estudos integrando estas questões podem elucidar estes aspectos.

No entanto, podemos ressaltar que este foi o primeiro estudo que avaliou o comprometimento funcional em três diferentes subtipos de migrânea incluindo a avaliação do desempenho de atividades presentes na vida diária, autorrelato de quedas, presença de tontura e medo de cair.

Nossos dados contribuem para o melhor entendimento das consequências das alterações de equilíbrio, antes mencionadas como subclínicas. Se as mesmas progredirem com o passar do tempo, como já sugerido ${ }^{9}$ - devido a recorrência das crises de migrânea ou mesmo em associação ao processo de envelhecimento - a interferência na vida do paciente pode se exacerbar, resultando em possíveis limitações funcionais.

Devido à presença de um adequado tamanho amostral e uma vez que a análise ponderou potenciais confundidores, podemos afirmar que a presença da migrânea é um fator independente para a presença de alterações de equilíbrio semi-estático e dinâmico, independente da idade, presença de tontura, IMC, tempo de doença, nível de atividade física e número de medicamentos em uso.

Assim, futuros estudos direcionados para a investigação tanto do impacto destas alterações na qualidade de vida dos pacientes quanto a sua evolução ao longo do tempo podem culminar em propostas de prevenção do deterioramento dos sistemas de controle postural. Além disso, a associação entre métodos que avaliem diferentes dimensões do equilíbrio em conjunto com exames otoneurológicos e de imagem podem colaborar na formulação de hipóteses a respeito da etiologia destas alterações. A adequada avaliação e inclusão de intervenções relacionadas à reabilitação do controle postural podem beneficiar pacientes com migrânea, com o objetivo de prevenir o declínio funcional. 


\section{Conclusões}

6.1. Conclusões primárias

6.2. Conclusões secundárias 


\section{CONCLUSÕES}

\subsection{CONCLUSÕES PRIMÁRIAS}

- A presença da migrânea exerceu influência sobre todas as atividades funcionais avaliadas, estando relacionada à redução do desempenho em atividades estáticas e dinâmicas em comparação aos indivíduos sem a doença. A presença da aura e cronicidade nos pacientes com migrânea piorou o controle postural diante da redução de informações sensoriais como visão e propriocepção no teste de equilíbrio estático. Estes resultados apresentam relevância clínica, já que moderados e grandes tamanhos de efeito foram evidenciados entre todos os grupos de migranosos, mas especialmente naqueles com aura e migrânea crônica, em relação a controles.

\subsection{CONCLUSÕES SECUNDÁRIAS}

- A prevalência da tontura fora de crise é maior em pacientes com migrânea com aura, migrânea crônica e migrânea sem aura, nesta ordem crescente de magnitude, com diferenças entre controles e migranosos, e migranosos com aura e crônica em relação ao grupo sem aura. A prevalência de tontura dentro da crise não diferiu entre os grupos de migrânea. Migranosos crônicos e com aura apresentam moderada incapacidade relacionada aos sintomas de tontura, com maiores alterações nas dimensões funcionais e físicas. A mesma foi classificada como leve em controles e migranosos sem aura.

- Pacientes com migrânea com aura apresentam de forma significativa maior história de quedas e autorrelato de desequilíbrio e lesões devido à queda, bem como maior número de quedas no último ano em comparação aos demais grupos. Migranosos crônicos apresentam a segunda maior queixa nos mesmos itens, seguidos de migranosos sem aura, também com diferenças entre eles. Estas alterações demonstram maior associação com o risco de quedas nos grupos com aura e migrânea crônica. Migranosos crônicos e com aura também apresentaram alta preocupação com a possibilidade de quedas, em contraste com a baixa pontuação de controles e migranosos sem aura.

- As alterações encontradas nos testes funcionais sugerem que pacientes com migrânea podem estar expostos a um maior risco de quedas e subsequente incapacidade funcional. Neste sentido, a fisioterapia pode ter um papel importante na reabilitação deste grupo de pacientes. 


\section{Referências Bibliográficas}




\section{REFERÊNCIAS BIBLIOGRÁFICAS}

1. Headache Classification Committee of the International Headache Society. The International Classification of Headache Disorders, 3rd edition (beta version). Cephalalgia 2013; 33(9): 629-808.

2. Akdal G, Balci BD, Angin S, Ozturk V, Halmagyi GM. A longitudinal study of balance in migraineurs. Acta Otolaryngol 2012; 132(1): 27-32.

3. Akdal G, Donmez B, Ozturk V, Angin S. Is balance normal in migraineurs without history of vertigo? Headache 2009; 49(3): 419-25.

4. Carvalho GF, Chaves TC, Dach F, et al. Influence of Migraine and of Migraine Aura on Balance and Mobility - A Controlled Study. Headache 2013; 53(7): 1116-22.

5. Celebisoy N, Gokcay F, Sirin H, Bicak N. Migrainous vertigo: clinical, oculographic and posturographic findings. Cephalalgia 2008; 28(1): 72-7.

6. Furman JM, Sparto PJ, Soso M, Marcus D. Vestibular function in migraine-related dizziness: a pilot study. J Vestib Res 2005; 15(5-6): 327-32.

7. Harno H, Hirvonen T, Kaunisto MA, et al. Subclinical vestibulocerebellar dysfunction in migraine with and without aura. Neurology 2003; 61(12): 1748-52.

8. Ishizaki K, Mori N, Takeshima T, et al. Static stabilometry in patients with migraine and tension-type headache during a headache-free period. Psychiatry Clin Neurosci 2002; 56(1): 85-90.

9. Ongun N, Atalay NS, Degirmenci E, Sahin F, Bir LS. Tetra-ataxiometric Posturography in Patients with Migrainous Vertigo. Pain physician 2016; 19(1): E87-96.

10. Panichi R, Cipriani L, Sarchielli P, et al. Balance control impairment induced after OKS in patients with vestibular migraine: an intercritical marker. European archives of otorhino-laryngology : official journal of the European Federation of Oto-Rhino-Laryngological Societies 2015; 272(9): 2275-82.

11. Rossi C, Alberti A, Sarchielli P, et al. Balance disorders in headache patients: evaluation by computerized static stabilometry. Acta Neurol Scand 2005; 111(6): 407-13.

12. So CW, Bent LR. Increased vestibular contribution to posture control in individuals with chronic headache. J Vestib Res 2009; 19(1-2): 49-58.

13. Teggi R, Colombo B, Bernasconi L, Bellini C, Comi G, Bussi M. Migrainous vertigo: results of caloric testing and stabilometric findings. Headache 2009; 49(3): 435-44.

14. Cha YH, Baloh RW. Migraine associated vertigo. J Clin Neurol 2007; 3(3): 121-6.

15. Baloh RW. Neurotology of migraine. Headache 1997; 37(10): 615-21. 
16. Crevits L, Bosman T. Migraine-related vertigo: towards a distinctive entity. Clin Neurol Neurosurg 2005; 107(2): 82-7.

17. Calhoun AH, Ford S, Pruitt AP, Fisher KG. The point prevalence of dizziness or vertigo in migraine--and factors that influence presentation. Headache 2011; 51(9): 1388-92.

18. Bisdorff A. Migraine and dizziness. Curr Opin Neurol 2014; 27(1): 105-10.

19. Milhaud D, Bogousslavsky J, van Melle G, Liot P. Ischemic stroke and active migraine. Neurology 2001; 57(10): 1805-11.

20. Hoekstra-van Dalen RA, Cillessen JP, Kappelle LJ, van Gijn J. Cerebral infarcts associated with migraine: clinical features, risk factors and follow-up. J Neurol 1996; 243(7): $511-5$.

21. Kruit MC, van Buchem MA, Hofman PA, et al. Migraine as a risk factor for subclinical brain lesions. JAMA 2004; 291(4): 427-34.

22. Parker W. Migraine and the vestibular system in adults. Am J Otol 1991; 12(1): 25-34.

23. Hong SM, Kim SK, Park CH, Lee JH. Vestibular-evoked myogenic potentials in migrainous vertigo. Otolaryngol Head Neck Surg 2011; 144(2): 284-7.

24. Cal R, Bahmad Jr F. Migraine associated with auditory-vestibular dysfunction. Braz J Otorhinolaryngol 2008; 74(4): 606-12.

25. Kayan A, Hood JD. Neuro-otological manifestations of migraine. Brain 1984; 107 ( Pt 4): $1123-42$.

26. Swartz RH, Kern RZ. Migraine is associated with magnetic resonance imaging white matter abnormalities: a meta-analysis. Arch Neurol 2004; 61(9): 1366-8.

27. Kruit MC, van Buchem MA, Launer LJ, Terwindt GM, Ferrari MD. Migraine is associated with an increased risk of deep white matter lesions, subclinical posterior circulation infarcts and brain iron accumulation: the population-based MRI CAMERA study. Cephalalgia 2010; 30(2): 129-36.

28. Dieterich M, Brandt T. Episodic vertigo related to migraine (90 cases): vestibular migraine? J Neurol 1999; 246(10): 883-92.

29. Silberstein SD. Migraine. Lancet 2004; 363(9406): 381-91.

30. Goadsby PJ, Lipton RB, Ferrari MD. Migraine--current understanding and treatment. N Engl J Med 2002; 346(4): 257-70.

31. Russell MB, Iselius L, Olesen J. Migraine without aura and migraine with aura are inherited disorders. Cephalalgia 1996; 16(5): 305-9.

32. Rasmussen BK, Jensen R, Schroll M, Olesen J. Epidemiology of headache in a general population--a prevalence study. J Clin Epidemiol 1991; 44(11): 1147-57. 
33. Bigal ME, Lipton RB, Stewart WF. The epidemiology and impact of migraine. Curr Neurol Neurosci Rep 2004; 4(2): 98-104.

34. Lipton RB, Bigal ME, Diamond M, Freitag F, Reed ML, Stewart WF. Migraine prevalence, disease burden, and the need for preventive therapy. Neurology 2007; 68(5): 3439.

35. Stewart WF, Lipton RB, Simon D. Work-related disability: results from the American migraine study. Cephalalgia 1996; 16(4): 231-8; discussion 15.

36. Global Burden of Disease Study C. Global, regional, and national incidence, prevalence, and years lived with disability for 301 acute and chronic diseases and injuries in 188 countries, 1990-2013: a systematic analysis for the Global Burden of Disease Study 2013. Lancet 2015; 386(9995): 743-800.

37. Bigal ME, Fernandes LC, Bordini CA, Speciali JG. [Hospital costs of acute headaches in a Brazilian public emergency room unit]. Arq Neuropsiquiatr 2000; 58(3A): 664-70.

38. Speciali JG, Farias da Silva W. Cefaleias: Editora Lemos; 2002.

39. Kelman L. The triggers or precipitants of the acute migraine attack. Cephalalgia 2007; 27(5): 394-402.

40. Silberstein SD LR, Goadsby PJ. Headache in Clinical Practice. Oxford: Isis Medical Media; 1998.

41. Giffin NJ, Ruggiero L, Lipton RB, et al. Premonitory symptoms in migraine: an electronic diary study. Neurology 2003; 60(6): 935-40.

42. Cutrer FM. Pathophysiology of Migraine. Seminars in Neurology 2010; 30(2): 11.

43. Kelman L, Tanis D. The relationship between migraine pain and other associated symptoms. Cephalalgia 2006; 26(5): 548-53.

44. Burstein R, Noseda R, Borsook D. Migraine: multiple processes, complex pathophysiology. J Neurosci 2015; 35(17): 6619-29.

45. Diener HC, Dodick DW, Goadsby PJ, Lipton RB, Olesen J, Silberstein SD. Chronic migraine--classification, characteristics and treatment. Nature reviews Neurology 2011; 8(3): 162-71.

46. Lanteri-Minet M. Economic burden and costs of chronic migraine. Curr Pain Headache Rep 2014; 18(1): 385.

47. Schwedt TJ. Chronic migraine. BMJ 2014; 348: g1416.

48. Bose P, Goadsby PJ. The migraine postdrome. Curr Opin Neurol 2016; 29(3): 299301.

49. Vincent M. The phatophysiology of migraine. Medicina 1997; 30: 8. 
50. Noseda R, Burstein R. Migraine pathophysiology: anatomy of the trigeminovascular pathway and associated neurological symptoms, CSD, sensitization and modulation of pain. Pain 2013; 154 Suppl 1.

51. Speciali JG. Entendendo a enxaqueca. Ribeirão Preto: Editora Funpec; 2003.

52. Leao AA. Further observations on the spreading depression of activity in the cerebral cortex. J Neurophysiol 1947; 10(6): 409-14.

53. Olesen J, Friberg L, Olsen TS, et al. Timing and topography of cerebral blood flow, aura, and headache during migraine attacks. Ann Neurol 1990; 28(6): 791-8.

54. Sand T, Vingen JV. Visual, long-latency auditory and brainstem auditory evoked potentials in migraine: relation to pattern size, stimulus intensity, sound and light discomfort thresholds and pre-attack state. Cephalalgia 2000; 20(9): 804-20.

55. Welch KM, Nagesh V, Aurora SK, Gelman N. Periaqueductal gray matter dysfunction in migraine: cause or the burden of illness? Headache 2001; 41(7): 629-37.

56. Goldberg MP, Ransom BR. New light on white matter. Stroke 2003; 34(2): 330-2.

57. Fasold O, von Brevern M, Kuhberg M, et al. Human vestibular cortex as identified with caloric stimulation in functional magnetic resonance imaging. Neuroimage 2002; 17(3): 1384-93.

58. Sandor PS, Mascia A, Seidel L, de Pasqua V, Schoenen J. Subclinical cerebellar impairment in the common types of migraine: a three-dimensional analysis of reaching movements. Ann Neurol 2001; 49(5): 668-72.

59. Baker BJ, Curtis A, Trueblood P, Vangsnes E. Vestibular functioning and migraine: comparing those with and without vertigo to a normal population. J Laryngol Otol 2013; 127(12): 1169-76.

60. Goadsby PJ, Knight Y. Inhibition of trigeminal neurones after intravenous administration of naratriptan through an action at 5-hydroxy-tryptamine (5-HT(1B/1D)) receptors. Br J Pharmacol 1997; 122(5): 918-22.

61. Helm MR. Vestibulo-ocular reflex abnormalities in patients with migraine. Headache 2005; 45(4): 332-6.

62. Ishiyama A, Jacobson KM, Baloh RW. Migraine and benign positional vertigo. Ann Otol Rhinol Laryngol 2000; 109(4): 377-80.

63. Wrisley DM, Whitney SL, Furman JM. Vestibular rehabilitation outcomes in patients with a history of migraine. Otol Neurotol 2002; 23(4): 483-7.

64. Troost BT. Vestibular migraine. Curr Pain Headache Rep 2004; 8(4): 310-4.

65. Bir LS, Ardic FN, Kara CO, Akalin O, Pinar HS, Celiker A. Migraine patients with or without vertigo: comparison of clinical and electronystagmographic findings. J Otolaryngol 2003; 32(4): 234-8. 
66. Akdal G, Ozge A, Ergor G. The prevalence of vestibular symptoms in migraine or tension-type headache. J Vestib Res 2013; 23(2): 101-6.

67. Whitney SL, Wrisley DM, Brown KE, Furman JM. Physical therapy for migrainerelated vestibulopathy and vestibular dysfunction with history of migraine. Laryngoscope 2000; 110(9): 1528-34.

68. Aradi M, Schwarcz A, Perlaki G, et al. Quantitative MRI studies of chronic brain white matter hyperintensities in migraine patients. Headache 2013; 53(5): 752-63.

69. Bernick C, Kuller L, Dulberg C, et al. Silent MRI infarcts and the risk of future stroke: the cardiovascular health study. Neurology 2001; 57(7): 1222-9.

70. Longstreth WT, Jr., Manolio TA, Arnold A, et al. Clinical correlates of white matter findings on cranial magnetic resonance imaging of 3301 elderly people. The Cardiovascular Health Study. Stroke 1996; 27(8): 1274-82.

71. Vermeer SE, Prins ND, den Heijer T, Hofman A, Koudstaal PJ, Breteler MM. Silent brain infarcts and the risk of dementia and cognitive decline. $N$ Engl J Med 2003; 348(13): 1215-22.

72. Broglio SP, Tomporowski PD, Ferrara MS. Balance performance with a cognitive task: a dual-task testing paradigm. Med Sci Sports Exerc 2005; 37(4): 689-95.

73. Wade LR, Weimar WH, Davis J. Effect of personal protective eyewear on postural stability. Ergonomics 2004; 47(15): 1614-23.

74. Choy NL, Brauer S, Nitz J. Changes in postural stability in women aged 20 to 80 years. J Gerontol A Biol Sci Med Sci 2003; 58(6): 525-30.

75. Boulgarides LK, McGinty SM, Willett JA, Barnes CW. Use of clinical and impairment-based tests to predict falls by community-dwelling older adults. Phys Ther 2003; 83(4): 328-39.

76. Liston RA, Brouwer BJ. Reliability and validity of measures obtained from stroke patients using the Balance Master. Arch Phys Med Rehabil 1996; 77(5): 425-30.

77. Wang RY, Yen L, Lee CC, Lin PY, Wang MF, Yang YR. Effects of an ankle-foot orthosis on balance performance in patients with hemiparesis of different durations. Clin Rehabil 2005; 19(1): 37-44.

78. Cheng PT, Wang CM, Chung CY, Chen CL. Effects of visual feedback rhythmic weight-shift training on hemiplegic stroke patients. Clin Rehabil 2004; 18(7): 747-53.

79. Pickerill ML, Harter RA. Validity and reliability of limits-of-stability testing: a comparison of 2 postural stability evaluation devices. Journal of athletic training 2011; 46(6): 600-6.

80. Thomas M, Jankovic J, Suteerawattananon M, et al. Clinical gait and balance scale (GABS): validation and utilization. J Neurol Sci 2004; 217(1): 89-99. 
81. Balance Manager Systems Clinical Operations Guide. Clackamas (OR): NeuroCom International, Inc.; 2011.

82. Bisdorff A, Von Brevern M, Lempert T, Newman-Toker DE. Classification of vestibular symptoms: towards an international classification of vestibular disorders. $J$ Vestib Res 2009; 19(1-2): 1-13.

83. Agrawal Y, Carey JP, Della Santina CC, Schubert MC, Minor LB. Disorders of balance and vestibular function in US adults: data from the National Health and Nutrition Examination Survey, 2001-2004. Arch Intern Med 2009; 169(10): 938-44.

84. Gassmann KG, Rupprecht R, Freiberger E, Group IZGS. Predictors for occasional and recurrent falls in community-dwelling older people. Zeitschrift fur Gerontologie und Geriatrie 2009; 42(1): 3-10.

85. Lasisi AO, Gureje O. Disability and quality of life among community elderly with dizziness: report from the Ibadan study of ageing. J Laryngol Otol 2010; 124(9): 957-62.

86. Organization WH. WHO global report on falls prevention in older age. Geneva, Switzerland: World Health Organization; 2008.

87. Gawryszewski VP, Koizumi MS, Mello-Jorge MH. [Morbidity and mortality from external causes in Brazil, 2000]. Cadernos de saude publica 2004; 20(4): 995-1003.

88. Jorstad EC, Hauer K, Becker C, Lamb SE, ProFa NEG. Measuring the psychological outcomes of falling: a systematic review. J Am Geriatr Soc 2005; 53(3): 501-10.

89. Bruce DG, Devine A, Prince RL. Recreational physical activity levels in healthy older women: the importance of fear of falling. J Am Geriatr Soc 2002; 50(1): 84-9.

90. Yardley L, Beyer N, Hauer K, Kempen G, Piot-Ziegler C, Todd C. Development and initial validation of the Falls Efficacy Scale-International (FES-I). Age Ageing 2005; 34(6): 614-9.

91. Ben Achour Lebib S, Missaoui B, Miri I, Ben Salah FZ, Dziri C. [Role of the Neurocom Balance Master in assessment of gait problems and risk of falling in elderly people]. Ann Readapt Med Phys 2006; 49(5): 210-7.

92. Shumway-Cook A, Horak FB. Assessing the influence of sensory interaction of balance. Suggestion from the field. Phys Ther 1986; 66(10): 1548-50.

93. Horak FB, Wrisley DM, Frank J. The Balance Evaluation Systems Test (BESTest) to differentiate balance deficits. Phys Ther 2009; 89(5): 484-98.

94. Ruckenstein MJ, Shepard NT. Balance function testing: a rational approach. Otolaryngol Clin North Am 2000; 33(3): 507-18.

95. Duarte M, Freitas SM. Revision of posturography based on force plate for balance evaluation. Rev Bras Fisioter 2010; 14(3): 183-92.

96. Hof AL, Gazendam MG, Sinke WE. The condition for dynamic stability. Journal of Biomechanics 2005; 38: 1-8. 
97. Winter DA, Patla AE, Ishac M, Gage WH. Motor mechanisms of balance during quiet standing. J Electromyography Kinesiology 2003; 13: 49-56.

98. Winter DA, Patla AE, Prince F, Shac M, Gielo-Perczak K. Stiffness control of balance in quiet standing. Journal Neurophysiology 1998; 80: 1211-21.

99. Carr J, Shepherd R. Ciência do Movimento - Fundamentos para a Fisioterapia na Reabilitação. São Paulo; 2003.

100. Stuart DG, Gurfinkel VS, Wiesendanger M. Motor Control Press. Tucson; 1995.

101. Ondo WEA. Computerized posturography analysis of progressive supranuclear palsy: a case-control comparison with Parkinson's disease and healthy controls. Arch Neurol 2000; 57: 1464-9.

102. Clark S, Rose DJ, Fujimoto K. Generalizability of the limits of stability test in the evaluation of dynamic balance among older adults. Arch Phys Med Rehabil 1997; 78(10): 1078-84.

103. King MB, Judge JO, Wolfson L. Functional base of support decreases with age. Journal of gerontology 1994; 49(6): M258-63.

104. Bohannon RW. Reference values for the timed up and go test: a descriptive metaanalysis. J Geriatr Phys Ther 2006; 29(2): 64-8.

105. Mattacola CG, Jacobs CA, Rund MA, Johnson DL. Functional assessment using the step-up-and-over test and forward lunge following ACL reconstruction. Orthopedics 2004; 27(6): 602-8.

106. Janssen WG, Bussmann HB, Stam HJ. Determinants of the sit-to-stand movement: a review. Phys Ther 2002; 82(9): 866-79.

107. Suzuki CS, de Moraes SA, de Freitas ICM. Physical activity and correlates among adults living in Ribeirao Preto, Southeastern Brazil. Revista de saude publica 2011; 45(2): 311-20.

108. Kim Y, Park I, Kang M. Convergent validity of the international physical activity questionnaire (IPAQ): meta-analysis. Public health nutrition 2013; 16(3): 440-52.

109. Castro AS, Gazzola JM, Natour J, Gananca FF. [Brazilian version of the dizziness handicap inventory]. Pro Fono 2007; 19(1): 97-104.

110. Whitney SL, Wrisley DM, Brown KE, Furman JM. Is perception of handicap related to functional performance in persons with vestibular dysfunction? Otol Neurotol 2004; 25(2): $139-43$.

111. Camargos FF, Dias RC, Dias JM, Freire MT. Cross-cultural adaptation and evaluation of the psychometric properties of the Falls Efficacy Scale-International Among Elderly Brazilians (FES-I-BRAZIL). Rev Bras Fisioter 2010; 14(3): 237-43. 
112. Delbaere K, Close JC, Mikolaizak AS, Sachdev PS, Brodaty H, Lord SR. The Falls Efficacy Scale International (FES-I). A comprehensive longitudinal validation study. Age Ageing 2010; 39(2): 210-6.

113. Cohen J. CHAPTER 1 - The Concepts of Power Analysis. Statistical Power Analysis for the Behavioral Sciences (Revised Edition): Academic Press; 1977: 1-17.

114. Moreira MN, Bilton TL, Dias RC, Ferriolli E, Perracini MR. What are the Main Physical Functioning Factors Associated With Falls Among Older People With Different Perceived Fall Risk? Physiother Res Int 2016.

115. Medical.Advisory.Secretariat. Prevention of falls and fall-related injuries in community-dwelling seniors: an evidence-based analysis. Ontario health technology assessment series 2008; 8(2): 1-78.

116. Bergland A, Wyller TB. Risk factors for serious fall related injury in elderly women living at home. Injury prevention : journal of the International Society for Child and Adolescent Injury Prevention 2004; 10(5): 308-13.

117. Rubenstein LZ. Falls in older people: epidemiology, risk factors and strategies for prevention. Age Ageing 2006; 35 Suppl 2: ii37-ii41. 


\section{APÊNDICES}

APÊNDICE A - Ficha Inicial de Triagem dos Pacientes aplicado no Ambulatório de Cefaleia - HC/FMRP-US 
APÊNDICE A - Ficha Inicial de Triagem dos Pacientes aplicado no Ambulatório de Cefaleia - HC/FMRP-USP

AVALIAÇÃO

Data:

Nome: Escolaridade:

Idade Estado Civil:

Profissão:

Telefone: Peso: Altura:

\section{ANAMNESE}

( ) Migrânea sem aura. （） Migrânea com aura. （ ) Migrânea Crônica. （ ) Controle.

Comorbidades:

Medicamentos:

História de trauma em MMII? ( ) Não. Local: Tempo?

\section{QUEDAS/VERTIGEM}

História de quedas: N. quedas no último ano:

Tropeços/Desequilíbrios: Há quanto tempo:

Lesão decorrente: Causa:

Presença de vestibulopatias: ( ) Sim ( ) Não

Presença de tontura? ( ) Sim ( ) Não Fora da crise: ( ) Sim ( ) Não

Sintomas: ( ) vertigem (rotatória) ( ) Outro:

\section{CEFALEIA}

Cefaleia nos últimos 3 meses? (S) (N) Aura: (S) (N) Anos de cefaleia:

Frequência de crises/mês: Duração das crises/horas: Intensidade da dor:
Localização da dor:
( ) Hemicraniana
( ) Holocraniana
( ) Frontal
( ) Temporal
( ) Occiptal
( ) Outro:

Dor na avaliação: ( ) Não Eva: 


\section{ANEXOS}

ANEXO A - Aprovação pelo Comitê de Ética

ANEXO B - Questionário Internacional de Atividade Física - IPAQ

ANEXO C - DHI Brasileiro

ANEXO D - FES-I Brazil 
ANEXO A - Aprovação pelo Comitê de Ética.

\section{HOSPITAL DAS CLINIICAS DA FACULDADE DE MEDICINA DE RIBEIRÃO PRETO DA UNIVERSIDADE DE SÃO PAULO}

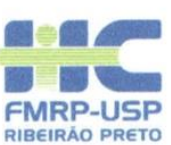

Ribeirão Preto, 08 de março de 2013

Oficio $\mathrm{n}^{\circ} 719 / 2013$

$\mathrm{CEP} / \mathrm{MGV}$

Prezadas Senhoras,

O trabalho intitulado "ALTERAÇÕES NO EQUILÍBRIO FUNCIONAL EM PACIENTES COM MIGRÂNEA CRÔNICA E EPISÓDICA", foi analisado pelo Comitê de Ética em Pesquisa, em sua $361^{a}$ Reunião Ordinária realizada em 04/03/2013, e enquadrado na categoria: APROVADO, bem como o Termo de Consentimento Livre e Esclarecido, $2^{\text {a }}$ versão, datada de 05/02/2013, de acordo com o Processo HCRP nº 16693/2012.

De acordo com Carta Circular $n^{\circ}$ 003/2011/CONEP/CNS, datada de 21/03/2011, o sujeito de pesquisa ou seu representante, quando for o caso, deverá rubricar todas as folhas do Termo de Consentimento Livre $e$ Esclarecido - TCLE - apondo sua assinatura na última do referido Termo; o pesquisador responsável deverá da mesma forma, rubricar todas as folhas do Termo de Consentimento Livre e Esclarecido - TCLE - apondo sua assinatura na última página do referido Termo.

Este Comitê segue integralmente a Conferência Internacional de Harmonização de Boas Práticas Clinicas (IGH-GCP), bem como a Resolução $n^{\circ}$ 196/96 CNS/MS.

Lembramos que devem ser apresentados a este CEP, O Relatório Parcial e o Relatório Final da pesquisa.

Atenciosamente.

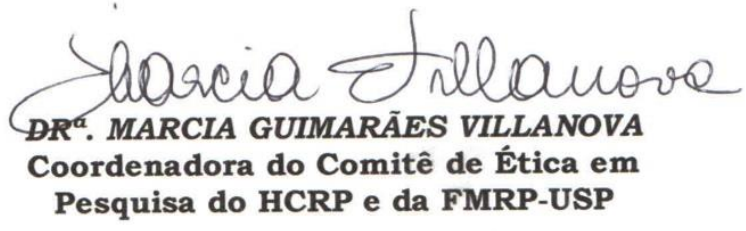

Ilustríssimas Senhoras

GABRIELA FERREIRA CARVALHO

PROF $^{\text {a }}$. DR ${ }^{\mathrm{a}}$. DÉBORA BEVILAQUA GROSSI (Orientadora)

Depto. de Biomecânica, Medicina e Reabilitação do Aparelho Locomotor

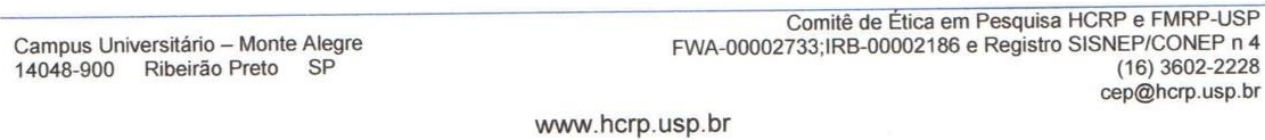




\section{ANEXO B - Questionário Internacional de Atividade Física - IPAQ.}

Nós estamos interessados em saber que tipos de atividade física as pessoas fazem como parte do seu dia a dia. As perguntas estão relacionadas ao tempo que você gasta fazendo atividade física na ÚLTIMA semana. As perguntas incluem as atividades que você faz no trabalho, para ir de um lugar a outro, por lazer, por esporte, por exercício ou como parte das suas atividades em casa. Por favor responda cada questão mesmo que considere que não seja ativo. Para responder as questões lembre que:

Atividades físicas VIGOROSAS são aquelas que precisam de um grande esforço físico e que fazem respirar MUITO mais forte que o normal e Atividades físicas MODERADAS são aquelas que precisam de algum esforço físico e que fazem respirar UM POUCO mais forte que o normal

Para responder as perguntas pense somente nas atividades que você realiza por pelo menos 10 minutos contínuos de cada vez.

1a Em quantos dias da última semana você CAMINHOU por pelo menos 10 minutos contínuos em casa ou no trabalho, como forma de transporte para ir de um lugar para outro, por lazer, por prazer ou como forma de exercício?

dias ___ por SEMANA ( ) Nenhum

$1 \mathrm{~b}$ Nos dias em que você caminhou por pelo menos 10 minutos contínuos quanto tempo no total você gastou caminhando por dia? horas: Minutos:

2a. Em quantos dias da última semana, você realizou atividades MODERADAS por pelo menos 10 minutos contínuos, como por exemplo pedalar leve na bicicleta, nadar, dançar, fazer ginástica aeróbica leve, jogar vôlei recreativo, carregar pesos leves, fazer serviços domésticos na casa, no quintal ou no jardim como varrer, aspirar, cuidar do jardim, ou qualquer atividade que fez aumentar moderadamente sua respiração ou batimentos do coração (NÃO INCLUA CAMINHADA)

dias por SEMANA ( ) Nenhum

2b. Nos dias em que você fez essas atividades moderadas por pelo menos 10 minutos contínuos, quanto tempo no total você gastou fazendo essas atividades por dia? horas: Minutos:

3a Em quantos dias da última semana, você realizou atividades VIGOROSAS por pelo menos 10 minutos contínuos, como por exemplo correr, fazer ginástica aeróbica, jogar futebol, pedalar rápido na bicicleta, jogar basquete, fazer serviços domésticos pesados em casa, no quintal ou cavoucar no jardim, carregar pesos elevados ou qualquer atividade que fez aumentar MUITO sua respiração ou batimentos do coração.

dias ___ por SEMANA ( ) Nenhum

3b Nos dias em que você fez essas atividades vigorosas por pelo menos 10 minutos contínuos quanto tempo no total você gastou fazendo essas atividades por dia? horas: Minutos:

Estas últimas questões são sobre o tempo que você permanece sentado todo dia, no trabalho, na escola ou faculdade, em casa e durante seu tempo livre. Isto inclui o tempo sentado estudando, sentado enquanto descansa, fazendo lição de casa visitando um amigo, lendo, sentado ou deitado assistindo TV. Não inclua o tempo gasto sentando durante o transporte em ônibus, trem, metrô ou carro.

4a. Quanto tempo no total você gasta sentado durante um dia de semana? horas minutos

4b. Quanto tempo no total você gasta sentado durante em um dia de final de semana? 
ANEXO C - DHI Brasileiro.

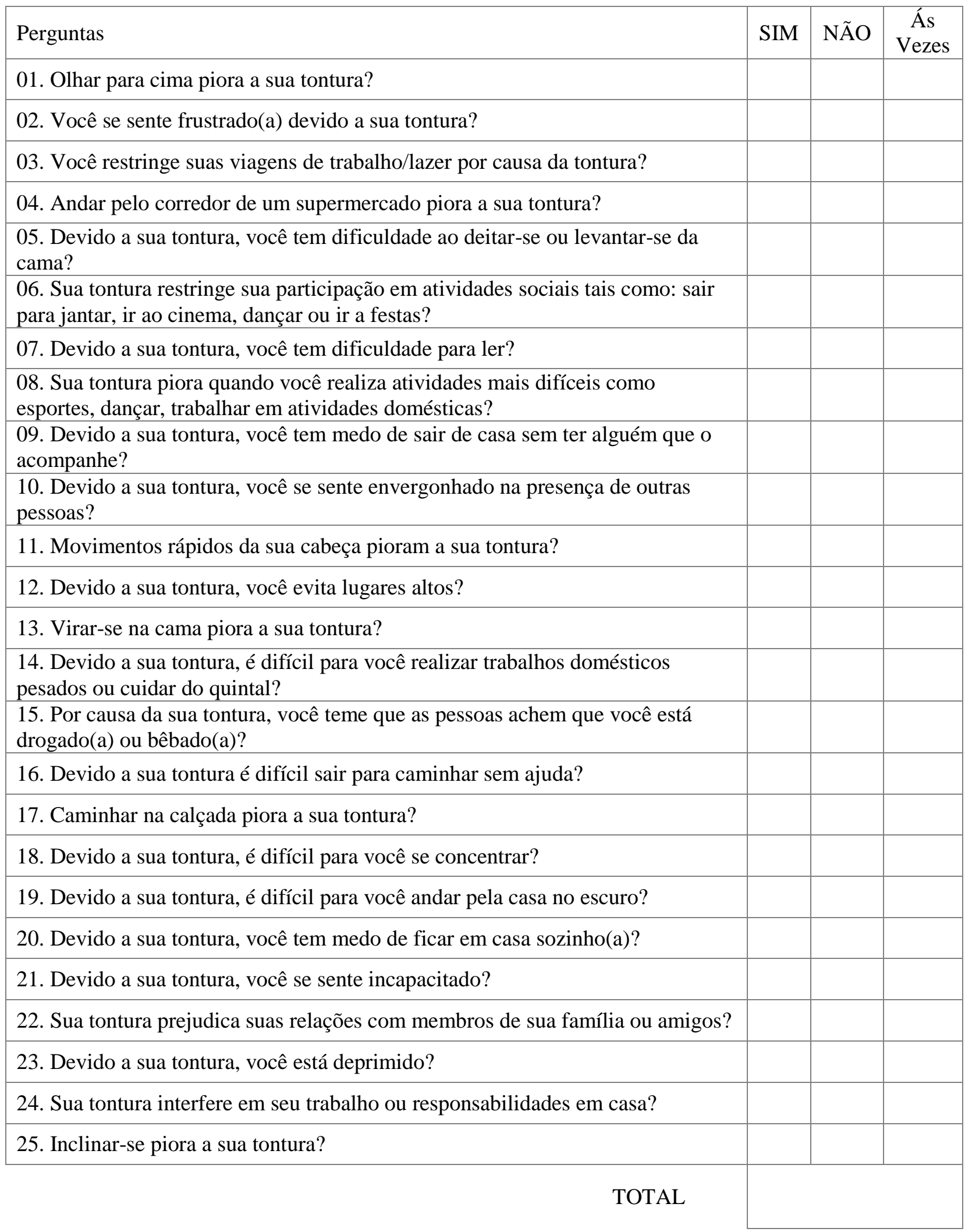


ANEXO D - FES-I Brasil.

Nós gostaríamos de fazer algumas perguntas sobre qual é sua preocupação a respeito da possibilidade de cair. Responda imaginando como você normalmente faz a atividade. Se você atualmente não faz a atividade, responda de maneira a mostrar como você se sentiria em relação a quedas se você tivesse que fazer. Para cada atividade marque o número que mais se aproxima com sua opinião sobre o quão preocupado você fica com a possibilidade de cair.

\begin{tabular}{|l|l|l|l|l|}
\cline { 2 - 4 } \multicolumn{1}{c|}{} & $\begin{array}{c}\text { Nem um } \\
\text { pouco } \\
\text { preocupado }\end{array}$ & $\begin{array}{c}\text { Um pouco } \\
\text { preocupado }\end{array}$ & $\begin{array}{c}\text { Muito } \\
\text { preocupado }\end{array}$ & $\begin{array}{c}\text { Extremamente } \\
\text { preocupado }\end{array}$ \\
\hline $\begin{array}{l}\text { 1. Limpando a casa (ex. Passar } \\
\text { pano, tirar poeira) }\end{array}$ & & & \\
\hline 2. Vestindo ou tirando a roupa & & & \\
\hline 3. Preparando refeições simples & & & \\
\hline 4. Tomando banho & & & \\
\hline 5. Indo às compras & & & \\
\hline $\begin{array}{l}\text { 6. Sentando ou levantando de uma } \\
\text { cadeira }\end{array}$ & & & \\
\hline 7. Subindo ou descendo escadas & & & \\
\hline 8. Caminhando pela vizinhança & & & \\
\hline $\begin{array}{l}\text { 9. Pegando algo acima da sua } \\
\text { cabeça ou no chão }\end{array}$ & & & \\
\hline $\begin{array}{l}\text { 10. Indo atender o telefone antes } \\
\text { que pare de tocar }\end{array}$ & & & \\
\hline $\begin{array}{l}\text { 11. Andando sobre superfície } \\
\text { escorregadia }\end{array}$ & & & \\
\hline 12. Visitando amigo ou parente & & & \\
\hline $\begin{array}{l}\text { 13. Andando em lugares cheios de } \\
\text { gente }\end{array}$ & & & \\
\hline $\begin{array}{l}\text { 14. Caminhando sobre superfície } \\
\text { irregular (pedras, buracos) }\end{array}$ & & & \\
\hline $\begin{array}{l}\text { ladeira Subindo ou descendo uma } \\
\text { lado }\end{array}$ & & & \\
\hline 16. Indo a uma atividade social & & & \\
\hline
\end{tabular}

